\title{
Endogenous Fluctuations and the Role of Monetary Policy ${ }^{1}$
}

by

\author{
Mordecai Kurz, Stanford University, \\ with \\ Hehui Jin, Stanford University and Maurizio Motolese, Catholic University of Milan \\ (this draft: September 26, 2001) \\ PRELIMINARY DRAFT
}

\section{Introduction}

Why is monetary policy a desirable social tool and why is public action in this area

justified at all? Different and conflicting answers to this question have been offered over the years but the question has defied resolution. The controversial nature of the question arises from the fact that any answer is linked to two crucially related questions: why does a competitive market economy experience excess fluctuations and why is money non-neutral. In other words, a theory of stabilizing monetary policy must provide a unified explanation to why our economy experiences fluctuations and why monetary policy can have an impact on these fluctuations.

In a sequence of earlier papers we have argued that most of the volatility in financial markets are caused by the belief structure of the agents (see Kurz (1997), (1997a), (1997b), KurzSchneider (1996), Kurz-Beltratti (1997), Kurz-Motolese (2001)). Using the theory of Rational Belief Equilibrium (henceforth, RBE; see Kurz (1994), (1997)), these papers introduced an unified model which explains, simultaneously, a long list of financial phenomena regarded as "anomalies". The model's key feature is the heterogeneity of agent's beliefs. Agents may be

\footnotetext{
1 This research was supported by a grant of the Smith Richardson Foundation to the Stanford Institute for Public Policy Research (SIEPR). We thank Kenneth Judd for constant advice which was crucial at several points in the development of this work. We also thanks Peter Hammond, Felix Kubler and Carsten Nielsen for many insightful conversations regarding the content and methods of this paper and to Albert Chun and Peyron Law for assistance in preparing the data in Section 3. We are pleased to honor Ned Phelps whose work has anticipated some of the developments in this paper.
} 
"bulls" who are rational but optimistic about future capital gains, or "bears" who are rational but pessimistic about future capital gains. Phenomena, such as the Equity Premium Puzzle, are then explained by the fact that pessimistic "bears" who aim to avoid capital losses drive interest rates low and the equity premium high ( for a unified treatment see Kurz and Motolese (2001)).

This paper initiates our study of the impact of diversity of rational beliefs on endogenous fluctuations in a monetary economy and our examination of the implied role of monetary policy. The investment model in this paper is simplistic and designed only to enable an exposition of the main ideas that underlie our approach. Hence, the paper offers conceptual and theoretical developments, not precise calibrations. As a result, the numerical results of the simulations presented later should be taken only as an illustration of the ideas and as an indication of the ability of the model to generate results with characteristics that are qualitatively similar to the data of the economy. With these qualifications stated, the paper offers four basic perspectives:

A. Economic fluctuations have an important technological shock component but it is non negative and with small variance. This raises the need for a propagation mechanism of economic volatility. An RBE generates economic volatility endogenously through the belief structure of market participants. Our simulations show that the level of volatilitty generated is in the order of the order of magnitude observed in the economy.

B. Money non-neutrality is a generic property of equilibria with diverse belief hence in an RBE monetary shocks have real effects even when they are fully observed. Since these real effects depend upon the distribution of market beliefs, this distribution is an important explanatory variable of market performance.

C. In an economy where agents hold diverse beliefs, principles of ex-ante Pareto optimality do not provide adequate guide for public policy. Agents with diverse but inconsistent beliefs are entirely rational in acting upon these beliefs, but they induce excess economic fluctuations. Hence, Pareto optimal allocations in the usual ex-ante sense can thus be excessively volatile with resulting ex-post fluctuations which are socially undesirable. Monetary policy should seek, what we call, Long Term Pareto Improvement. It sets aside individual beliefs and establishes the public goal to be a reduction in the volatility of equilibrium prices and output so as to increase expected utilities relative to a 
consistent probability over feasible risky sequences. Such a probability is proposed naturally by the theory of Rational Belief and is based on the empirical distribution of events.

D. Our theory offers a unified perspective. It explains why a market economy exhibits excess economic volatility and it shows why stabilizing monetary policy is desirable and feasible. Finally, it points towards future research in which we hope to contribute to improving the conduct of monetary policy.

To explore these ideas we develop a monetary model with two infinitely lived agents who hold heterogenous Rational Beliefs, and study its volatility characteristics under the assumption of exogenous money supply. We use numerical simulations to demonstrate the theoretical properties of the model but do not attempt at an accurate calibration. Being a theoretical paper, numerical simulations are used merely as a tool for the study of the model's characteristics.

Many of the controversies in monetary theory arise from the use of models utilizing different assumptions. For this reason we start by explicitly reviewing our assumptions in relation to other current work on economic fluctuations and monetary economics.

\section{Our Assumptions in Relation to the Literature}

We start with Real Business Cycle (RBC) models which insist all economic fluctuations are caused by technological shocks and hence monetary phenomena do not matter. It has been well known that average labor productivity is procyclical and the Solow residual, heavily used by $\mathrm{RBC}$, is a poor measure of technological shocks as it depends upon endogenous variables such as capacity utilization (e.g. Greenwood, Hercowitz and Huffman (1988), Burnside, Eichenbaum and Rebelo (1995) and Basu (1996 )). Computational limitations preclude us from introducing endogenous capacity utilization in this paper but we hope to correct for this in future research. As 
for the sign and size of productivity shocks we agree with the critique of most writers (e.g. Summers (1986) and Eichenbaum (1991)) that exogenous technological shocks constitute a small fraction of the Solow residual and negative technological shocks cannot be justified. ${ }^{2}$ Since an exogenous process of non-negative productivity shocks with small variance cannot explain the observed data, an alternative propagation mechanism is needed. Examples of attempts of such models within the RBC tradition include Wen (1998a),(1998b) and King and Rebelo (1999).

Our model assumes a very small variance of the exogenous technological shocks but explicitly incorporates an investment goods sector to model the uncertainty associated with the outcome of all new investments. The output of each input into the investment sector is stochastic hence investment decisions are made based on the assessment of this risk. The investment sector itself is very simple. It consists of alterative projects that vary in productivity depending upon random shocks which are idiosyncratic to that sector. The decision on which line of investment is optimal, depends upon the belief of investors. We then use the model to investigate the impact of the distribution of beliefs on aggregate fluctuations of investments, outputs and prices.

We now highlight point $\mathrm{B}$ above, regarding the non-neutrality of monetary equilibria with diverse beliefs. The New Classical Economics rejected the Keynesian perspective by insisting that due to money neutrality, changes in money supply change only the price level without any real effect. Mindful of the empirical evidence that monetary policy does have real effects, the study of monetary policy under Rational Expectations Equilibrium (henceforth, REE) focused, in the early stages, on the effects of informational imperfections. Lucas' (1972) argued that money has real

2 In a recent paper Cole and Ohanian (2000) argue that the Great Depression resulted from a cumulative $15 \%$ negative technological shock to the U.S. economy during 1929-1932. We cannot support such a conclusion. 
effect because people confuse changes in the price level for changes in relative prices. Furthermore, although market participants may hold Rational Expectations, the Central Bank can surprise them by making unexpected policy changes that will have real effect. By implication, monetary policy has a real effect when it is unanticipated; all anticipated actions are neutralized by immediate adjustments of the price level. Empirical evidence has not supported this conclusion (see, for example, Mishkin (1982)). The evidence shows that both anticipated as well as unanticipated changes in money have an impact on output.

We note that the above arguments need not hold in an equilibrium where agents hold diverse beliefs. An equilibrium in which rational agents hold diverse beliefs should be understood to be one where agents have different theories about the dynamics of the economy. In particular, in an RBE agents have a non-stationary perspective on the economy hence they have different views about the true probability distributions of the equilibrium stochastic process of exogenous and endogenous variables. Since they hold different conditional probabilities, they arrive at different conclusions when they condition their probability beliefs on current information. That is, agents interpret current information differently. Hence, even fully observed monetary shocks could be interpreted differently by agents and money non-neutrality is implied (for earlier work, see Motolese (2000), (2001)).

An integrated view of monetary equilibrium has been developed by the Dynamic New Keynesian Theory (DNK). This view is erected on two basic assumptions. (1) The market economy consists of monopolistically competitive firms that are price setters, and (2) prices are "sticky" due to the existence of long term contracts that prevent firms from freely adjusting prices (e.g. Taylor (1980), Calvo (1983), Yun (1996), Goodfriend and King (1997), Clarida, Gali, and 
Gertler (1999), Rotemberg and Woodford (1999), Woodford (1999), (2000), (2001a), (2001b). In many papers, authors work with Calvo's (1983) idealization where at any date only a fraction of the firms are "allowed" to change prices while others cannot. In such an economy fluctuations of output are caused by exogenous shocks but their effects are further amplified by incorrect price setting by firms and hence the economy is not operating efficiently. Changes in interest rates and money supply have real effects since not all firms charge the same price: some are able to adjust prices but others are not "permitted" to alter prices in response to shocks and must produce output under the wrong prices. In such an economy the object of monetary policy is to restore economic efficiency by countering the negative effect of price rigidity. Under an optimal policy the effects of price rigidity would be essentially removed.

In an effort to bolster the DNK theory, research focused on credit constraints as an added mechanism of volatility amplification. The central idea is that the imperfections in the credit markets act as an amplification mechanism. The literature on credit rationing is extensive, but there is not even agreed upon definition of what constitute credit market imperfections (e.g. see survey of Jaffe and Stiglitz (1990)). Recent work proposes that an important effect of monetary policy operates through its impact on the availability of credit to borrowing firms. Kyotaki and Moore (1997), Bernanke and Gertler (1989) Bernanke, Gertler and Gilchrist (1999), and Calstrom and Fuerst (1997) argue that fluctuations in the price of assets alters the collateral available to entrepreneurs who wish to borrow and invest. A favorable technological shock or expansionary monetary policy remove credit constraints and allows entrepreneurs to carry out more expansionary investment policies while a negative exogenous shock or tight monetary policy acts in the opposite direction. The mechanism at work is the change in the risk premium of bankruptcy 
which results from variations in the level of the collateral available to borrowers. Bernanke, Gertler and Gilchrist (1997) call this effect a "Financial Accelerator."

Credit is an important component of monetary analysis which should be incorporated in our model. However, the "Financial Accelerator" above was developed under strong assumptions that (i) entrepreneurs are risk neutral, (ii) the random outcomes of their investment activities are not observable by the bank, and (iii) entrepreneurs die at a random exponential rate and their collateral assets disappear upon death. We hope to develop a simpler model in which a credit amplification is operative under weaker assumptions.

Although the DNK offers a unified perspective of the justification for monetary policy, our RBE presented below is an equilibrium for an economy which is fully competitive in which prices are fully flexible. We shall thus not adopt any of the assumptions of the DNK. In doing so we are not rejecting the proposition that some money non-neutrality is due to wage or price rigidity. Indeed, there may be many factors which contribute to money non-neutrality.

The final issue is the rationale for monetary policy. Consider the Lucas (1972) view of money neutrality and the literature which holds that money has an effect only when the monetary authority "surprises" the private sector. If agents are surprised or "confused" between monetary and real shocks then in some sense the allocation in the economy is not efficient. ${ }^{3}$ Hence, the reason why a rational central bank would want to surprise the public is because it would want to correct for lack of Pareto efficiency. However, if lack of Pareto efficiency is associated with cyclical fluctuations, monetary policy would not be useful since it will be fully anticipated ( see,

\footnotetext{
${ }^{3}$ Note that under conditions of asymmetric and $\backslash$ or incomplete information even the definition of Pareto optimality is not entirely agreed upon and is thus an open research question.
} 
Lucas [1972] and Sargent and Wallace [1975]). The monetarist view is thus internally consistent: if monetary policy is effective it should be used to correct for Pareto inefficiency but such policy cannot accomplish counter cyclical stabilization since it would be fully anticipated.

Most Optimal Policy models do not address the question of why the central bank should want to follow a stabilization policy. They are mostly described by a reduced form system of equations incorporating the optimal behavior of the private sector given the monetary policy in place and assuming a Phillips curve as a structural equation. The Central Bank then selects directly the optimal mix of inflation and growth rate of GNP so as to minimize the fluctuations in the economy. A sample of contributions along this line include Taylor (1993), and papers in Taylor's (2000) edited volume on monetary policy rules. In this line of research the rationale for a monetary rule is left as a background issue. The implicit justification for a stabilization objective is the view that the private sector allocation is not Pareto Optimal, reflected by the fact that the growth rate of GNP andlor the rate of inflation fluctuate too much around their targets. The targets themselves are then treated as Pareto Optimal states of the economy.

The DNK theory is an exception. It explicitly assumes that prices are sticky, private sector allocation is not Pareto optimal and the justification for central bank stabilization policy is to restore Pareto optimality. An explicit statement establishing the link between policy objectives and private sector allocation is recently provided by Woodford [2001b] where minimization of a quadratic form of deviations from the Pareto optimal targets arises from a Taylor approximation of the utility of the representative agent. Under this theory the objective of monetary policy is to minimize the price dispersion across producers who could adjust prices and those who were prevented from adjusting their prices in response to exogenous shocks. Depending upon the 
specific model of price stickiness, this objective implies that the central bank is to steer nominal interest rates at each date so that the resulting rate of inflation is close to the one anticipated by those agents forced to fix prices in the previous date. We shall present an alternative view.

In the development below we do not seek to characterize optimal monetary policy and employ only the traditional "policy" of exogenous variations in the money supply. Our aim is to study the impact of diverse beliefs in an RBE on the dynamics of a monetary economy. Under Rational Beliefs agents disagree in interpreting observed data and this also applies to monetary policy. We demonstrate via simulations that the distribution of beliefs in an RBE has a significant effect on economic fluctuations and that under Rational Beliefs money is non-neutral. Given the fact that the distribution of beliefs causes endogenous amplification of economic fluctuations, we suggest that Pareto optimality is not an adequate criterion for monetary policy and develop in Section 3 an alternative view of the role of stabilization policy.

Before proceeding, we note that the idea that diverse expectations is important for equilibrium analysis is not new to economics. Diverse beliefs in financial markets are a central component of Thornton's (1802) view of paper money and financial markets. Expectations are mentioned often in Keynes (1936) although he never developed a formal theory of individual beliefs. Market expectations are central to "cumulative movements" in Pigou (see, Pigou's (1941), Chapter VI) and expectations are basic to the process of deviations from a stationary equilibrium in the Swedish school (e.g. see Myrdal's view of money in Myrdal (1939), chapter III). Also, the concept of "subjective values" based on diverse expectations is a cornerstone of Lindahl (1939) theory of money and capital. Finally, in evaluating the impact of rational expectations, Frydman and Phelps (1983) recognize the importance of diverse beliefs and seek a way to formulate models 
with such a feature. They justify their position on the ground that any theory with uniform market beliefs of agents is fundamentally non-robust, saying (page 26)

...But once the theoretical door is opened to one or more hypotheses of optimality in the expectations formation of the individual agents, the implied behavior of the (otherwise identical) model is often found to be wrenched into directions far from the behavior implied by the rational expectations hypothesis. In short, Pandora's box of disequilibrium behavior is opened up.

The theory of Rational Beliefs provides an analytical expression and a vocabulary for these ideas. Although a Rational Belief is a generalization of the rational expectations hypothesis, The RBE theory shows that, indeed as Frydman and Phelps (1983) conjectured, an economy with diverse beliefs behaves drastically different from an economy with a single, uniform, belief.

\section{The Economic Environment}

The model economy has four traded goods: a consumption good, capital good, labor services and money. Agents can buy existing capital goods on the open market but new capital goods are produced by two alternative activities whose output depends upon a random shock which affects only the investments sector. The decision of how much mature capital goods to buy on the open market and how much to invest in new projects depends upon the beliefs of the agents and upon the price of capital goods on the open market. Investments are irreversible. There are two infinitely lived agents with utility over consumption, labor services and real money holding. These agents do all the intertemporal decisions in this economy. The income of the agents consists of their labor income and the income they receive from assets which they trade in competitive markets. The first asset is an ownership unit of real capital goods employed by the firms in the economy. Aggregate supply of such units equals the number of units of capital in the economy. At each date a unit of capital pays a risky dividend and has a risky return consisting of dividends 
and capital gains. The second financial asset is a one period bill which pays a riskless nominal return and has a zero net supply. The third asset is fiat money issued by the central bank. Under the money supply policy studied in this paper a random change in the money supply results in a random change in the money holding of an agent. To avoid issues related to public budget constraint the expected growth rate of money equals the expected growth of output so the model exhibits zero long run inflation.

Competitive firms in this economy are myopic in outlook. At each date they hire labor services and rent capital from the agents who own the capital goods. They maximize current profits of producing consumer goods given the prices of consumer goods, capital goods, rental on capital and wage rate. Markets for labor and capital services are competitive. New investments are carried out directly by the two agents utilizing publicly available investment technology hence all intertemporal decisions are made by the agents while firms carry out current production. Investments are irreversible: once produced, capital goods cannot be turned back into consumption goods although they depreciate with use.

In sum, our model is entirely traditional in structure. There are competitive markets for consumption goods, capital services, labor services, units of ownership of capital goods, bonds and money and all prices are flexible. There are no informational asymmetries or friction. The main feature of our theory is that agents hold diverse Rational Belief, not Rational Expectations.

\subsection{The Technology}

The model has two sectors. The production of consumer goods is carried out by competitive firms who use the usual inputs of capital and labor while the production of capital 
goods is carried out directly by the agents using only consumer goods as inputs. This simplistic nature of the capital goods sector ${ }^{4}$ suggests that our notation would be simplified if all symbols related to the input of capital and labor do not carry the subscript $\mathrm{c}$ to indicate production of consumer goods. We thus use the following notation:

$P_{t}$ - price of consumption good (the "price level") at $t$;

$\frac{P_{t}}{P_{t-1}}=\pi_{t}=1+$ the rate of inflation at $t$;

$\mathrm{K}_{\mathrm{t}-1}$ - real capital stock employed in the production of consumer goods at $\mathrm{t}$;

$\mathrm{W}_{\mathrm{t}}^{\mathrm{N}}$ - nominal wage at $\mathrm{t}$;

$\tilde{\mathrm{q}}_{\mathrm{t}}^{\mathrm{s}}$ - nominal price at $\mathrm{t}$ of a unit of capital goods installed;

$\mathrm{q}_{\mathrm{t}}{ }^{\mathrm{s}}=\frac{\tilde{\mathrm{q}}_{\mathrm{t}}{ }^{\mathrm{s}}}{\mathrm{P}_{\mathrm{t}}}$ - the real price of capital at $\mathrm{t}$;

$\mathrm{L}_{\mathrm{t}}$ - labor input in the production of consumer goods at $\mathrm{t}$;

$\mathrm{N}_{\mathrm{t}}$ - input at $\mathrm{t}$, in units of consumption goods, into the production of capital goods;

$\mathrm{Y}_{\mathrm{t}}$ - real output of consumer goods at $\mathrm{t}$;

$I_{t}$ - real output of new capital goods produced at t by the investment technology;

\section{Output and Productivity.}

There is a large number of identical competitive firms and aggregate output of consumer

\footnotetext{
${ }^{4}$ The original design of our model called for a capital goods sector using regular production function with inputs of capital and labor. The problem is that with two capital goods and two agents the implied number of state variables is larger than can be accommodated by our computational procedure. In order to complete the manuscript in time for the Festschrift Conference in Honor of Edmund Phelps, we have elected to develop the ideas of the paper by drastically simplifying the capital goods sector. It now consists of two entirely hypothetical linear activities which use as inputs only consumer goods. This assumption simplifies the computations and makes it possible to develop the theoretical ideas. However, due to the hypothetical nature of these activities, a calibration of the model to the U.S. data was avoided as it would be artificial. In future research we hope to expand the model as originally designed.
} 
goods is defined by a standard production function

$$
\left.Y_{t}=A v_{t}\left(K_{t-1}\right)^{\sigma}\left(\xi_{t} L_{t}\right)^{1-\sigma} \quad \text { (typically with } A=1\right) \text {. }
$$

The productivity process $\left\{\xi_{\mathrm{t}}, \mathrm{t}=1,2 \ldots\right\}$ is a deterministic trend process satisfying

$$
\frac{\xi_{\mathrm{t}+1}}{\xi_{\mathrm{t}}}=\mathrm{v}^{*}
$$

while random productivity $\left\{v_{t+1}, t=1,2, \ldots\right\}$ is a Markov process of the form

$$
\log \left(v_{t+1}\right)=\lambda_{v} \log \left(v_{t}\right)+\rho_{t+1}^{v} \quad, \quad \rho_{t}^{v} \sim N\left(0, \sigma_{v}^{2}\right) \text { i.i.d. }
$$

Most productivity studies set the quarterly mean rate of technological change so that $v^{*}=1.0045$ and this is the value we use in all our computations.

The key parameters for the traditional RBC literature are $\left(\lambda_{v}, \sigma_{v}\right)$. To replicate the U.S. quarterly data they were set at $\lambda_{v}=.976, \sigma_{v}=.0072$ but evidence shows endogenous variables account for as much as $75 \%$ of the specified value of the variance and hence $\sigma_{v}$ should be a fraction of .0072 . The problem is that for lower values of this parameter the RBC model fails to generate volatility (see King and Rebelo [1999], Fig. 8, page 965). In accord with the empirical evidence, these parameters are set in our model at $\sigma=.35, \lambda_{v}=.976, \sigma_{v}=.002$.

The aggregate capital accumulation equation is, as usual,

$$
\mathrm{K}_{\mathrm{t}}=(1-\delta) \mathrm{K}_{\mathrm{t}-1}+\mathrm{I}_{\mathrm{t}}
$$

where $\delta$ is the rate of depreciation and $I_{t}$ are new units of capital goods placed into production at time $\mathrm{t}$ (inputs on which would have been expanded at $\mathrm{t}-1$ ) by the investment goods sector. Most studies set $\delta=.025$ and this is the value used in our model. Now let $\mathrm{k}_{\mathrm{t}}=\frac{\mathrm{K}_{\mathrm{t}}}{\xi_{\mathrm{t}}}$ and we have

$$
Y_{t}=A v_{t} \xi_{t} L_{t}\left(\frac{K_{t-1}}{\xi_{t} L_{t}}\right)^{\sigma}=A v_{t} \xi_{t} L_{t}\left(\frac{k_{t-1}}{v^{*} L_{t}}\right)^{\sigma}
$$

Introduce the notations $i_{t}=\frac{I_{t}}{\xi_{t}}, w_{t}=\frac{W_{t}^{N}}{\xi_{t} P_{t}}$ and $g_{t}=\frac{Y_{t}}{\xi_{t}}$ hence 


$$
g_{t}=\frac{Y_{t}}{\xi_{t}}=A v_{t} L_{t}\left(\frac{k_{t-1}}{v^{*} L_{t}}\right)^{\sigma}
$$

We thus have

$$
\mathrm{k}_{\mathrm{t}}=(1-\delta) \frac{\mathrm{k}_{\mathrm{t}-1}}{\mathrm{v}^{*}}+\mathrm{i}_{\mathrm{t}}
$$

Since $q_{t}=\frac{\tilde{q}_{t}^{s}}{P_{t}}$ is the real price of a unit of capital, in equilibrium the real wage rate $w_{t}$ and the rental rate on capital $\mathrm{R}_{\mathrm{t}}$ are defined by the marginal productivity conditions

$$
\begin{aligned}
& \mathrm{w}_{\mathrm{t}}=A v_{\mathrm{t}}(1-\sigma)\left(\frac{\mathrm{k}_{\mathrm{t}-1}}{\mathrm{v}^{*} \mathrm{~L}_{\mathrm{t}}}\right)^{\sigma} \\
& \mathrm{R}_{\mathrm{t}}=A v_{\mathrm{t}} \sigma\left(\frac{\mathrm{k}_{\mathrm{t}-1}}{\mathrm{v}^{*} \mathrm{~L}_{\mathrm{t}}}\right)^{\sigma-1}-\delta \mathrm{q}_{\mathrm{t}}{ }^{\mathrm{s}} .
\end{aligned}
$$

\section{The Investment Sector}

Heterogeneity of investment activities is the main new feature of our technology, used to model the risky choice among investment opportunities. Investments embody new technologies, new products and new processes of production. Such capacities may be successfully incorporated into the economy but may fail and be replaced by alternative products or methods of production. These features reflect the well documented fact that most new firms or enterprises fail and a significant proportion of investments in new technologies do not achieve their goal and need to be reconfigured or scrapped altogether. Uncertainty in production of capital goods also incorportates the risk of associated with the diversification strategy of firms across different product lines or economic sectors as distinct from specialization on one industry or product. In such cases the risk reflects many different factors. For example, drilling for oil is associated with the direct risk of 
finding oil; the risk of building massive capacity of fiber optics communication network results from the risk of future demand for such capacities, as has been recently illustrated in the last two years and the risk of massive building of real estate capacity on foreign credit is associated with future fluctuations of the foreign exchange rate as has been the case in the last financial crisis in South East Asia. Since our model does not have heterogenous commodities to reflect all these risks, we introduce this uncertainty in the form of the number of units of realized capital goods which result at each date from an input of one unit of consumption goods one date earlier.

The essential character of investment decisions in our model is their crucial dependence upon the structure of expectations in the economy. From the formal point of view we could introduce a large number of investment activities and then work out the optimal mix. However, an examination of the model shows that there is little to gain from using a large number of investment opportunities and simplicity of computations dictates our use of only two possible activities. In addition, since the main issue to be examined is the effect of heterogeneity of expectations on investments, the model's two activities make it much easier to understand both the rationality conditions on the beliefs of the agents and the mechanism propagating volatility. The two constant returns to scale investment activities transform consumer goods into a random number of units of capital goods depending upon the realized state $\varphi_{\mathrm{t}}$. The random output of the two activities is specified in the following way:

(5a) Technology I (M): Input: 1 unit of consumption good; $\underline{\text { Output }_{t+1}^{M}}=\kappa_{t+1}^{M}=d_{1}+\frac{d_{2}-d_{1}}{1+e^{-\chi^{\varphi} \varphi_{t+1}}}$ (5b) Technology II (S): $\underline{\text { Input: }} 1$ unit of consumption good; $\underline{\text { Output }} \mathrm{S}_{t+1}^{\mathrm{S}}=\kappa_{\mathrm{t+1}}^{\mathrm{S}}=\mathrm{s}_{1}+\frac{\mathrm{S}_{2}-\mathrm{s}_{1}}{1+\mathrm{e}^{-\chi^{\varphi} \varphi_{\mathrm{t}+1}}}$ where $\varphi_{\mathrm{t}} \sim \mathrm{N}\left(0, \sigma_{\varphi}\right)$, i.i.d. In any discussion of an REE agents will be assumed to know this 
distributional fact while in an RBE their perspective is different. They will know that the long term frequency of the states, called the stationary measure over the states, is represented by the i.i.d. random variable $\varphi_{\mathrm{t}} \sim \mathrm{N}\left(0, \sigma_{\varphi}\right)$ but they do not know that this is the truth. The true process may be any process that has the same empirical distribution.

We assume that relative to the distribution $\varphi_{\mathrm{t}} \sim \mathrm{N}\left(0, \sigma_{\varphi}\right)$, it is optimal to fully diversify investments leading to a perfect hedged position and no aggregate uncertainty. To clarify this assumption consider the case $\mathrm{d}_{1}=.85, \mathrm{~d}_{2}=.95, \mathrm{~s}_{1}=1.05, \mathrm{~s}_{2}=.75, \chi^{\varphi}=3$ used in the main simulations of this paper. If an agent invests 1 unit with proportions $\left(\mathrm{I}^{\mathrm{M}}=3 / 4, \mathrm{I}^{\mathrm{S}}=1 / 4\right)$ he ensures the production of .90 units of capital in all states. His expected value is also .90 hence diversification is optimal and in an economy where agents believe that $\varphi_{\mathrm{t}} \sim \mathrm{N}\left(0, \sigma_{\varphi}\right)$ is the truth, all agents will have a fully diversified investment portfolio with no fluctuations in the level or realized cost of investments.

In an economy with diverse beliefs agents do not fully diversify. The rational beliefs held by agents are specified in detail later and have a simple character. They believe that the mean value function of the process $\left\{\varphi_{\mathrm{t}}, \mathrm{t}=1,2,3, \ldots\right\}$ fluctuates over time and they have subjective models about this value. Since the long term moments of $\varphi_{\mathrm{t}}$ are $\left(0, \sigma_{\varphi}\right)$ and 0 outocorrelation, the rationality conditions require the agents' models to be statistically compatible with these. However, at each date they do not believe that the mean value is zero hence their optimal investment portfolio will vary depending upon their beliefs.

\footnotetext{
${ }^{5}$ Our assumption of the optimality of a perfect hedge is made for convenience only. It is motivated by computational ease since the perturbation method used here enables us to compute the equilibrium using the steady state as a reference point. The case where full diversification is not optimal raises only computational difficulties, not conceptual ones.
} 


\section{$1.2 \quad$ The Infinitely Lived Agents}

We first introduce the following notation: for $\mathrm{k}=1,2$

$\mathrm{C}_{\mathrm{t}}^{\mathrm{k}}$ - consumption of $\mathrm{k}$ at $\mathrm{t}$;

$l_{\mathrm{t}}^{\mathrm{k}}=1-\mathrm{L}_{\mathrm{t}}^{\mathrm{k}}-$ leisure of $\mathrm{k}$ at $\mathrm{t}$;

$\mathrm{K}_{\mathrm{t}}^{\mathrm{kd}}$ - amount of capital stock purchases by $\mathrm{k}$ on the open market at $\mathrm{t}$;

$\mathrm{K}_{\mathrm{t}-1}^{\mathrm{k}}$ - amount of capital owned by $\mathrm{k}$ at $\mathrm{t}$ and used in production at $\mathrm{t}$;

$\mathrm{N}_{\mathrm{t}}{ }^{\mathrm{kM}}$-input (in units of consumption goods)of $\mathrm{k}$ in investments technology $\mathrm{M}$ at $\mathrm{t}$;

$\mathrm{N}_{\mathrm{t}}^{\mathrm{kS}}$ - input (in units of consumption goods) of $\mathrm{k}$ in investments technology $\mathrm{S}$ at $t$;

$\mathrm{N}_{\mathrm{t}}^{\mathrm{k}}=\mathrm{N}_{\mathrm{t}}^{\mathrm{kM}}+\mathrm{N}_{\mathrm{t}}^{\mathrm{kS}}$ total input of agent $\mathrm{k}$ in investments technology at $\mathrm{t}$;

$\mathrm{I}_{\mathrm{t}}{ }^{\mathrm{k}}$ - total output of new investments (in units of capital goods) of $\mathrm{k}$ at date $\mathrm{t}$;

$\mathrm{B}_{\mathrm{t}}{ }^{\mathrm{k}}$ - amount of one period nominal bill purchased by agent $\mathrm{k}$ at $\mathrm{t}$;

$\mathrm{q}_{\mathrm{t}}^{\mathrm{b}}$ - the price of a one period bill at $\mathrm{t}$. This is a discount price;

$\mathrm{M}_{\mathrm{t}}^{\mathrm{k}}$ - amount of money held by agent $\mathrm{k}$ at $\mathrm{t}$;

$\frac{M_{t}}{M_{t-1}}=\varrho_{t}$ - random growth rate of money supply when it is a policy instrument;

$\mathrm{H}_{\mathrm{t}}$ - history of all observables up to $\mathrm{t}$.

Before formulating the agents' optimization we need to clarify the issue of timing. At date t agent $\mathrm{k}$ invests $\left(\mathrm{N}_{\mathrm{t}}^{\mathrm{kM}}, \mathrm{N}_{\mathrm{t}}{ }^{\mathrm{kS}}\right)$ and at the start of date $\mathrm{t}+1$ the random realization takes place in the investment goods sector, before the rate of technical progress is realized. The new capital $\mathrm{I}_{\mathrm{t}}{ }^{\mathrm{k}}$ joining production is added to $\mathrm{K}_{\mathrm{t}}^{\mathrm{d}}=\mathrm{K}_{\mathrm{t}}^{1 \mathrm{~d}}+\mathrm{K}_{\mathrm{t}}^{2 \mathrm{~d}}$ to form the capital $\mathrm{K}_{\mathrm{t}}$ used in production at date $\mathrm{t}+1$. This implies $\mathrm{I}_{\mathrm{t}}^{\mathrm{k}}=\kappa_{\mathrm{t}+1}^{\mathrm{M}} \mathrm{N}_{\mathrm{t}}^{\mathrm{kM}}+\mathrm{\kappa}_{\mathrm{t}+1}^{\mathrm{S}} \mathrm{N}_{\mathrm{t}}^{\mathrm{kS}}, \mathrm{k}=1,2$ which is somewhat odd notation. This odd feature is unavoidable since we compress into one date two random realizations: first of $\varphi_{t}$ and then of $v_{t}$ - the rate of technological progress. Now, denote by $N_{t}=N_{t}{ }^{1}+N_{t}^{2}$ the inputs into 
the investment sector. Output of new investments at date $t$ is affected by $\varphi_{t}$ and is defined by

$$
\mathrm{I}_{\mathrm{t}-1}^{\mathrm{k}}=\kappa_{\mathrm{t}}^{\mathrm{M}} \mathrm{N}_{\mathrm{t}-1}^{\mathrm{kM}}+\kappa_{\mathrm{t}}^{\mathrm{S}} \mathrm{N}_{\mathrm{t}-1}^{\mathrm{kS}} \quad \mathrm{k}=1,2
$$

We thus define $\mathrm{I}_{\mathrm{t}}^{\mathrm{N}}$, the value of new investments placed into production at date $\mathrm{t}$, to be

$$
\left.\mathrm{I}_{\mathrm{t}}^{\mathrm{N}}=\tilde{\mathrm{q}}_{\mathrm{t}}^{\mathrm{s}}\left(\mathrm{I}_{\mathrm{t}-1}^{1}+\mathrm{I}_{\mathrm{t}-1}^{2}\right) \quad \text { (while noting that } \mathrm{I}_{\mathrm{t}-1}=\mathrm{I}_{\mathrm{t}-1}^{1}+\mathrm{I}_{\mathrm{t}-1}^{2}\right)
$$

and GNP, denoted $Y_{t}^{N}$, by $Y_{t}^{N}=Y_{t}-N_{t}+I_{t}^{N}$. Define $g^{N}=\frac{Y_{t}^{N}}{\xi_{t}}, g_{t}=\frac{Y_{t}}{\xi_{t}}$, and the income identity becomes

$$
g_{t}^{N}=g_{t}-n_{t}+i_{t}^{N}
$$

Now, for any probability belief $\mathrm{Q}^{\mathrm{k}}$ of agent $\mathrm{k}$, his problem is then to maximize the utility

$$
\operatorname{Max} E_{Q^{k}}\left[\sum_{t=1}^{\infty} \beta_{k}^{t-1} \frac{1}{1-\gamma_{k}}\left(\left(C_{t}^{k}\left(l_{t}^{k}\right)^{\zeta}\right)^{1-\gamma_{k}}+\left(\frac{M_{t}^{k}}{P_{t}}\right)^{1-\gamma_{k}}\right) \mid H_{t}\right], \quad 0<\beta_{k}<1
$$

subject to the budget constraint

$$
\begin{gathered}
\mathrm{P}_{\mathrm{t}} \mathrm{C}_{\mathrm{t}}^{\mathrm{k}}+\mathrm{K}_{\mathrm{t}}^{\mathrm{kd}} \tilde{\mathrm{q}}_{\mathrm{t}}^{\mathrm{s}}+\left(\mathrm{N}_{\mathrm{t}}^{\mathrm{kM}}+\mathrm{N}_{\mathrm{t}}^{\mathrm{kS}}\right) \mathrm{P}_{\mathrm{t}}+\mathrm{B}_{\mathrm{t}}{ }^{\mathrm{k}} \mathrm{q}_{\mathrm{t}}^{\mathrm{b}}-\left(1-l_{\mathrm{t}}^{\mathrm{k}}\right) \tilde{\mathrm{W}}_{\mathrm{t}}-\mathrm{K}_{\mathrm{t}-1}^{\mathrm{k}}\left(\tilde{\mathrm{q}}_{\mathrm{t}}^{\mathrm{s}}+\mathrm{R}_{\mathrm{t}} \mathrm{P}_{\mathrm{t}}\right)-\mathrm{B}_{\mathrm{t}-1}^{\mathrm{k}}+\mathrm{M}_{\mathrm{t}}^{\mathrm{k}}-\mathrm{M}_{\mathrm{t}-1}^{\mathrm{k}} \mathrm{\varrho}_{\mathrm{t}}=0 \\
\mathrm{I}_{\mathrm{t}-1}^{\mathrm{k}}=\kappa_{\mathrm{t}}^{\mathrm{M}} \mathrm{N}_{\mathrm{t}-1}^{\mathrm{kM}}+\kappa_{\mathrm{t}}^{\mathrm{s}} \mathrm{N}_{\mathrm{t}-1}^{\mathrm{kS}}, \mathrm{N}_{\mathrm{t}}^{\mathrm{kM}} \geq 0, \mathrm{~N}_{\mathrm{t}}^{\mathrm{kS}} \geq 0 \\
\mathrm{~K}_{\mathrm{t}-1}^{\mathrm{k}}=\mathrm{K}_{\mathrm{t}-1}^{\mathrm{kd}}+\mathrm{I}_{\mathrm{t}-1}^{\mathrm{k}}
\end{gathered}
$$

Note the distinction between capital $\mathrm{K}_{\mathrm{t}}^{\mathrm{kd}}$ purchased at $\mathrm{t}$ on the open market and $\mathrm{K}_{\mathrm{t}-1}^{\mathrm{k}} \mathrm{used}$ in production at $\mathrm{t}$ and owned by the agent at that time. Also, the notation for $\mathrm{I}_{\mathrm{t}-1}^{\mathrm{k}}$ shows that we assume the inputs into investments take place at $\mathrm{t}-1$, the realization of all random factors in the investment sector take place at the start of date $t$ and hence $\mathrm{I}_{\mathrm{t}-1}^{\mathrm{k}}$ is the number of new units of capital produced at the end of $\mathrm{t}-1$ and placed into production at the start of date $\mathrm{t}$. We normalize the problem by $c_{t}{ }^{k}=\frac{C_{t}{ }^{k}}{\xi_{t}}, \quad q_{t}{ }^{s}=\frac{\tilde{q}_{t}{ }^{s}}{P_{t}}, b_{t}{ }^{k}=\frac{B_{t}{ }^{k}}{P_{t} \xi_{t}}, \quad \frac{M_{t}}{P_{t} \xi_{t}}=m_{t}, \frac{M_{t}{ }^{k}}{P_{t} \xi_{t}}=m_{t}{ }^{k}, \frac{M_{t-1}{ }^{k}}{P_{t} \xi_{t}}=\frac{m_{t-1}{ }^{k}}{\pi_{t} v_{t}}$, $\mathrm{n}_{\mathrm{t}}{ }^{\mathrm{k}}=\frac{\mathrm{N}_{\mathrm{t}}{ }^{\mathrm{k}}}{\xi_{\mathrm{t}}}, \quad \mathrm{i}_{\mathrm{t}}{ }^{\mathrm{k}}=\frac{\mathrm{I}_{\mathrm{t}}{ }^{\mathrm{k}}}{\xi_{\mathrm{t}}}, \quad \mathrm{k}_{\mathrm{t}}{ }^{\mathrm{k}}=\frac{\mathrm{K}_{\mathrm{t}}{ }^{\mathrm{k}}}{\xi_{\mathrm{t}}}, \quad \mathrm{K}_{\mathrm{t}}{ }^{\mathrm{kd}}=\frac{\mathrm{K}_{\mathrm{t}} \mathrm{kd}_{\mathrm{t}}}{\xi_{\mathrm{t}}}$. Using (5a)-(5b) and $\frac{\mathrm{P}_{\mathrm{t}+1}}{\mathrm{P}_{\mathrm{t}}}=\pi_{\mathrm{t}+1}$, the maximization problem becomes: 


$$
\operatorname{Max} E_{Q} \sum_{t=1}^{\infty} \beta_{k}^{t-1} \frac{1}{1-\gamma_{k}}\left[\left(c_{t}{ }^{k} \xi_{t}\left(l_{t}^{k}\right)^{\zeta}\right)^{1-\gamma_{k}}+\left(m_{t}{ }^{k} \xi_{t}\right)^{1-\gamma_{k}}\right], \quad 0<\beta_{k}<1
$$

subject to

$\left(6 b^{\prime}\right) c_{t}{ }^{k}=\left(1-l_{t}^{k}\right) w_{t}+\frac{k_{t-1}^{k}}{u^{*}}\left(q_{t}{ }^{s}+R_{t}\right)+\frac{m_{t-1}^{k} \varrho_{t}+b_{t-1}^{k}}{u^{*} \pi_{t}}-k_{t}{ }^{k d} q_{t}{ }^{s}-\left(n_{t}{ }^{k M}+n_{t}{ }^{k S}\right)-b_{t}{ }^{k} q_{t}{ }^{b}-m_{t}{ }^{k}$,

$$
\begin{gathered}
\mathrm{i}_{\mathrm{t}-1}^{\mathrm{k}}=\kappa_{\mathrm{t}}^{\mathrm{M}} \mathrm{n}_{\mathrm{t}-1}^{\mathrm{kM}}+\kappa_{\mathrm{t}}^{\mathrm{S}} \mathrm{n}_{\mathrm{t}-1}^{\mathrm{kS}}, \mathrm{n}_{\mathrm{t}-1}^{\mathrm{kM}} \geq 0, \mathrm{n}_{\mathrm{t}-1}^{\mathrm{kS}} \geq 0, \\
\mathrm{k}_{\mathrm{t}-1}^{\mathrm{k}}=\mathrm{k}_{\mathrm{t}-1}^{\mathrm{kd}}+\mathrm{i}_{\mathrm{t}-1}^{\mathrm{k}} .
\end{gathered}
$$

To simplify the statement of the Euler equations we ignore constraints (6c') and return to it only in Appendix B where we discuss the computational issues raised by the model. Hence, the first order conditions for labor supply are

$$
\mathrm{c}_{\mathrm{t}}^{\mathrm{k}}=\frac{1}{\zeta} l_{\mathrm{t}}^{\mathrm{k}} \mathrm{w}_{\mathrm{t}} .
$$

Next, the first order condition with respect capital purchased on the open market $\mathrm{k}_{\mathrm{t}}^{\mathrm{kd}}$ is

$$
\left(c_{t}\right)^{k}{ }^{-\gamma_{k}}\left(\left(l_{t}^{k}\right)^{\zeta}\right)^{1-\gamma_{k}} q_{t}^{s}=\beta_{k} E_{Q^{k}}\left(c_{t+1}^{k}\right)^{-\gamma_{k}}\left(\left(l_{t+1}^{k}\right)^{\zeta}\right)^{1-\gamma_{k}}\left[\frac{q_{t+1}^{s}+R_{t+1}}{\left(u^{*}\right)^{\gamma_{k}}}\right]
$$

The optimality condition with respect to $n_{t}{ }^{k M}$ is

$$
\left(c_{t}\right)^{k}{ }^{-\gamma}\left(\left(l_{t}^{k}\right)^{\zeta}\right)^{1-\gamma_{k}} q_{t}^{s}=\beta_{k} E_{Q^{k}}\left(c_{t+1}^{k}\right)^{-\gamma_{k}}\left(\left(l_{t+1}^{k}\right)^{\zeta}\right)^{1-\gamma_{k}}\left[\frac{\mathrm{q}_{t+1}^{s}+R_{t+1}}{\left(u^{*}\right)^{\gamma_{k}}} \kappa_{t+1}^{M}\right]
$$

and the condition with respect to $\mathrm{n}_{\mathrm{t}}^{\mathrm{kS}}$ is

$$
\left(c_{t}{ }^{k}\right)^{-\gamma_{k}}\left(\left(l_{t}^{k}\right)^{\zeta}\right)^{1-\gamma_{k}} q_{t}{ }^{s}=\beta_{k} E_{Q^{k}}\left(c_{t+1}^{k}\right)^{-\gamma}\left(\left(l_{t+1}^{k}\right)^{\zeta}\right)^{1-\gamma_{k}}\left[\frac{\mathrm{q}_{t+1}{ }^{s}+R_{t+1}}{\left(v^{*}\right)^{\gamma_{k}}} \kappa_{t+1}^{s}\right] .
$$

The first order condition with respect to $b_{t}^{k}$ is

$$
\left(c_{t}{ }^{k}\right)^{-\gamma_{k}}\left(l_{t}^{k}\right)^{\zeta\left(1-\gamma_{k}\right)} q_{t}{ }^{b}=\beta_{k} E_{Q^{k}}\left(c_{t+1}^{k} v_{t+1}\right)^{-\gamma_{k}}\left(l_{t+1}^{k}\right)^{\zeta\left(1-\gamma_{k}\right)} \frac{1}{\left(u^{*}\right)^{\gamma_{k}} \pi_{t+1}} .
$$

Finally, the optimum with respect to money holdings requires

$$
\left(c_{t}\right)^{k}{ }^{-\gamma_{k}}\left(l_{t}^{k}\right)^{\zeta\left(1-\gamma_{k}\right)}-\left(m_{t}{ }^{k}\right)^{-\gamma_{k}}=\beta_{k} E_{Q^{k}}\left[\left(c_{t+1}^{k} v_{t+1}\right)^{-\gamma_{k}}\left(l_{t+1}^{k}\right)^{\zeta\left(1-\gamma_{k}\right)}\right] \frac{\varrho_{t+1}}{\left(v^{*}\right)^{\gamma_{k}} \pi_{t+1}} .
$$

\subsection{Monetary Policy}

The monetary policy used in our model is the familiar monetary injection according to 
which the central bank increases the money supply by a random amount of $\left(\varrho_{t+1}-1\right) M_{t}$. In this

case the quantity $M_{t}{ }^{k}$, date $t$ money holding of agent $k$, increases to $\varrho_{t+1} M_{t}{ }^{k}$ at date $t+1$. Agents observe the monetary shock and since they also observe the real shocks $\left(v_{t}, \varphi_{t}\right)$ the state of the economy is fully observed.

We do not propose that random variations in the money supply is a serious monetary policy that may be pursued by any central bank. This paper is a theoretical investigation and our simulations provide only a quantitative evaluation of the order of magnitude of equilibrium variables. The policy of an exogenous money supply is then a simple tool to study the effect of beliefs on economic fluctuations and on money neutrality. It will also enable us to discuss the role which a real monetary policy should play in economic stabilization.

\subsection{Equilibrium}

For each set of probability beliefs $\left(Q^{1}, Q^{2}\right)$ of the agents on infinite sequences of observed variables, a monetary equilibrium of the economy is defined by equations: (3a), (3b), (4a), (4b), (6b'), (7a)- (7f), and by the following additional conditions:

Money growth. The money supply satisfies

$$
\mathrm{m}_{\mathrm{t}}=\frac{\varrho_{\mathrm{t}}}{\pi_{\mathrm{t}} \mathrm{v}_{\mathrm{t}}} \mathrm{m}_{\mathrm{t}-1} .
$$

Market clearing conditions. Given the accounting in (6a')-(6d') we aggregate to establish two equations. One accounting identity, specifying the amount of capital employed at date $t$

$$
\mathrm{K}_{\mathrm{t}-1}=\mathrm{K}_{\mathrm{t}-1}^{1}+\mathrm{K}_{\mathrm{t}-1}^{2}
$$

and a market clearing condition in the market for installed capital at date $\mathrm{t}$

$$
\mathrm{K}_{\mathrm{t}}^{1 \mathrm{~d}}+\mathrm{K}_{\mathrm{t}}^{2 \mathrm{~d}}=\mathrm{K}_{\mathrm{t}-1}(1-\delta)
$$


The dynamics of capital employed is then defined by

$$
\begin{gathered}
\mathrm{K}_{\mathrm{t}}=\mathrm{K}_{\mathrm{t}-1}(1-\delta)+\mathrm{I}_{\mathrm{t}-1} \\
\mathrm{I}_{\mathrm{t}-1}=\mathrm{I}_{\mathrm{t}-1}^{1}+\mathrm{I}_{\mathrm{t}-1}^{2}=\kappa_{\mathrm{t}}^{\mathrm{M}}\left(\mathrm{N}_{\mathrm{t}-1}^{1 \mathrm{M}}+\mathrm{N}_{\mathrm{t}-1}^{2 \mathrm{M}}\right)+\kappa_{\mathrm{t}}^{\mathrm{S}}\left(\mathrm{N}_{\mathrm{t}-1}^{1 \mathrm{~S}}+\mathrm{N}_{\mathrm{t}-1}^{2 \mathrm{~S}}\right) .
\end{gathered}
$$

After normalization we thus have the identities

$$
\begin{array}{cc}
\mathrm{k}_{\mathrm{t}}^{1}+\mathrm{k}_{\mathrm{t}}^{2}=\mathrm{k}_{\mathrm{t}} & \text { for all } \mathrm{t} \\
\mathrm{i}_{\mathrm{t}-1}^{\mathrm{k}}=\kappa_{\mathrm{t}}^{\mathrm{M}} \mathrm{n}_{\mathrm{t}-1}^{\mathrm{kM}}+\kappa_{\mathrm{t}}^{\mathrm{S}} \mathrm{n}_{\mathrm{t}-1}^{\mathrm{kS}}, \mathrm{k}=1,2 & \text { for all } \mathrm{t}
\end{array}
$$

and the market clearing conditions

$$
\begin{array}{ll}
\mathrm{k}_{\mathrm{t}}=\mathrm{k}_{\mathrm{t}-1} \frac{(1-\delta)}{\mathrm{v}^{*}}+\mathrm{i}_{\mathrm{t}-1} & \text { for all } \mathrm{t} \\
\mathrm{k}_{\mathrm{t}}^{1 \mathrm{~d}}+\mathrm{k}_{\mathrm{t}}^{2 \mathrm{~d}}=\mathrm{k}_{\mathrm{t}-1} \frac{(1-\delta)}{\mathrm{v}^{*}} & \text { for all } \mathrm{t} \\
\mathrm{b}_{\mathrm{t}}^{1}+\mathrm{b}_{\mathrm{t}}^{2}=0 & \text { for all } \mathrm{t} \\
\left(1-l_{\mathrm{t}}^{1}\right)+\left(1-l_{\mathrm{t}}^{2}\right)=\mathrm{L}_{\mathrm{t}} & \text { for all } \mathrm{t} \\
\mathrm{m}_{\mathrm{t}}^{1}+\mathrm{m}_{\mathrm{t}}^{2}=\mathrm{m}_{\mathrm{t}} & \text { for all } \mathrm{t}
\end{array}
$$

We turn now to the central question of the beliefs of the agents.

\section{A Rational Belief Equilibrium With Exogenous Money Supply}

In this section we construct the RBE with money supply policy and explain the family of Rational Beliefs which we study. For completeness of exposition we provide in Appendix A an account of the definition of a Rational Belief. For details see Kurz (1997) and for a summary of the theory and the method of constructing an RBE, see Kurz-Motolese (2001). In Appendix A and Section 2.3 we explain the method of assessment variables, used extensively in this paper, for describing a Rational Belief. 


\subsection{The Equilibrium Map}

Our procedure is to construct an RBE for the economy, use perturbation methods to compute it and study its dynamic properties via simulations. However, to define an RBE we need to specify the beliefs of the agents and these cannot be explicitly specified without saying something about the empirical distribution implied by that RBE and its induced stationary measure ${ }^{6}$. To break this circularity we start by studying the structure of an RBE and use it for a general specification of the structure of the stationary measure around which we construct the beliefs of the agents (for details of this constructive approach, see Kurz-Motolese [2001], Section 2.4). Such constructive procedure is possible only when we study a specific family of Rational Beliefs and we comment later on this approach as a method of using the distribution of beliefs in the market to explain aggregate phenomena. We carry out this procedure in several steps.

Recall that in the optimization (6a')-(6b') agent $k$ derives optimal decisions by using belief $\mathrm{Q}_{\mathrm{y}}{ }^{\mathrm{k}}$ conditional on public information and on $\mathrm{y}_{\mathrm{t}}{ }^{\mathrm{k}}$, the value of his own assessment variable. We assume that all portfolios and exogenous shocks $\left(\mathrm{v}_{t}, \mathrm{\varrho}_{t}, \varphi_{t}\right)$ are observable. The observables are $x_{t}=\left(v_{t}, \varrho_{t}, \varphi_{t}, k_{t-1}^{1 d}, n_{t-1}^{1 M}, n_{t-1}^{1 S}, b_{t-1}^{1}, k_{t-1}^{2 d}, n_{t-1}^{2 M}, n_{t-1}^{2 S}, b_{t-1}^{2}, m_{t-1}^{1}, m_{t-1}^{2}, q_{t}^{s}, q_{t}^{b}, \pi_{t}\right)$. To simplify denote lagged endogenous variables $\mathrm{x}_{\mathrm{t}-1}^{\mathrm{E}}=\left(\mathrm{k}_{\mathrm{t}-1}^{1 \mathrm{~d}}, \mathrm{n}_{\mathrm{t}-1}^{1 \mathrm{M}}, \mathrm{n}_{\mathrm{t}-1}^{1 \mathrm{~S}}, \mathrm{~b}_{\mathrm{t}-1}^{1}, \mathrm{~m}_{\mathrm{t}-1}^{1}, \mathrm{k}_{\mathrm{t}-1}^{2 \mathrm{~d}}, \mathrm{n}_{\mathrm{t}-1}^{2 \mathrm{M}}, \mathrm{n}_{\mathrm{t}-1}^{2 \mathrm{~S}}, \mathrm{~b}_{\mathrm{t}-1}^{2}, \mathrm{~m}_{\mathrm{t}-1}^{2}\right)$. Agent $\mathrm{k}$ will thus condition on $\left(x_{t}, y_{t}{ }^{k}\right)$ and hence optimal decisions are functions of the form

$$
\mathrm{k}_{\mathrm{t}}^{\mathrm{kd}}=\mathrm{k}^{\mathrm{kd}}\left(\mathrm{v}_{\mathrm{t}}, \varrho_{\mathrm{t}}, \varphi_{\mathrm{t}}, \mathrm{x}_{\mathrm{t}-1}^{\mathrm{E}}, \mathrm{q}_{\mathrm{t}}^{\mathrm{s}}, \mathrm{q}_{\mathrm{t}}^{\mathrm{b}}, \pi_{\mathrm{t}}, \mathrm{y}_{\mathrm{t}}^{\mathrm{k}}\right) \quad \mathrm{k}=1,2 ;
$$

\footnotetext{
${ }^{6}$ The empirical distribution of the observable variables or their moments induce a probability measure over infinite sequences of observables which is central to the theory of Rational Beliefs. The definition and construction of this probability measure is explained in Appendix A. Any statement in the text about "the stationary measure" or "the empirical distribution" is always a reference to this probability measures. Its centrality to the theory arises from the fact that this probability is derived from public information which is common to all agents and hence the stationary measure is known to all agents and agreed upon by all to reflect the empirical distribution of equilibrium quantities.
} 


$$
\begin{array}{lll}
\mathrm{n}_{\mathrm{t}}^{\mathrm{kM}}=\mathrm{i}^{\mathrm{kM}}\left(v_{\mathrm{t}}, \varrho_{\mathrm{t}}, \varphi_{\mathrm{t}}, \mathrm{x}_{\mathrm{t}-1}^{\mathrm{E}}, \mathrm{q}_{\mathrm{t}}^{\mathrm{s}}, \mathrm{q}_{\mathrm{t}}^{\mathrm{b}}, \pi_{\mathrm{t}}, \mathrm{y}_{\mathrm{t}}{ }^{\mathrm{k}}\right) & \mathrm{k}=1,2 ; \\
\mathrm{n}_{\mathrm{t}}^{\mathrm{kS}}=\mathrm{i}^{\mathrm{kS}}\left(v_{\mathrm{t}}, \varrho_{\mathrm{t}}, \varphi_{\mathrm{t}}, \mathrm{x}_{\mathrm{t}-1}^{\mathrm{E}}, \mathrm{q}_{\mathrm{t}}^{\mathrm{s}}, \mathrm{q}_{\mathrm{t}}^{\mathrm{b}}, \pi_{\mathrm{t}}, \mathrm{y}_{\mathrm{t}}{ }^{\mathrm{k}}\right) & \mathrm{k}=1,2 ; \\
\mathrm{b}_{\mathrm{t}}{ }^{\mathrm{k}}=\mathrm{b}^{\mathrm{k}}\left(\mathrm{v}_{\mathrm{t}}, \varrho_{\mathrm{t}}, \varphi_{\mathrm{t}}, \mathrm{x}_{\mathrm{t}-1}^{\mathrm{E}}, \mathrm{q}_{\mathrm{t}}^{\mathrm{s}}, \mathrm{q}_{\mathrm{t}}^{\mathrm{b}}, \pi_{\mathrm{t}}, \mathrm{y}_{\mathrm{t}}{ }^{\mathrm{k}}\right) & \mathrm{k}=1,2 ; \\
\mathrm{m}_{\mathrm{t}}{ }^{\mathrm{k}}=\mathrm{b}^{\mathrm{k}}\left(v_{\mathrm{t}}, \varrho_{\mathrm{t}}, \varphi_{\mathrm{t}}, \mathrm{x}_{\mathrm{t}-1}^{\mathrm{E}}, \mathrm{q}_{\mathrm{t}}{ }^{\mathrm{s}}, \mathrm{q}_{\mathrm{t}}^{\mathrm{b}}, \pi_{\mathrm{t}}, \mathrm{y}_{\mathrm{t}}{ }^{\mathrm{k}}\right) & \mathrm{k}=1,2 ; \\
l_{\mathrm{t}}^{\mathrm{k}}=\ell^{\mathrm{k}}\left(v_{\mathrm{t}}, \varrho_{\mathrm{t}}, \varphi_{\mathrm{t}}, \mathrm{x}_{\mathrm{t}-1}^{\mathrm{E}}, \mathrm{q}_{\mathrm{t}}^{\mathrm{s}}, \mathrm{q}_{\mathrm{t}}^{\mathrm{b}}, \pi_{\mathrm{t}}, \mathrm{y}_{\mathrm{t}}{ }^{\mathrm{k}}\right) & \mathrm{k}=1,2 .
\end{array}
$$

Market clearing conditions imply that the equilibrium price process $\left\{\left(\mathrm{q}_{\mathrm{t}}{ }^{\mathrm{s}}, \mathrm{q}_{\mathrm{t}}{ }^{\mathrm{b}}, \pi_{\mathrm{t}}\right), \mathrm{t}=1,2, \ldots\right\}$ is thus defined by a map of the form

$$
\left[\begin{array}{c}
\mathrm{q}_{\mathrm{t}}^{\mathrm{s}} \\
\mathrm{q}_{\mathrm{t}}^{\mathrm{b}} \\
\pi_{\mathrm{t}}
\end{array}\right]=\Phi\left(\mathrm{v}_{\mathrm{t}}, \varrho_{\mathrm{t}}, \varphi_{\mathrm{t}}, \mathrm{y}_{\mathrm{t}}{ }^{1}, \mathrm{y}_{\mathrm{t}}^{2}, \mathrm{x}_{\mathrm{t}-1}^{\mathrm{E}}\right)
$$

(10) reveals that the volatility of equilibrium prices is determined by three factors: by exogenous states $\left(v_{t}, \varrho_{t}, \varphi_{t}\right)$, by lagged endogenous variables $x_{t-1}^{E}$ and by the states of belief $\left(y_{t}{ }_{t}^{1}, y_{t}^{2}\right)$. "Endogenous Uncertainty" was defined by Kurz (1974),(1997) as that component of economic volatility which is generated by the distribution of beliefs in the market, represented by $\left(y_{t}^{1}, y_{t}^{2}\right)$. In Section 2.3 we explain that an assessment variables $y_{t}{ }^{k}$ is a simple mathematical representation of a private state of belief. $\mathrm{y}_{\mathrm{t}}{ }^{\mathrm{k}}$ is a privately selected parameter of the agent's belief, uniquely defining his conditional probability belief over observables. The states of an agent's belief are restricted by the rationality of belief conditions, detailed in Appendix A. Rationality conditions are, in essence, familiar moment restrictions which impose empirical regularity on the beliefs induced by $\mathrm{y}_{\mathrm{t}}{ }^{\mathrm{k}}$ for each agent $\mathrm{k}$ and on the manner they affect the conditional probabilities of the observables used by the agent. These restrictions will be specified later.

The Euler equations and the definition of consumption in (6b')-(6d') show that at any date 
$\mathrm{t}$ agent $\mathrm{k}$ needs to forecast three categories of variables:

(i) exogenous variables $\left(v_{t+1}, \varrho_{t+1}, \varphi_{t+1}\right)$ conditional upon $\left(v_{t}, \varrho_{t}, \varphi_{t}\right)$ and other information at $\mathrm{t}$;

(ii) his own decisions at $\mathrm{t}+1,\left(\mathrm{k}_{\mathrm{t}+1}^{\mathrm{kd}}, \mathrm{n}_{\mathrm{t}+1}^{\mathrm{kM}}, \mathrm{n}_{\mathrm{t}+1}^{\mathrm{kS}}, \mathrm{b}_{\mathrm{t}+1}^{\mathrm{k}}, \ell_{\mathrm{t}+1}^{\mathrm{k}}, \mathrm{m}_{\mathrm{t}+1}^{\mathrm{k}}\right)$, which he forecasts based on his own optimal decision functions and a forecast $\mathrm{y}_{\mathrm{t}+1}^{\mathrm{k}}$, of his own assessment;

(iii) other endogenous variables, particularly prices $\left(\mathrm{q}_{\mathrm{t}+1}^{\mathrm{s}}, \mathrm{q}_{\mathrm{t}+1}^{\mathrm{b}}, \pi_{\mathrm{t}+1}\right)$, conditional upon all public information and his own assessment $y_{t}{ }^{k}$.

Forecasting of the agents is explored in the next section when we formulate the beliefs structure. Since the rationality of belief conditions require that all moments of an agent's subjective model be exactly the same as the moments of the empirical distribution (which we call, "the stationary measure") derived from the market data, a formulation of the beliefs (or perception models) of agents necessitates our specifying first the general structure of the stationary measure.

\subsection{Construction of the stationary measure}

Our RBE will be a stochastic perturbation of an economy which has long term steady state variables denoted by $(*)$. Since equilibrium quantities satisfy the Euler equations and the equilibrium map (10), the empirical distribution of all variables is determined jointly by the equilibrium map and the long term behavior of the four key variables $\left(\mathrm{v}_{\mathrm{t}}, \varrho_{\mathrm{t}}, \varphi_{\mathrm{t}}, \mathrm{y}_{\mathrm{t}}{ }^{1}, \mathrm{y}_{\mathrm{t}}^{2}\right)-$ the productivity shock, the monetary shock, investment cost shock and the states of belief. Hence, the construction of an RBE (which follows the same steps used in Kurz and Motolese (2001)) requires us to specify first the long term behavior of $\left(v_{t}, \varrho_{t}, \varphi_{t}, y_{t}^{1}, y_{t}^{2}\right)$. These variables, in turn, determine the long term empirical distribution of the system. Once this is done, we specify the 
beliefs and perception of the agents and impose the rationality conditions which fix the consistency between the empirical distribution of observed market variables and the subjective models of the agents.

We thus assume that the long term behavior of the exogenous variables $\left(v_{t}, \varrho_{t}, \varphi_{t}\right)$ and of the assessment variables $\left(\mathrm{y}_{\mathrm{t}}{ }^{1}, \mathrm{y}_{\mathrm{t}}{ }^{2}\right)$ have the following structure:

$$
\begin{array}{ll}
\log v_{t+1}=\lambda_{\mathrm{v}} \log v_{\mathrm{t}}+\rho_{\mathrm{t}+1}^{\mathrm{v}}, & \rho_{\mathrm{t}}^{\mathrm{v}} \sim \mathrm{N}\left(0, \sigma_{\mathrm{v}}^{2}\right) \text { i.i.d. } \\
\log \varrho_{\mathrm{t}+1}=\log \varrho^{*}+\lambda_{\varrho}\left[\log \varrho_{\mathrm{t}}-\log \varrho^{*}\right]+\rho_{\mathrm{t}+1}^{\varrho}, & \rho_{\mathrm{t}}^{\varrho} \sim \mathrm{N}\left(0, \sigma_{\varrho}^{2}\right) \text { i.i.d. } \\
\varphi_{\mathrm{t}+1}=\rho_{\mathrm{t}+1}^{\varphi}, & \rho_{\mathrm{t}}^{\varphi} \sim \mathrm{N}\left(0, \sigma_{\varphi}^{2}\right) \text { i.i.d. }
\end{array}
$$

The sequence of states $\left\{\left(y_{t}{ }^{1}, y_{t}{ }^{2}\right), t=1,2, \ldots\right\}$ is a realization of a stochastic process of the form

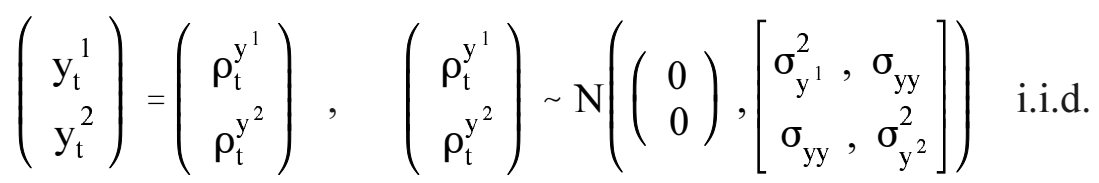

Equation (11a) was discussed earlier. Equations (11b)-(11d) are hypothetical and quantify the assumptions made earlier. Persistence in the monetary shock is introduced in order to evaluate the impact of such persistence; the i.i.d. assumption of the shocks $\varphi_{\mathrm{t}}$ in the investment sector have already been discussed and its implications will be evaluated later. (11d) specifies the empirical regularity of the states of belief and the i.i.d. assumption simplifies the computations and enables a transparant statement of the rationality conditions which are specified later.

We make the following additional simplifying assumptions:

(A1) $\quad\left(\rho_{\mathrm{t}}^{\mathrm{v}}, \rho_{\mathrm{t}}^{\varrho}, \varphi_{\mathrm{t}}, \rho_{\mathrm{t}}^{\mathrm{y}^{1}}, \rho_{\mathrm{t}}^{\mathrm{y}^{2}}\right)$ are mutually independent;

(A2) $\varrho^{*}=v^{*}$ hence $\left(v^{*}, v^{*}\right)$ are the steady state values of $\left(v_{t}, \varrho_{t}\right)$ in the riskless economy and the long term average inflation rate is zero in both REE and RBE; 
(A3) To conform to the RBC literature we specify $\lambda_{v}=.976, \sigma_{v}=.002$ to ensure high persistence in the random technological shock and low variance in accord with our discussion in the introduction to this paper;

(A4) As monetary shocks and the stochastic investment technology are hypothetical, we specify $\sigma_{\varphi}=1, \lambda_{\varrho}=.95, \sigma_{\varrho}=.0052$. This implies the standard deviation of monetary shocks over time is $1 \%$ per quarter. These assumptions are intended to enable a quantitative evaluation of the workings of our model by postulating persistence in the monetary shocks with a reasonable standard deviation. As for $\left(\mathrm{y}_{\mathrm{t}}{ }^{1}, \mathrm{y}_{\mathrm{t}}^{2}\right)$, we assume $\sigma_{\mathrm{y}^{1}}=\sigma_{\mathrm{y}^{2}}=.8$, correlation coefficient $\rho\left(\mathrm{y}^{1}, \mathrm{y}^{2}\right)=.95$ hence $\sigma_{\mathrm{yy}}=.608$.

This completes the specification of the stochastic structure which determines the empirical distribution of all observed variables in the model.

\subsection{The Belief Structure}

\section{3a General Assumptions}

In this section we specify our assumptions about the beliefs of the agents. Assessment variables are the method we use to describe an agent's belief and the structure of such variables is discussed in Appendix A. For completeness, we include a review of this issue here.

(i) The mathematical structure of assessment variables. Let $\mathrm{X}$ be a space of observables and suppose we want to describe, in a tractable manner, the non-stationarity of a dynamical system on

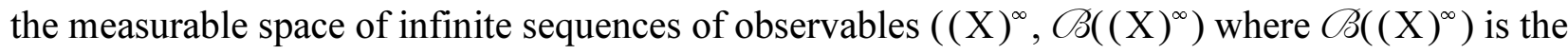
Borel $\sigma$ - field of $(X)^{\infty}$. The Conditional Stability Theorem (see, Kurz and Schneider (1996) and 
Nielsen (1996)) describes non-stationarity via artificial variables $y_{t} \in Y$ with a marginal probability space $\left((\mathrm{Y})^{\infty}, \mathscr{B}\left((\mathrm{Y})^{\infty}, \mu\right)\right.$. It postulates $(\mathrm{X} \times \mathrm{Y})$ to be the state space, introduces a universal probability measure $\mathrm{Q}$ and space $\left((\mathrm{X} \times \mathrm{Y})^{\infty}, \mathscr{B}\left((\mathrm{X} \times \mathrm{Y})^{\infty}, \mathrm{Q}\right)\right.$ and defines the desired non-stationary probability to be $\mathrm{Q}_{\mathrm{y}} \equiv \mathrm{Q}((\bullet) \mid \mathrm{y})$ the, conditional probability of $\mathrm{Q}$ with respect to the sequence y. Q must satisfy the condition that for all $A \in C\left(\mathrm{X}^{\infty}\right)$ and $\mathrm{B} \in \mathscr{\beta}\left(\mathrm{Y}^{\infty}\right)$

$$
\mathrm{Q}(\mathrm{A} \times \mathrm{B})=\int_{\mathrm{B}} \mathrm{Q}_{\mathrm{y}}(\mathrm{A}) \mu(\mathrm{dy})
$$

The effective conditional probability space $\left((\mathrm{X})^{\infty}, \mathcal{B}\left((\mathrm{X})^{\infty}, \mathrm{Q}_{\mathrm{y}}\right)\right.$ implies non-stationary dynamics of the observables since probabilities of events in $\mathscr{B}\left((\mathrm{X})^{\infty}\right)$ are not time independent: they change with the parameters $y_{t}$ which are time dependent. Although the $y_{t}$ are fixed parameters from the point of view of the agent, the stochastic structure above pins down the empirical regularity and timing of these parameters in relation to observables. If $\mathrm{Q}_{\mathrm{y}}$ describes all the non-stationarity of the given system, then we interpret the sequence $\left\{\mathrm{y}_{\mathrm{t}}, \mathrm{t}=1,2, \ldots\right\}$ as a mathematical description of non-stationarity. This approach is common in econometrics where $\mathrm{Y}$ is the set of possible "regimes", $y_{t}$ identifies the regime at $t$ and hence the $y_{t}$ are viewed as "regime variables."

(ii) Economic Interpretation. In this paper we use the above method to describe the perceived non stationarity of agents. Thus, $\mathrm{Q}_{\mathrm{y}_{\mathrm{t}}}{ }^{\mathrm{k}}$ is the date $\mathrm{t}$ probability belief of future observables by $\mathrm{k}$ and $\mathrm{y}_{\mathrm{t}}$, the assessment variable, is used to describe the agent's belief in deviations of the mean value, variance or other moments of the distributions of observable variables from the values specified by the stationary measure. In simple terms, $\mathrm{y}_{\mathrm{t}}{ }^{\mathrm{k}}$ are used to describe how the agent's forecasts deviate from the stationary econometric forecast which is constructed by using all past data under the assumption that the environment is stationary. Several things should be evident: 
(i) deviations from the long term forecast is a judgement based on limited recent data rather than on the regularity of the long term data. Such judgments of "structural breaks" in the process of the observables may be right or wrong. Rational agents are often wrong.

(ii) in a non-stationary environment there is little data to reject an opinion of change in structure.

It is thus usually not possible to demonstrate with high likelihood, that a belief was right or wrong, even in retrospect. Also, even if sufficient data becomes available to determine with high probability if a change of structure actually occurred, such information arrives too late since all important economic decisions would have already been made.

(iii) rational agents do not deviate systematically from the long term stationary econometric forecasts. Hence a Rational Belief is required to generate the same long term moments as the stationary measure. This implies that all long term averages of the agent's conditional forecasts equal the conditional forecast made under the stationary measure.

(iii) Assessment variables provide the minimal structure needed for modeling diverse beliefs. A theory which uses the distribution of beliefs to explain observed market phenomena faces the problem of determining the level of detail in which agents describe how they arrive at the beliefs which they hold. That is, what is the level of detail in which the subjective model of the agent needs to be spelled out? If one insists on complete specification of such modeling, the theory is doomed to get bogged down in endless details about inference from small samples and about information processing. Although such an approach would raise interesting issues, from the perspective of equilibrium theory it is counterproductive and unnecessary. An examination of the Euler equations shows that all equilibrium analysis requires is a specification of the distribution of 
beliefs in the market, expressed as the subjective forecasting equations which are the perceived counterparts of (11a)-(11d). For an agent whose subjective model deviates from (11a)-(11d) we also need to assess the statistical regularity at which he deviates in relation to the observables in order to ensure that the rationality conditions are satisfied. The method of assessment variables provides the minimum structure needed to accomplish exactly this task. We note that the RBE rationality conditions impose exactly the same restrictions as the standard moment conditions with respect to the observables. Hence, to check if the moment restrictions are satisfied, all that we need to know is the empirical regularity of the distribution of beliefs $\left(y_{t}^{1}, y_{t}^{2}\right)$ and the specific manner in which each one of the $y_{t}{ }^{k}$ impacts the perception of the agent in relation to observable variables. Hence, within the structure postulated in this paper the question "how did the agents arrive at their specified perception models" (see perceived models below), is not applicable.

\section{(iv) Rational agents may be wrong and assessment variables are not subject to rationality}

conditions. In an RBE agents typically do not believe that the past is a good guide to the future. An economy with changing technology and products is one in which the commodity space changes with time and hence $\mathrm{y}_{\mathrm{t}}{ }^{\mathrm{k}}$ at different times are tools to describe beliefs about different commodities or technologies. Hence, $y_{t_{1}}{ }^{k}$ and $y_{t_{2}}{ }^{k}$ for $t_{1}$ and $t_{2}$ in different time intervals are simply different objects making comparisons impossible. Under such circumstances one cannot even define a statistical relationships between $y_{t}{ }^{k}$ and the observables and hence there is no sense in which rationality conditions can be required to apply. Thus, the RBE theory has insisted that the $\mathrm{y}_{\mathrm{t}}{ }^{\mathrm{k}}$ are privately perceived parameters and no rationality conditions should apply to them.

The problem is that a model with an infinite dimensional commodity space and an 
infinitely varying regimes is analytically and computationaly untractable. An idealization that results in a tractable modeling strategy is to assume that the commodity space is fixed in size $\mathrm{e}^{7}$ and $\mathrm{y}_{\mathrm{t}}{ }^{\mathrm{k}}$, although private parameter meaningful to agent $\mathrm{k}$ only, be required to have a consistent meaning to an agent through time. But then how do we model the fact that in reality an agent cannot "test" his theory and no rationality conditions should apply to the sequence of $y_{t}{ }^{k}$ ? There are two possible theoretical idealizations which may be employed. First, the infinitely lived agent should be viewed as consisting of an infinite sequence of family members each making economic decisions over a relatively short time. Every decision maker knows only his own $\mathrm{y}_{\mathrm{t}}{ }^{\mathrm{k}}$, but not those of his predecessors. In that case even if an agent can have sufficient data to convince himself that his theory was right or wrong, such data arrives too late to be useful since all important decisions would have already been made. A second interpretation would simply insist that the infinitely lived agent does not remember past values of $y_{t}{ }^{k}$. In either case we formulate the idea that the two agents in the model simply do not know the perceived models of their predecessors. This expresses the idea that any theory of agents about investing in telecommunication technology in the 1990's cannot be improved upon by using experience from investments in PC technology of the 1980 or oil fields in the 1970's.

(v) Assessment variables are not "objective" information. We stress that $\mathrm{y}_{\mathrm{t}}{ }^{\mathrm{k}}$ are generated by an agent himself, providing a vocabulary to describe his belief. From an informational perspective,

\footnotetext{
7 Hence, one defines commodities by their attributes such as "transportation equipment" instead of "airplanes" or "communication services" instead of "telephone". Over time, we then experience change in the cost of producing these services and their prices rather than change in the definitions of the products or services themselves.
} 
$y_{t}{ }^{k}$ are privately perceived variables reflecting how an agent interprets current information. These variables have purely subjective meaning and should not be taken as objective and transferable "information". Technically speaking, decision functions of agent i are not measurable with respect to $y_{t}^{j}$ for $i \neq j$ : agent $i$ would not be able at date $t$ to interpret $y_{t}^{j}$ even if he could "know" it.

(vi) Anonymity Assumption : In an economy with two agents the belief of each one of them has an impact on prices. We require agents to act competitively and assume their own beliefs have no effect on prices and thus they ignore the effect of their own beliefs on equilibrium prices.

In contrast to the anonymity assumption, agents know that market distribution of beliefs impacts prices and hence their forecasting models need to forecast the impact of future distribution of market beliefs on prices without associating their own beliefs with market prices. To explain how this works in our model we note that knowing the stationary measure means knowing all long term unconditional and conditional distributions given observed variables. Hence, using past data agents calculate the long term conditional distribution of prices and other endogenous variables given vectors of observed variables $\mathrm{x}=\left(\mathrm{x}_{\mathrm{t}-1}^{\mathrm{E}}, \mathrm{v}_{\mathrm{t}}, \varrho_{\mathrm{t}}, \varphi_{\mathrm{t}}\right)^{8}$. However, for any vector $\mathrm{x}=\left(\mathrm{x}_{\mathrm{t}-1}^{\mathrm{E}}, \mathrm{v}_{\mathrm{t}}, \varrho_{\mathrm{t}}, \varphi_{\mathrm{t}}\right)$ of "fundamental" variables the long term distribution of prices and other endogenous variables in an RBE is determined by the time variability of the states of belief $\left(y_{t}{ }^{1}, y_{t}^{2}\right)$. Since states of belief are not observed or known by the agents, they deduce their impact from the long term distribution of endogenous variables conditional upon $\left(\mathrm{x}_{\mathrm{t}-1}^{\mathrm{E}}, \mathrm{v}_{\mathrm{t}}, \varrho_{\mathrm{t}}, \varphi_{\mathrm{t}}\right)$. States

${ }^{8}$ Recall that $\mathrm{x}_{\mathrm{t}-1}^{\mathrm{E}}=\left(\mathrm{k}_{\mathrm{t}-1}^{1 \mathrm{~d}}, \mathrm{n}_{\mathrm{t}-1}^{1 \mathrm{M}}, \mathrm{n}_{\mathrm{t}-1}^{1 \mathrm{~S}}, \mathrm{~b}_{\mathrm{t}-1}^{1}, \mathrm{k}_{\mathrm{t}-1}^{2 \mathrm{~d}}, \mathrm{n}_{\mathrm{t}-1}^{2 \mathrm{M}}, \mathrm{n}_{\mathrm{t}-1}^{2 \mathrm{~S}}, \mathrm{~b}_{\mathrm{t}-1}^{2}, \mathrm{~m}_{\mathrm{t}-1}^{1}, \mathrm{~m}_{\mathrm{t}-1}^{2}\right)$ is the vector of lagged endogenous variables and $\left(v_{t}, Q_{t}, \varphi_{t}\right)$ is the vector of three exogenous variables in the model. 
of belief account for the higher volatility of the endogenous variables unexplained by the fundamentals $\left(\mathrm{x}_{\mathrm{t}-1}^{\mathrm{E}}, \mathrm{v}_{\mathrm{t}}, \varrho_{\mathrm{t}}, \varphi_{\mathrm{t}}\right)$. We have named this component of volatility "Endogenous Uncertainty" (e.g. Kurz (1974), (1997)) and this argument shows that in learning the stationary measure agents also get to discover the component of the stationary measure which is induced by the distribution of beliefs. In general, they do not have to believe that the impact of the distribution of beliefs on endogenous variables at any date is the same as their known long term component of the stationary measure. For simplicity we make the simplifying assumption

(vii) Forecasting Assumption PI : Agents believe that the endogenous impact of market states of belief on prices and other endogenous variables is the same as that component which is estimated from the stationary measure.

We finally turn to our last simplifying assumption regarding the forecasting of prices in the model. (viii) Forecasting Assumption PII ${ }^{9}$ : Agents forecast prices using the equilibrium map (10) and perceive the impact of states of belief on prices and other endogenous variables via a variable $z_{t}$ with distributional properties which are the same as the long run distributional properties of the unobserved states of belief $\left(\mathrm{y}_{\mathrm{t}}{ }^{1}, \mathrm{y}_{\mathrm{t}}{ }^{2}\right)$.

Assumption PII is not entirely compatible with postulates of the RBE theory which holds

${ }^{9}$ From the perspective or the theory of Rational Belief this is a strong assumption introduced here mainly to simplify the computation of equilibrium below. A more general approach to a definition of an RBE takes the view that agents treat prices as random variables with unknown probabilities. They then construct their own theories of what the stochastic process of prices is. In such a general setting the stationary measure is endogenously established as a probability of observables only and it cannot be constructed in advance along the simpler lines followed here. 
that agents do not know equilibrium maps or true probability distributions. Assumption PII is made to enable the computations of equilibria with a large number of state variables. We observe that this strong condition amounts to assuming that the RBE of this paper are incomplete Radner Equilibria (see, Radner (1972)) with an expanded state space of the unobserved states of beliefs since the usual Radner equilibrium does not incorporate such unobserved state variables. The market is incomplete since agents have only two assets to trade market uncertainty ${ }^{10}$.

Diverse perceived equilibrium maps is a problem which we hope to explore in future research $^{11}$. However, we stress that in the present model the crucial feature of the RBE is the assumption that states of beliefs are private, that agents do not observe the state of beliefs of others and could not reconstruct them from the equilibrium map since the beliefs of other agents in the past are different and incomparable objects. We turn now to the specification of the belief or perception models of the agents.

\section{$2.3 b \quad$ The Perception Models}

In (11d) we specified the asymptotic behavior of the joint state of belief to be described as a realization of an i.i.d. process. The rationality conditions require that marginal distributions of $\mathrm{y}_{\mathrm{t}}{ }^{\mathrm{k}}$ must have compatible asymptotic properties. Hence, we postulate that the state of belief of

\footnotetext{
${ }^{10}$ For a discussion of the relationship between an RBE and other equilibrium concepts, including sunspot equilibria, see Kurz and Motolese (2001) Section 2.2d, pages 513-517.

${ }^{11}$ An RBE in which agents have their own separate theories of the equilibrium map leads to a much richer theory but dramatically increases the dimension of the state space. The reason is that in a model with diverse beliefs a random variable whose probability distribution is perceived differently by two different agents must be treated in the model as two different random variables. Since their realization is observed by both agents, conditions of observability only appears in the conditional probabilities of the agents. The assumption of diverse perceived equilibrium maps is then associated with additional rationality conditions on the equilibrium maps themselves.
} 
agent $\mathrm{k}$, on his own, takes the form

$$
\mathrm{y}_{\mathrm{t}}^{\mathrm{k}}=\sigma_{\mathrm{z}_{\mathrm{k}}} \mathrm{z}_{\mathrm{t}}^{\mathrm{y}^{\mathrm{k}}}
$$

where $\mathrm{z}_{\mathrm{t}}^{\mathrm{y}^{\mathrm{k}}}$ is a realization of a normal i.i.d. random variable $\tilde{\mathrm{z}}_{\mathrm{t}}^{\mathrm{y}^{\mathrm{k}}} \sim \mathrm{N}(0,1)$. This assumption is adopted because it enables a direct statement of the rationality conditions and it simplifies the computations. On their own, these variables mean nothing; they attain their meaning only when we specify how the agent uses them. Also, keep in mind that a state of belief at date $\mathrm{t}$ is a parameter, not a random variable. We specify the statistical regularity of the state of belief since this regularity is the basis for the rationality conditions to be explained. In the simulations we set the parameter $\sigma_{\mathrm{z}^{\mathrm{k}}}=.8$ for $\mathrm{k}=1,2$.

\section{Perceived Productivity Shocks and their Rationality Conditions}

The beliefs of agent $\mathrm{k}$ is expressed as a stochastic difference equation which takes the following form

$$
\log v_{t+1}^{k}=\lambda_{v} \log v_{t}^{k}+\lambda^{k v}\left(\varrho_{t}^{k}\right) y_{t}^{k}+\sigma_{z^{k v}}\left(\varrho_{t}^{k}\right) \hat{z}_{t+1}^{k v}, \quad \hat{z}_{t}^{k v} \sim N(0,1) .
$$

The agent believes that $\lambda_{v}$ is as specified in (11a) but that the mean value function of the process varies with $y_{t}{ }^{k}$. Since the stationary measure in (11a)-(11d) assumes no long term covariance between productivity shocks, monetary shocks or states of belief, the rationality conditions impose these restrictions. They require that conditional on $\varrho_{\mathrm{t}}^{\mathrm{k}}$, the long term statistics of observables generated by (15) and (11a) are the same when the states of belief $\mathrm{y}_{\mathrm{t}}{ }^{\mathrm{k}}$ are treated as unobserved shifts in the mean value function of the process. More generally, conditional on any set of state variables, the moments of the observables implied by the agent's model must be the same as the moments implied by the stationary measure. No rationality conditions are imposed on $y_{t}{ }^{k}$ or on 
the correlation between $\mathrm{y}_{\mathrm{t}}{ }^{\mathrm{k}}$ and $\log \left(\mathrm{v}_{\mathrm{t}+1}^{\mathrm{k}}\right)$, in accord with our discussion earlier in this section.

In (15) agents form beliefs that $\lambda^{\mathrm{kv}}\left(\varrho_{\mathrm{t}}^{\mathrm{k}}\right)$ and $\sigma_{\mathrm{z}^{\mathrm{kv}}}\left(\varrho_{\mathrm{t}}^{\mathrm{k}}\right)$ depend upon the monetary shock. This assumption is discussed later, in the context of evaluating our results. Focusing here on the rationality conditions, observe first that when discussing perception we write $\varrho_{t}^{\mathrm{k}}$ but rationality requires that for observables, perception equals realizations hence $\varrho_{t}^{\mathrm{k}}=\varrho_{t}$. Next, conditional upon $\varrho_{t}^{k}$ the time averages of $y_{t}{ }^{k}$ and of $\hat{z}_{t}^{k v}$ are both 0 , implying that the time average of the expression

$$
\Upsilon_{t+1}^{k v}=\lambda^{k v}\left(\varrho_{t}^{k}\right) y_{t}^{k}+\sigma_{z^{k v}}\left(\varrho_{t}^{k}\right) \hat{z}_{t+1}^{k v}
$$

is also 0 , as required by (11a). However, (11a) also requires that conditional upon $\varrho_{t}^{k}$ the second moment of $\Upsilon_{t}^{k v}$ equals $\sigma_{v}^{2}$. This leads to the rationality condition on the variance

$$
\left(\lambda^{\mathrm{kv}}\left(\varrho_{\mathrm{t}}^{\mathrm{k}}\right)\right)^{2} \sigma_{\mathrm{z}^{\mathrm{k}}}^{2}+\left(\sigma_{\mathrm{z}^{\mathrm{kv}}}\left(\varrho_{\mathrm{t}}^{\mathrm{k}}\right)\right)^{2}=\sigma_{\mathrm{v}}^{2} .
$$

In fact, conditional upon $\varrho_{t}^{k}$ the empirical distribution of $\Upsilon_{t+1}^{k v}\left(\varrho_{t}^{k}\right)$ is exactly $N\left(0, \sigma_{v}^{2}\right)$. We use a specific functional form in which monetary shocks impact $\lambda^{\mathrm{kv}}\left(\varrho_{t}^{\mathrm{k}}\right)$ and this function is

$$
\lambda^{\mathrm{kv}}\left(\varrho_{\mathrm{t}}^{\mathrm{k}}\right)=\frac{\lambda^{\mathrm{kv}}}{1+\mathrm{e}^{-\chi^{\mathrm{e}\left(\log \varrho_{\mathrm{t}}^{\mathrm{k}}\right)}}}, \quad \chi^{\varrho}>0 .
$$

In $(15 \mathrm{c})$ the function is increasing in the size of monetary shocks and hence such shocks increase the effect of $y_{t}{ }^{k}$ on the perceived mean value of $\log v_{t+1}^{k}$ in (15). The combined equations (15b)-(15c) restrict the values of $\lambda^{\mathrm{kv}}$ and $\sigma_{\mathrm{z}^{\mathrm{kv}}}$ which agents can select in (15). In the simulations we set the values of $\left(\lambda^{\mathrm{kv}}, \chi^{\varrho}\right)$ and the rationality conditions above determine the functional form of $\sigma_{\mathrm{z}^{\mathrm{kv}}}\left(\varrho_{\mathrm{t}}^{\mathrm{k}}\right)$. We have already explained that $\lambda_{\mathrm{v}}=.976, \sigma_{\mathrm{v}}=.002$ and $\sigma_{\mathrm{z}^{\mathrm{k}}}=.8$ for $\mathrm{k}=1,2$. Hence, the feasible range for $\lambda^{\mathrm{kv}}$ is very small. In the simulations we set $\lambda^{\mathrm{kv}}=.002, \chi^{\varrho}=20$ (since $\log \varrho_{t}^{k}$ fluctuates mostly between .03 and -.03) and (15b)-(15c) determine $\sigma_{z^{k v}}$. 


\section{Perceived Monetary Shocks and their Rationality Conditions}

Analogous to (15), the beliefs of agents about future monetary shocks are expressed by

$$
\log \varrho_{t+1}^{k}=\log u^{*}+\lambda_{\varrho}\left(\log \varrho_{t}^{k}-\log u^{*}\right)+\lambda^{k e}\left(\varrho_{t}^{k}\right) y_{t}{ }^{k}+\sigma_{z^{k e}}\left(\varrho_{t}^{k}\right) \hat{z}_{t+1}^{k e} \quad, \quad \hat{z}_{t}^{k e} \sim N(0,1) .
$$

Since the time averages of $y_{t}{ }^{k}$ and of $\hat{z}_{t+1}^{k e}$ are 0 , the time average of

$$
\left.\Upsilon_{t+1}^{k e}=\lambda^{k e}\left(\varrho_{t}^{k}\right) y_{t}^{k}+\sigma_{z^{k e}}\left(\varrho_{t}^{k}\right)\right)_{t+1}^{k e}
$$

is also 0 , as required by (11b). However, (11b) also requires that conditional upon $\varrho_{t}^{k}$ the second moment of $\Upsilon_{t+1}^{\mathrm{ko}}$ equals $\sigma_{\varrho}^{2}$. This leads to the rationality condition on the variance

$$
\left(\lambda^{\mathrm{ke}}\left(\varrho_{\mathrm{t}}^{\mathrm{k}}\right)\right)^{2} \sigma_{\mathrm{z}^{\mathrm{k}}}^{2}+\left(\sigma_{\mathrm{z}^{\mathrm{ke}}}\left(\varrho_{\mathrm{t}}^{\mathrm{k}}\right)\right)^{2}=\sigma_{\varrho}^{2} .
$$

As for the correlation of $\Upsilon_{t+1}^{k e}$ with $\varrho_{t}$, since conditionally upon $\varrho_{t}$ the mean value of $\Upsilon_{t+1}^{k e}$ is 0 , it follows that taking expectations with respect to $\varrho_{t}$ is 0 , as required by (11b). As in (15c) the specific functional form in which monetary shocks affect (16) is

$$
\lambda^{\mathrm{ke}}\left(\varrho_{\mathrm{t}}^{\mathrm{k}}\right)=\frac{\lambda^{\mathrm{k} \varrho}}{1+\mathrm{e}^{-\chi^{\mathrm{e}}\left(\log \mathrm{e}_{\mathrm{t}}^{\mathrm{k}}\right)}} .
$$

These equations restrict the values of $\lambda^{\mathrm{ke}}$ and $\sigma_{\mathrm{z}^{\mathrm{ke}}}$ which the agent can select in (16). We have already selected $\lambda_{\varrho}=.95, \sigma_{\varrho}=.0052, \sigma_{z^{k}}=.8, \chi^{\varrho}=20$ and we now add $\lambda^{\mathrm{k} \varrho}=.01$. These, together with (16b)-(16c) determine the function $\sigma_{z^{k e}}\left(\varrho_{t}\right)$.

\section{Perceived Investment Sector Shocks and their Rationality Conditions}

The perceived shocks in the investment sector are the main propagation mechanism of the model. Indeed, if agents believe that the true process of $\varphi_{\mathrm{t}}$ is i.i.d. as in (11c), they fully diversify their portfolios with $\frac{\mathrm{n}_{\mathrm{t}}^{\mathrm{kS}}}{\mathrm{n}_{\mathrm{t}}^{\mathrm{kS}}+\mathrm{n}_{\mathrm{t}}^{\mathrm{kD}}}=\frac{1}{4}$ resulting in a perfect hedged position and an investment stream of $.9\left(\mathrm{n}_{\mathrm{t}}^{\mathrm{kS}}+\mathrm{n}_{\mathrm{t}}^{\mathrm{kD}}\right)$, independent of $\varphi_{\mathrm{t}}$. In this REE case fluctuations in $\varphi_{t}$ have no effect on the economy. We thus stress that our reference steady state is a risky economy in which 
portfolios are perfectly hedged. In an RBE agents do not believe that (11c) is the truth and hence fluctuations occur: when $\mathrm{y}_{\mathrm{t}}{ }^{\mathrm{k}}>0$ the distribution of $\mathrm{k}$ 's belief moves in favor of project $M$ and when $\mathrm{y}_{\mathrm{t}}{ }^{\mathrm{k}}<0$ the distribution moves in favor of $S$. We postulate the agents perceive shifts in the mean value of $\varphi_{\mathrm{t}}$ in accord with their assessment variables and these shifts of structure take the form:

$$
\left.\varphi_{t+1}^{k}=\lambda^{k \varphi}\left(\varrho_{t}^{k}\right) y_{t}^{k}+\sigma_{z^{k \varphi}}\left(\varrho_{t}^{k}\right)\right)_{t+1}^{k \varphi}, \quad \hat{z}_{t}^{k \varphi} \sim N(0,1) .
$$

Note that variations in the values of $y_{t}{ }^{k}$ impact the perceived mean of $\varphi_{t}^{k} \operatorname{not}$ of $\log \left(\varphi_{t}^{k}\right)$. Since the time averages of $y_{t}{ }^{k}$ and of $\hat{z}_{t+1}^{k \varphi}$ are 0 , the time average of $\lambda^{k \varphi}\left(\varrho_{t}^{k}\right) y_{t}{ }^{k}+\sigma_{z^{k \varphi}}\left(\varrho_{t}^{k}\right) \hat{z}_{t+1}^{k \varphi}$ is also 0 which is the mean of $\varphi_{t}$. As in (15b)-(16b) the rationality condition on the variance is

$$
\left(\lambda^{\mathrm{k} \varphi}\left(\varrho_{\mathrm{t}}^{\mathrm{k}}\right)\right)^{2} \sigma_{\mathrm{z}^{\mathrm{k}}}^{2}+\left(\sigma_{\mathrm{z}^{\mathrm{k} \varphi}}\left(\varrho_{\mathrm{t}}^{\mathrm{k}}\right)\right)^{2}=\sigma_{\varphi}^{2}
$$

where, again, we specify.

$$
\lambda^{\mathrm{k} \varphi}\left(\varrho_{\mathrm{t}}^{\mathrm{k}}\right)=\frac{\lambda^{\mathrm{k} \varphi}}{1+\mathrm{e}^{-\chi^{\mathrm{e}}\left(\log \mathrm{Q}_{\mathrm{t}}^{\mathrm{k}}\right)}} .
$$

These equations restrict the values of $\lambda^{\mathrm{k} \varphi}$ and $\sigma_{\mathrm{z}^{\mathrm{k} \varphi}}$ the agent can select in (17). We have set $\sigma_{\varphi}^{2}=1$ although in a realistic model this parameter should be estimated from the data. Since the process is hypothetical we set $\lambda^{\mathrm{k} \varphi}=1$ and (17a) determines the function $\sigma_{\mathrm{z}^{\mathrm{k} \varphi}}\left(\varrho_{\mathrm{t}}^{\mathrm{k}}\right)$. These specifications will be discussed later.

We finally can state the implication of Forecasting Assumption PI. It says that agents use (11d) for forecasting the future impact of states of belief on endogenous variables and hence we impose the consistency between (11d) and (14) leading to the rationality restrictions:

$$
\sigma_{\mathrm{z}^{\mathrm{k}}}=\sigma_{\mathrm{y}^{\mathrm{k}}} \quad \text { for } \mathrm{k}=1,2 .
$$

\subsection{Comments About the Computation Model and the Parameters}

We compute equilibria using a method of perturbation around the steady state of a riskless 
economy and the details of the computational model are outlined in Appendix B where additional technical assumptions are specified. Here we make some comments to clarify exposition.

Steady State and the Initial Asset Distribution

(i) Given the growth context assumed, in order for the model to have a steady state, we assume $\gamma^{1}=\gamma^{2}=\gamma=1.5, \beta_{1}=\beta_{2}=\beta=.99$ reflecting the quarterly model and $\zeta=3.5$ to ensure that an agent's labor supply equals .2 in steady state .

(ii) Since the riskless steady state depends upon the initial distribution of assets, we assume the symmetry $\theta_{0}^{1}=\theta_{0}^{2}=\frac{1}{2}, \quad \mathrm{~b}_{0}^{1}=\mathrm{b}_{0}^{2}=0, \mathrm{k}_{0}^{\mathrm{kd}}=\frac{1}{2} \mathrm{k}^{\mathrm{d} *}, \mathrm{n}_{0}^{\mathrm{kM}}=\frac{1}{2} \mathrm{n}^{\mathrm{M} *}, \mathrm{n}_{0}^{\mathrm{kS}}=\frac{1}{2} \mathrm{n}^{\mathrm{S} *}$.

(iii) It follows from (i) and (ii) that the only heterogeneity in the model is the diversity of beliefs of the agents.

Accuracy of the Euler equations.

The model has 9 state variables and 12 endogenous variables. In computing equilibria we expand functions to second degree polynomials and hence we compute 780 derivatives. This leads to a much higher precision than in most of the literature, based on log-linearization. A solution is accepted as an equilibrium only if the Euler equations are satisfied with precision of $10^{-3}$ in the $5 \%$ neighborhood of the steady state values of the aggregates (e.g. for values of capital $k_{t}$ in the interval $\left..95 \mathrm{k}^{*} \leq \mathrm{k}_{\mathrm{t}} \leq 1.05 \mathrm{k}^{*}\right)$ and $10^{-2}$ in the $10 \%$ neighborhood of the steady state.

Definition of an REE vs. RBE

Belief parameters of the agents are symmetric. The only asymmetry in the model arises in the 
investment sector as between the two activities. Parameters of the model are based on actual econometric estimates of the corresponding parameters in the economy when available, or they are hypothetical. Beliefs are characterized by the following parameters which are the same for $\mathrm{k}=1,2$

$$
\sigma_{z^{k}}=.8, \lambda^{\mathrm{kv}}=.002, \lambda^{\mathrm{ke}}=.01, \lambda^{\mathrm{k} \varphi}=1 \text { and } \rho_{\mathrm{yy}}=.95, \quad \chi^{\varrho}=20 .
$$

An REE is simply characterized by the conditions, for $\mathrm{k}=1,2$

$$
\lambda^{\mathrm{kv}}=\lambda^{\mathrm{k} \varrho}=\lambda^{\mathrm{k} \varphi}=0, \quad \sigma_{\mathrm{z}^{\mathrm{k}}}^{2}=0, \sigma_{\mathrm{z}^{\mathrm{kv}}}^{2}=\sigma_{\mathrm{v}}^{2}, \sigma_{\mathrm{z}^{\mathrm{ke}}}^{2}=\sigma_{\varrho}^{2}, \sigma_{\mathrm{z}^{\mathrm{k} \varphi}}^{2}=\sigma_{\varphi}^{2}, \mathrm{y}_{\mathrm{t}}^{1}=\mathrm{y}_{\mathrm{t}}^{2}=0 .
$$

As explained in the text, the impact of the small values of $\sigma_{v}$ and $\sigma_{\varrho}$ on the rationality conditions is to reduce the feasible values of $\lambda^{\mathrm{kv}}, \lambda^{\mathrm{ke}}, \sigma_{\mathrm{z}^{\mathrm{kv}}}, \sigma_{\mathrm{z}^{\mathrm{kv}}}$ to a point where they do not have a major effect on the results. The RBE is driven mostly by the two belief parameters $\left(\sigma_{z^{k}}, \lambda^{k \varphi}\right)$ which are the same for $\mathrm{k}=1,2$ and by the parameters of the investment sector.

\subsection{Simulation Results And What Do We Learn From Them.}

We review the results and then evaluate the general implications.

\section{5a Volatility Characteristics}

Table 1 reports the standard deviations, first-order auto-correlations and contemporaneous correlations with output for the key variables in the REE and RBE simulations. All variables are log deviations from the model's deterministic trend. All data is further detrended with HP filter. We view the REE results as a reference to the structure of volatility that would be generated by small and persistent exogenous productivity shocks. Indeed, we know from the RBC literature that with a standard deviation $\sigma_{v}=.002$ such shocks generate only a fraction of the observed 
Table 1: Volatility Characteristics

\begin{tabular}{|l|c|c|c|c|c|c|c|c|}
\hline & \multicolumn{2}{|l|}{$\begin{array}{l}\text { Standard } \\
\text { Deviation }\end{array}$} & \multicolumn{2}{l|}{$\begin{array}{l}\text { Relative Standard } \\
\text { Deviation }\end{array}$} & \multicolumn{2}{l|}{$\begin{array}{l}\text { First-order } \\
\text { auto- } \\
\text { correlation }\end{array}$} & \multicolumn{2}{l|}{$\begin{array}{l}\text { Correlation with } \\
\text { GNP }\end{array}$} \\
\hline & REE & RBE & REE & RBE & REE & RBE & REE & RBE \\
\hline $\log \mathrm{g}^{\mathrm{N}}$ & .33 & 1.80 & 1.00 & 1.00 & .72 & -.08 & 1.00 & 1.00 \\
\hline $\log \mathrm{i}^{\mathrm{N}}$ & .79 & 9.08 & 2.39 & 5.04 & .71 & -.09 & .99 & .91 \\
\hline $\log \mathrm{c}$ & .18 & 1.28 & .55 & .71 & .74 & -.06 & .99 & -.30 \\
\hline $\log \mathrm{L}$ & .12 & 2.04 & .36 & 1.13 & .71 & -.07 & .98 & .30 \\
\hline
\end{tabular}

volatility. Table 1 confirms these observations. In contrast, the table reveals that the level of volatility generated in the RBE is order of magnitude larger than the level generated by small productivity shock. These results exhibit the ability of the RBE to propagate volatility endogenously through the investment decisions of the agents.

Turning to Figure 1, the three panels in that figure exhibit time series of HP filtered observations on $\log (\mathrm{gnp}), \log ($ investment) and $\log$ (hours). They supplement Table 1 and show the relative volatility induced endogenously by the RBE vs. the exogenous technological shocks.

\section{FIGURE 1: THREE PANELS}

Table 1 also shows that the RBE fails to exhibit a correlation structure which is generated by the strong persistence of exogenous productivity shocks. This failure is instructive since it results from our assumptions and provides a deeper understanding of the propagation mechanism of the model.

To explain the above failure of the model, observe first that since agents seek to smooth consumption, their investment and consumption plans depend crucially upon their perception of the persistence of the random shocks they face. High persistence in productivity shocks, which leads to persistence in the random component of the wage rate and the return on investments, leads 
to plans which associate higher investments with higher consumption and hence induce positive correlation among output, consumption and investments. Keeping this in mind, recall the volatility of the RBE is generated by shocks in the investment goods sector and by the temporal behavior of the states of belief. We assume in (11c) that $\varphi_{t}=\rho_{t}^{\varphi}, \rho_{t}^{\varphi} \sim N\left(0, \sigma_{\varphi}^{2}\right)$, i.i.d. In addition, the states of belief are constructed so that over the long term they act as the realization of a sequence of normal variables which are conditionally i.i.d. The conditioning upon the monetary shocks generates some persistence, but the level is small and its effect is second order. Hence, when agents in the RBE believe that attractive investment opportunities are present, they perceive them to be temporary, with little persistence. These strong i.i.d. assumptions guarantee small or negative serial correlation of the variables, and Table 1 shows this to be the case. Moreover, without persistence, large perceived returns on investment projects provide a strong motive for agents to substitute consumption for investments and even to work harder to finance such projects. This explains the negative correlation between consumption and GNP and the negative correlation between consumption and investments. It also explains the low correlation between hours of work and GNP. It is then clear that for a calibrated RBE to exhibit the correlation structure observed in the economy, the RBE will need to exhibit persistence in the rate of return on investments andlor in the states of belief ${ }^{12}$. Casual observations suggest significant persistence in technological opportunities generated by major innovations. Data on states of belief is not extensive but some analysis of the distribution of forecasts made by major financial and industrial corporations compiled by the Blue Chip forecasting suggests high persistence of states of belief.

\footnotetext{
12 To introduce persistence in the states of belief or in the $\varphi_{\mathrm{t}}$ process we would need to add state variables to a model whose equilibrium is already difficult to compute. We have elected not to do so since we view this work as a theoretical analysis which utilizes computation methods rather than a calibration effort.
} 


\section{5b Volume of Trade}

Our economy has two assets which are traded on open markets: nominal bonds and units of ownership in built capital goods. In order to define the volume of trade in the model we make two observations. First, since the nominal debt instrument is of short duration, it matures each period and needs to be traded on the open market again. Since bonds are in zero net supply, the volume of trade in this market is defined by $\mid \mathrm{q}_{t}{ }^{\mathrm{b}} \mathrm{b}_{\mathrm{t}}{ }^{\mathrm{k}}$. The volume of trade in capital goods is more complicated since old units of capital depreciate so that the stock owned by agent $\mathrm{k}$ at date $\mathrm{t}$ before trading is $\left[\mathrm{k}_{\mathrm{t}-1}^{\mathrm{kd}}+\mathrm{i}_{\mathrm{t}-1}^{\mathrm{k}}\right] \frac{1-\delta}{\mathrm{u}^{*}}$. The new amount which he buys is $\mathrm{k}_{\mathrm{t}}^{\mathrm{kd}}$ hence the value of his trade at date $\mathrm{t}$ is $\mathrm{q}_{\mathrm{t}}^{\mathrm{s}}\left(\mathrm{k}_{\mathrm{t}}^{\mathrm{kd}}-\left[\mathrm{k}_{\mathrm{t}-1}^{\mathrm{kd}}+\mathrm{i}_{\mathrm{t}-1}^{\mathrm{k}}\right] \frac{1-\delta}{\mathrm{v}^{*}}\right)$. Since the economy is growing, a meaningful measure of the volume of trade is the value relative to GNP. Thus define the relative volume by

$$
\mathrm{TR}_{\mathrm{t}}=\frac{1}{\mathrm{GNP}_{\mathrm{t}}}\left(\left|\mathrm{q}_{\mathrm{t}}^{\mathrm{s}}\left(\mathrm{k}_{\mathrm{t}}^{1 \mathrm{~d}}-\left[\mathrm{k}_{\mathrm{t}-1}^{1 \mathrm{~d}}+\mathrm{i}_{\mathrm{t}-1}^{1}\right] \frac{1-\delta}{\mathrm{v}^{*}}\right)\right|+\left|\mathrm{q}_{\mathrm{t}}{ }^{\mathrm{b}} \mathrm{b}_{\mathrm{t}}{ }^{1}\right|\right) .
$$

Table 2 reports some statistics based on 1000 simulated observations on TR. The RBE model generates a dramatic volume of trade in relation to GNP and exhibits a large standard deviation of TR. Table 2 reveals that the extreme values are far apart suggesting sharp variations in volume, a result which is consistent with Kurz and Motolese's (2001) results on the dynamics of trade. We

Table 2: Volume of Trade on Financial Markets

\begin{tabular}{|l|c|c|}
\hline & REE & RBE \\
\hline mean TR & 0 & 2.61 \\
\hline$\sigma_{\mathrm{TR}}$ & 0 & 1.74 \\
\hline$\rho\left(\mathrm{TR}_{\mathrm{t}}, \mathrm{TR}_{\mathrm{t}-1}\right)$ & - & .26 \\
\hline $\operatorname{Max}_{\mathrm{TR}}$ & 0 & 11.72 \\
\hline $\operatorname{MinTR}_{\mathrm{t}}$ & 0 & .07 \\
\hline
\end{tabular}


have not studied the pattern of trade with great care. The variance of $\mathrm{q}_{\mathrm{t}}^{\mathrm{s}}$, the price of capital is low and we think this results from the linear investment technology. We also note that the sum of money and bond holdings in the model is large, with average ratio to GNP of about 12 .

\section{5c The Effect of Increasing the Availability of Risky Investment Opportunities.}

The high volatility of investments during the high productivity years of the 1990 is well documented. However, other periods of major investment opportunities are also associated with high volatility of investments and these do not arise only due to technological shocks. Risky opportunities in telecommunication in the 1990's had the same effect on the volatility of investment as opportunities in oil drilling in the 1970's or real estate investments in South East Asia in the 1990's. It would thus be of interest to know how the volatility in our model varies with variations in the range of risky investment opportunities.

To address the above issue note that the range of risky investment opportunities in the market are reflected in the hypothetical parameters of the investment sector. Consider the two projects in the model. Project $\mathrm{M}$ is characterized by the two parameters $(.85, .95)$ and project $\mathrm{S}$ by $(1.05, .75)$. These numbers imply that when $\varphi_{\mathrm{t}}$ takes large positive values project $\mathrm{M}$ uses one unit of consumption good to produce .95 units of capital goods and project S produces .75 units. When $\varphi_{\mathrm{t}}$ takes large negative values project $\mathrm{M}$ produces .85 units of capital and project $\mathrm{S}$ produces 1.05 . Hence, project $\mathrm{S}$ is more specialized and more risky. Now suppose we vary the degree of riskiness of project $\mathrm{S}$ by selecting alternative values so as to generate mean preserving spreads of the return distributions while (i) keeping the expected value of the project equal to .90 , and, (ii) keeping project $\mathrm{M}$ in its present form. How would these variations change the 
equilibrium level of volatility of aggregate investments? More specifically, consider the following five variations of project S returns: $(.95, .85),(1.00, .80),(1.05, .75),(1.10, .70),(1.15, .65)$. Table 3 reports the equilibrium standard deviations of key variables for these alternative specifications

Table 3: Volatility of Key Variables for Varying Ranges of Risky Projects (standard deviations in percents)

\begin{tabular}{|l|c|c|c|c|c|c|}
\hline & $(.95, .85)$ & $(1.00, .80)$ & $(1.05, .75)$ & $(1.10, .70)$ & $(1.15, .65)$ & $\begin{array}{c}\text { REE } \\
\text { All }\end{array}$ \\
\hline $\log \left(\mathrm{g}^{\mathrm{N}}\right)$ & .62 & 1.12 & 1.80 & 2.63 & 3.51 & .33 \\
\hline $\log \left(\mathrm{i}^{\mathrm{N}}\right)$ & 2.33 & 5.23 & 9.08 & 13.46 & 18.11 & .79 \\
\hline $\log (\mathrm{c})$ & .19 & .68 & 1.28 & 1.99 & 2.66 & .18 \\
\hline $\log (\mathrm{L})$ & .11 & 1.00 & 2.04 & 3.08 & 4.13 & .12 \\
\hline $\log (\pi)$ & 1.22 & 2.37 & 4.12 & 6.33 & 8.41 & 1.22 \\
\hline
\end{tabular}

of the investment sector. Standard deviations are calculated for HP filtered data. These results show a dramatic increase in volatility of investments as the range of and asymmetry among investment opportunities grows to include more risky projects. Keep in mind that for any of these specifications, the volatility in an REE remains the same since regardless of the level of risk, agents in the REE diversify and hold a fully hedged investment positions.

\section{5d Money Neutrality and the Phillips Curve}

It goes without saying that money is neutral in any of the REE of our model in the strict sense that any change in the money supply results in an instantaneous proportionate change of the price level. It can be seen that any RBE also has a money neutrality property but this one is money neutrality on average. It means that the average rate of inflation over time equals the average rate of increase of the money supply minus the average rate of growth of output. In all RBE the mean 
rate of increase in the money supply is $v^{*}$ and this is the long run growth rate of the economy hence the long run rate of inflation is $0 . \mathrm{RBE}$ are, however, generically money non-neutral.

To see that money is not neutral in an RBE we carry out a simple test. We first simulate the equilibrium under the assumption that both the technological shocks $v_{t}$ as well as the money shocks $\varrho_{t}$ are turned off and compute the statistics generated. Next we turn on the monetary shocks at the level of, say $\sigma_{\varrho}=.05$, and recompute the statistics for the economy. Table 4 presents the comparative results of this experiment. The fact that money injection has a real effects is clear and the explanation for why money is not neutral is also simple. Monetary shocks have an effect on the diverse expectations of agents and although they observe the rate at which the money supply change, their demand for money (which depends upon their beliefs) changes but not in the Table 4: Money Non-Neutrality of RBE (standard deviations in percents)

\begin{tabular}{|l|c|c|}
\hline & $\log \left(\varrho_{\mathrm{t}}\right)=0, \log \left(\mathrm{v}_{\mathrm{t}}\right)=0$ & $\sigma_{\mathrm{e}}=.05, \log \left(\mathrm{v}_{\mathrm{t}}\right)=0$ \\
\hline $\log \left(\mathrm{g}^{\mathrm{N}}\right)$ & 1.93 & 2.05 \\
\hline $\log \left(\mathrm{i}^{\mathrm{N}}\right)$ & 9.38 & 10.12 \\
\hline $\log (\mathrm{c})$ & 1.38 & 2.18 \\
\hline $\log (\mathrm{L})$ & 2.11 & 3.26 \\
\hline
\end{tabular}

same way. The resulting percentage change in the price level is thus not equal to the percentage change in the money supply.

The analysis of the Phillips Curve in an exact General Equilibrium context is not an easy matter. It entails a relationship between two endogenous variables both of which are functions defined by the equilibrium map (10) and this leaves no room for a good instrument with which to estimate the relationship without a bias. We have thus chosen to simulate the model twice: first 
with $\sigma_{\mathrm{Q}}>0, \sigma_{\mathrm{v}}>0$ and second with $\sigma_{\mathrm{e}}>0, \log \left(v_{\mathrm{t}}\right)=0$. We generate samples of 5,000 observations and estimate the following basic and simple regression model:

$$
\log \left(\pi_{t}\right)=a_{0}+a_{1} \log \left(g_{t}^{N}\right)+a_{2} \log \left(\varrho_{t}\right)+a_{3} \log \left(\pi_{t-1}\right)+\vartheta_{t}
$$

keeping in mind that $\log \left(\mathrm{g}_{\mathrm{t}}^{\mathrm{N}}\right)$ is the $\log$ of the deviation of GNP from trend.

Estimation for REE

(i) with $\sigma_{\mathrm{e}}>0, \sigma_{\mathrm{v}}>0$ :

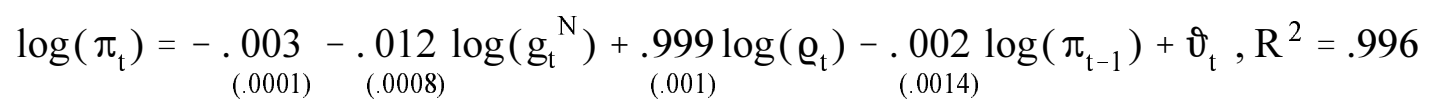

(ii) with $\sigma_{\mathrm{e}}>0, \log \left(v_{\mathrm{t}}\right)=0$ :

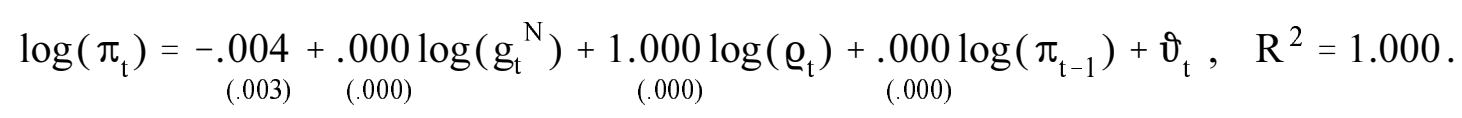

\section{Estimation for RBE}

(i) with $\sigma_{\mathrm{e}}>0, \sigma_{\mathrm{v}}>0$ :

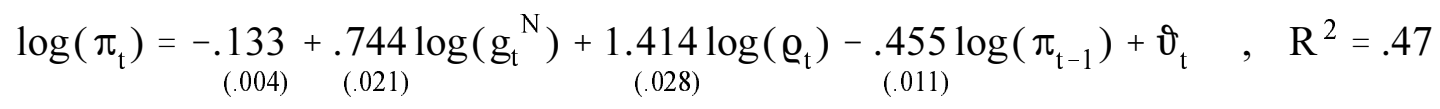

(ii) with $\sigma_{\mathrm{e}}>0, \log \left(\mathrm{v}_{\mathrm{t}}\right)=0$ :

$$
\log \left(\pi_{\mathrm{t}}\right)=\underset{(.004)}{-.319}+\underset{(.026)}{1.845} \log \left(\mathrm{g}_{\mathrm{t}}^{\mathrm{N}}\right)+\underset{(.022)}{1.419} \log \left(\mathrm{Q}_{\mathrm{t}}\right)-\underset{(.008)}{.468 \log }\left(\pi_{\mathrm{t}-1}\right)+\vartheta_{\mathrm{t}} \quad, \quad \mathrm{R}^{2}=.67 .
$$

Although we have tried many different specifications, the central conclusions are the same. The REE regressions show clear money neutrality. As for the RBE, in all regressions the Phillips Curve coefficient of $\log (\mathrm{GNP})$ is large and positive.

\section{5e Impulse Response to Monetary Shocks}

Our final results relate to the impulse response functions of monetary shocks. The study of 
such functions reveals the manner in which the real effect of monetary shocks works through the model economy. Consider a one time monetary shock of the economy in steady state. Such a shock is different from a productivity shock since a productivity shock forces the economy out of steady state through the direct first order effects it has on output and resource prices. A monetary shock has only a second order, indirect effect, on the economy via its impact on parameters such as $\lambda^{\mathrm{kv}}\left(\varrho_{\mathrm{t}}^{\mathrm{k}}\right), \lambda^{\mathrm{ke}}\left(\varrho_{\mathrm{t}}\right), \lambda^{\mathrm{k} \varphi}\left(\varrho_{\mathrm{t}}\right)$ which are $\underline{\text { multiplied }}$ by the states of belief $\mathrm{y}_{\mathrm{t}}^{\mathrm{k}}$. To see the implication recall that every endogenous variable in the economy is represented by a polynomial whose derivatives we evaluate at the steady state solution of the economy. Hence, the equilibrium is a perturbation of the steady state and the belief parameters $\left(\mathrm{y}_{\mathrm{t}}^{1}, \mathrm{y}_{\mathrm{t}}^{2}\right)$ are represented in each polynomial as regular variables. For technical reasons, the steady state of an RBE requires us to set $y_{t}^{1}=0, y_{t}^{2}=0$. Since in any impulse response function all variables are evaluated at steady state, to determine the impact of a monetary shock we need to evaluate this effect at steady state. An examination of the perception models shows that the impact of a monetary shock works through terms like

$$
\left.\Upsilon_{t+1}^{k v}=\lambda^{k v}\left(\varrho_{t}^{k}\right) y_{t}^{k}+\sigma_{z^{k v}}\left(\varrho_{t}^{k}\right)\right)_{t+1}^{k v}
$$

in (15a),(16a) and (17). That is, monetary shocks work through their effect on terms which are multiplied by $\mathrm{y}_{\mathrm{t}}{ }^{\mathrm{k}}$ and by the random terms. Indeed, this multiplicative form is the direct result of the rationality conditions: additive terms would violate rationality. But now the answer is clear: at steady state we set $\mathrm{y}_{\mathrm{t}}{ }^{\mathrm{k}}=0$ and also all random variables are set equal to zero hence no monetary shock can have any effect. These considerations lead to the conclusions that any monetary impulse of this RBE at the steady state has only a direct effect on inflation: a change in money supply causes a proportionate change in price level, leaving all real variables unchanged. 
The picture changes drastically if we select an alternate state of belief $\left(\mathrm{y}^{1 *}, \mathrm{y}^{2 *}\right) \neq(0,0)$ and hold it fixed. We now compute the long term averages of equilibrium variables (including exogenous shocks), denoted by $\mathrm{x}^{*}$, and create a new hypothetical steady state $\left(\mathrm{y}^{1 *}, \mathrm{y}^{2 *}, \mathrm{x}^{*}\right)$ for the economy. In an REE $\left(\mathrm{y}^{1 *}, \mathrm{y}^{2 *}, \mathrm{x}^{*}\right)=\left(0,0, \mathrm{x}^{*}\right)$ for all $\left(\mathrm{y}^{1 *}, \mathrm{y}^{2 *}\right)$ since the states of belief do not matter and the real economy is exactly the same as the original steady state where the state of belief is $(0,0)$. Having defined this hypothetical steady state we can now examine the impulse response functions to a monetary shock. The interpretation of these responses is entirely natural: they measure the impact of a monetary shock on real variables around $\left(\mathrm{y}^{1 *}, \mathrm{y}^{2 *}, \mathrm{x}^{*}\right)$. Since the risky economy fluctuates and is never at the $\left(\mathrm{y}^{1 *}, \mathrm{y}^{2 *}\right)=(0,0)$ steady state, the magnitude of the impulse response varies with the point in space at which the economy is evaluated. Under such conditions the usual steady state with $\left(\mathrm{y}^{1 *}, \mathrm{y}^{2 *}\right)=(0,0)$ has no special significance and positions away from this steady state provide a better approximation of how the risky economy would actually respond to monetary shocks.

Based on the above considerations we selected $\left(\mathrm{y}^{1 *}=.4, \mathrm{y}^{2 *}=.4\right)$ which is half a standard deviation of the empirical distribution of $\left(\mathrm{y}_{\mathrm{t}}^{1}, \mathrm{y}_{\mathrm{t}}^{2}\right)$ and study the response to an initial monetary shock of $\log \left(\varrho_{t}\right)=2 \%$. The results are presented in Figure 2 .

\section{FIGURE 2: FIVE PANELS OF IMPULSE RESPONSE}

Some comments on these results:

(i) GNP. This impulse response function exhibits the familiar hump shaped form, known from empirical work on the effect of monetary shocks and hence is qualitatively in accord with standard results. The maximal deviation of GNP from trend due to a $2 \%$ monetary shock is about $.04 \%$. Keep in mind, however, that this response function is generated entirely 
endogenously by the structure of market beliefs.

(ii) Investment. This function reveals the impact of the endogenous propagation mechanism of the model. The $2 \%$ monetary shock alters private expectations and causes a large $.3 \%$ burst of investments which slowly decreases in magnitude. It is the size and sharp nature of this burst which explains the impulse response of other variables.

(iii) Consumption. Although the impulse response function of consumption exhibits the familiar hump shaped form, it has the unusual feature of starting with a negative impulse at date 0 . This response is due to the special features of our model. The monetary shock alters investor's expectations and results in a burst of investments. Due to lack of persistence in perceived returns on investments, agents who take advantage of these opportunities reduce present consumption by $.06 \%$ in order to finance their investments. Following the initial decline consumption rises, reaches a maximal deviation from trend of $.035 \%$, and the deviation stays positive for a long time. This phenomenon is amplified by the fact that the agents react to monetary policy in the same way. As a result, neither one is able to borrow as there are no lenders willing to offer funds given the structure of beliefs. Indeed, the impulse response function of borrowing is 0 since both agents want to borrow but cannot.

(iv) Nominal Interest Rate. The model has no riskless asset hence the impulse response function of the nominal interest rate is relatively simple. A $2 \%$ monetary shock causes only a $1.8 \%$ instantaneous inflation at date 0 . The burst of investments leads to an increased demand for funds which pushes real interest rates higher. As the investments effect declines, the full price level adjustment is completed.

(iv) Hours. This function shows the final dimension of the increased demand for investments 
generated by a monetary shock. As agents perceive higher rates of return on investments

they desire to work more hours to finance such investments, revealing a $.1 \%$ rise of hours. The impulse response to monetary shocks is thus strongly affected by the reaction of private expectations to the shock. Indeed, the reaction appears too strong and unrealistic with respect to consumption. However, our objective is only to argue that this response is important. In future research will shall reformulate the model so that responses are more realistic.

\section{5f Why Do Monetary Shocks Have Real Effects and Positive Shocks Increase Output: A}

\section{Simple Intuitive Explanation}

Why do monetary shocks have real effects and why do positive shocks have positive effects on output? These are two separate questions for which we provide intuitive answers but address them separately. The real effects of money in an RBE is a generic property which arises from the diversity of beliefs. Monetary shocks have a real effect because agents have diverse forecasts of inflation, of productivity and of rates of return on investments. They disagree about the effects of monetary shocks on inflation because they have different forecasts of the rate of return on investments and hence of the demand for money which results from differing investment rates. In addition, agents disagree about the distribution of future monetary shocks and hence disagree upon the cost of holding money. It is wrong to think that this argument boils down to a sunspot argument saying that money "has an effect because agents expect it to have an effect." Agents have different forecasts of the real variables in the economy and once they disagree on the inflation forecast given any monetary shock, monetary shocks have real effects. This is analogous to Lucas' (1972) argument who explained non-neutrality by agent's “confusion" between monetary 
shocks and real shocks. In an RBE there is no confusion, there is a disagreement about forecasting the future and this is sufficient for money to have real effects (for a similar argument see Motolese (2000),(2001)). Once agents perceive money to have a real effect, it is rational for them to incorporate monetary shocks as a component affecting their own beliefs about all variables in the economy (i.e. for $\varrho_{t}$ to affect agent's perceptions). At this point we turn to the second question.

Why do positive monetary shocks increase output? Given the fact, explained in the previous paragraph, that money has an effect on the belief of agents, the answer to the last question is simple: a positive monetary shock in the model generates optimism among agents about higher rates of return on investments and thus causes them to be willing to engage in more risky investments. When this occurs they increase their inputs into investment projects. For that purpose they work harder and even lower a bit their consumption in order to finance the desired investments. In our model these effects are short lived because there is no persistence in either the beliefs or in investment opportunities. However, the fact that these effects are short lived has nothing to do with the idea of agents being "surprised" by the monetary shocks. Our explanation is typical of the mechanism which operates in any RBE model. In future work we hope to modify the model so that this conclusion becomes more transparent.

In our model the mechanism is a bit complicated because of the strong assumption that there are only two investment opportunities and only one i.i.d. random variable to determine their productivity. The result is that whenever agents are optimistic about higher returns in project $\mathrm{S}$ they must be pessimistic about returns in project M. Hence, it is impossible for them to be optimistic about future returns in both projects. When $\mathrm{y}_{\mathrm{t}}{ }^{\mathrm{k}}>0$ they are optimistic about project M, they increase investments in $\mathrm{M}$ but decrease investments in $\mathrm{S}$. The opposite is true when $\mathrm{y}_{\mathrm{t}}{ }^{\mathrm{k}}<0$ : 
they are optimistic about return in $\mathrm{S}$ and pessimistic about return in M. Nevertheless, in our model monetary shocks alter the impact of $y_{t}{ }^{k}$ on the perceptions of future returns on assets. Hence, in order to stipulate that agents take more risk in response to a monetary shock we require that $\left|\lambda^{\mathrm{k} \varphi}\left(\varrho_{\mathrm{t}}\right)\right|$ in equation (17b) increases with $\varrho_{\mathrm{t}}$. This achieves the task since when $\left|\lambda^{\mathrm{k} \varphi}\left(\varrho_{\mathrm{t}}\right)\right|$ increases with $\varrho_{t}$, a larger monetary shock amplifies the impact of $y_{t}{ }^{k}$ on the forecasted return on investments. Indeed, it increase the forecasted deviation of $\varphi_{t+1}$ from 0 and hence increases the expected returns on investments. This, in turn, increases the desire to invest.

Our assumptions about the investment sector intend to make a perfect hedge possible and a perturbation analysis relative to a reference economy feasible. Consider an alternative, and more realistic model which we cannot incorporate in the analysis at this time. It postulates that the investment sector consists of two random variables $\left(\varphi_{1}, \varphi_{2}\right), \varphi_{\mathrm{j}} \sim \mathrm{N}\left(\mathrm{e}^{*}, 1\right)$ with correlation $\rho\left(\varphi_{1}, \varphi_{2}\right)$. An allocation of $X=.5$ in project 1 and $Y=.5$ in project 2 with $X+Y=1$ has a mean return of $\mathrm{e}^{*}$, as in the current model, but a variance of $\frac{1}{2}\left(1+\rho\left(\varphi_{1}, \varphi_{2}\right)\right)$. If the correlation is close to -1 a diversification across projects results in a small risk in the reference economy. Now the substitution among projects is no longer a constraint imposed by the model. Agents can be optimistic about both projects and are not forced to be pessimistic about one when they become optimistic about the other. Indeed, they can optimally increase investments in both projects. In such an economy the results of a monetary shock would be simple and unambiguous in accord with the explanation given earlier. In that case a positive monetary shock would cause agents to become more optimistic about higher rates of return on all risky investments.

But then, one may object, our conclusion regarding the positive effect of monetary shocks hinges on the shocks having the "right" effect on beliefs (via a parameter like $\lambda^{k \varphi}\left(\varrho_{t}\right)$ ). This is 
entirely true: the positive association will not be present unless parameters like $\left|\lambda^{\mathrm{k} \varphi}\left(\varrho_{t}\right)\right|$ change in the "right" way. But then recall that in an RBE monetary shocks have real effects and all agents recognize this. Once real effects - positive or negative - are present in the economy then, like all endogenous uncertainty, they become part of reality and impact the beliefs of agents. In fact, the idea that actions of the central bank affect the expectations of agents is central to modern thinking about monetary policy. Most discussions about credibility of the central bank have to do with the impact of policy on beliefs and the effect of policy on beliefs is central to the DNK theory discussed earlier (e.g. Woodford (2001b)).

The fact that policy has an impact on beliefs is clear; the only question is what that impact is. In this paper we do not develop a formal theory of the impact of policy on beliefs. Instead, we assumed that such an effect exists and it is a Rational Belief. The assumption that parameters like $\lambda^{\mathrm{k} \varphi}$ have the right sign are then conditions which specify what it takes for a monetary shock in our model to have a positive effect on output. These are also conditions which specify what agents think about government. If agents believe that actions of the central bank are beneficial, their beliefs reflect such facts and parameters like $\lambda^{\mathrm{k} \varphi}\left(\varrho_{t}\right)$ express it. This discusson also supports the view that a monetary equilibrium cannot be complete without a full specification of monetary policy. In Section 3 we discuss some issues related to optimal monetary policy which we plan to pursue in future research. Before this we sum up our conclusions.

\section{$2.5 \mathrm{~g}$ What Have We Learned from the Model?}

Computational economics is a useful tool for theoretical work in dynamic equilibrium analysis when analytical results are difficult to obtain. It is obvious that many of our numerical 
results will change with changes in parameters or specification. Our model has several unrealistic features which result in no persistence of investment opportunities, no persistence in the beliefs and too sharp a response of consumption to monetary shocks. Also, the linear structure of the investment sector is too simplistic and results in low volatility of the price of traded capital goods. Hence, any effort to calibrate the model requires significant model restructuring. However, our objective was to formulate an analytical framework in which the impact of diverse beliefs can be evaluated and, in our view, the present model demonstrated the importance of this economic factor.

There are other conclusions which, we believe, can be drawn at this time, since they are generic to any RBE model and we offer a short summary of these:

(i) An RBE provides a propagation mechanism which is capable of producing fluctuations of significant magnitude. The mechanism operating in the investment sector of this model works throughout the economy with respect to all intertemporal decisions, giving rise to propagation effects in consumer durables, home construction, financial markets, public investments etc. (ii) An RBE provides a natural explanation for the high volatility of investments and the large volume of trade on financial markets. The RBE is a natural setting to study, in an integrated way, the real economy and financial markets so that fluctuations in both sectors are jointly propagated. (iii) In an RBE money is generically non-neutral and the Phillips curve arises as a natural statistical consequence of the effect of expectations on output and inflation. We accept the view that other factors such as wage rigidity and imperfect price adjustment contribute to money non-neutrality. (iv) Monetary shocks generate customary impulse response functions of output, investments and 
consumption but this has nothing to do with "surprises" which agents experience. It arises in the $\mathrm{RBE}$ of this paper due to the fact that a positive monetary shock reduces the risk premium which agents require in order to engage in risky investments.

We add a methodological observations. We have used the "distribution of beliefs" as an explanatory variable of market performance. Indeed, the use of the distribution of belief as an explanatory variable is central to all paper on Endogenous Uncertainty and market volatility cited in this paper. It is our view that the distribution of beliefs is as a valid an explanatory variable as any information about characteristics of agents or technology used routinely in economic analysis to explain market performance. For this same reason we think that the distribution of beliefs is a useful information for the formulation of monetary policy. That is, since an important component of economic fluctuations is endogenous, caused by the beliefs of agents, the conduct of monetary policy could be improved by incorporating information about the distribution of beliefs in the market. In the final Section 3 we offer a brief discussion of the rationale and objective of central bank policy, in light of the conclusions of this paper.

\section{What is the Rationale for and Object of Monetary Policy?}

\subsection{Theoretical considerations.}

We now return to the question put forward in the Introduction to this paper, in order to discuss the justification for monetary policy. We start by stressing that due to the endogenous component of volatility the level of risk in a market economy is greater than the level induced by the exogenous shocks which the economy sustains. But then, the fact that social risk is caused by human conduct suggests the possibility that society may elect to place some limits on individual 
choice so as to reduce the level of such endogenous volatility. This was a line of thought discussed by Kurz [1997] (see page ix-x) and explored by Nielsen [1998], [2000]. The main problem confronted by this approach is the fact that an RBE with complete hedging opportunities is ex-ante Pareto optimal and hence any public policy with an effect, will make some agents worse off in terms of their ex-ante expected utility. Keeping this fact in mind we now argue that the theory of RBE offers a simple and crucially important role for the Central Bank in a market economy. We suggest that the aim of monetary policy is to reduce the excess endogenous volatility component of interest rates, aggregate price level, aggregate output and other measures of economic activity. Since a Central Bank cannot reduce the volatility caused by exogenous shocks, the task of reducing the endogenous component of economic fluctuations is both attainable and socially desirable. However, this task requires some choices.

On the one hand freedom of choice of investors is the foundation of all efficiency considerations leading to the commonly accepted concept of ex-ante Pareto optimality of the allocation in a market economy. On the other hand, the price of such freedom is the excessive level of volatility of prices and quantities in the market which is caused by the diverse and often inconsistent beliefs of investors. To support our position that monetary policy is justified in an RBE, we need to argue that the ex-post excess volatility of a market economy is undesirable. The problem of reconciling ex-ante and ex-post social outcomes is not new. It was discussed by Diamond (1967), Drèze (1970), Starr (1973), Mirrlees (1974), Hammond (1981), (1983), Nielsen (1998)(2000), Silvestre (1999) and others. The interest in an ex-post concept of optimality was motivated by two considerations. First, researchers held the view that in an uncertain world agents may hold "incorrect" probability beliefs and hence regret their decisions 
(e.g. Hammond (1981), page 236). Also, social preferences over income distribution could be sensitive to ex-post outcomes rather than ex-ante anticipated distribution of consumptions.

Second, diverse probability beliefs which may be inconsistent across agents raise difficulties in defining a "representative consumer" who holds a social expected utility. ${ }^{13}$ Hammond's (1981),(1983) concept of Ex-Post Welfare Function proposes that society disregard the probability beliefs of the individual agents in favor of society's own probabilities over states.

Our theory contains some elements which permit us to go beyond the concept of Ex-Post Welfare Function in order to provide a social motivation for public policy in a market economy and specify the probabilities which are appropriate for public evaluation. To explain these recall that in an RBE agents typically hold diverse non-stationary beliefs reflecting their views of the economic conditions at each date. Society, represented by the central bank, recognizes that when agents hold diverse and inconsistent beliefs, some or all of them are wrong. Since society does not have better information than private agents, the central bank cannot determine whose beliefs are right. Consequently, monetary policy must be symmetric with respect to the diverse beliefs. Over time any agent may hold a correct or an incorrect belief in the form of a subjective transition or a joint distribution over observables and public policy must be optimal in the long run, in the sense that it should be a good policy for any configuration of beliefs that agents may hold over time. The rationality of belief conditions in an RBE imply that the mean belief of any agent over time is exactly the stationary measure ${ }^{14}$ and this probability is also the expected probability belief of a

\footnotetext{
13 Diverse and inconsistent subjective probability beliefs raise difficulties in defining an equilibrium in games with incomplete information and have lead to the "Harsanyi Doctrine"of a common prior in game theory.

14 That is, the mean transition function or joint density over observable variables, employed by an agent at different dates, is equal to the transition function or joint density over all observable variables in the economy
} 
random agent that may be present in the economy at any date. Hence, public policy should be optimal with respect to the stationary measure of an RBE. Observe that the stationary measure is one upon which the agents actually agree: it is the probability on sequences deduced from the empirical distribution of economic variables and this distribution is known to all.

In the RBE of Section 2 the stationary measure is determined by the joint probability distribution of the exogenous shocks $\left(v_{t}, \varrho_{t}, \varphi_{t}\right)$, the equilibrium map and by transitions (11d) which determined the distribution of states of belief over time. Since $v_{t} \in \mathbb{R}_{+}, \varrho_{t} \in \mathbb{R}_{+}, \varphi_{t} \in \mathbb{R}$ and $\left(\mathrm{y}_{\mathrm{t}}^{1}, \mathrm{y}_{\mathrm{t}}^{2}\right) \in(\mathbb{R}, \mathbb{R})$, it follows that the state space for the economy is $\mathrm{S}=\left(\mathbb{R}_{+} \times \mathbb{R}_{+} \times \mathbb{R} \times \mathbb{R} \times \mathbb{R}\right)$. As a probability $\mathrm{m}$ on the measurable space $\left(\mathrm{S}^{\infty}, \not{B}\left(\mathrm{~S}^{\infty}\right)\right)$, the stationary measure is unique to each RBE. With this in mind, we turn to a formal definition of Long Term Pareto Improving Policy in an RBE. To motivate the focus on improving policies rather than efficient policies, note that utility sequences are defined by sequences of consumption, labor and money holdings. The definitions of feasible consumption and labor are standard, but feasibility with respect to real money holding is not. Such a concept requires a definition of feasible sequences of nominal money holdings and corresponding rates of inflation; such rates cannot be defined disregarding the market mechanism. We thus focus on policies that would compare two RBE with the same specified stationary measure, reflecting the fact that monetary policy action could change the RBE but not the stationary measure. Thus, let $\left\{\left(\mathrm{c}_{\mathrm{t}}{ }^{\mathrm{k}}, 1-\mathrm{l}_{\mathrm{t}}^{\mathrm{k}}, \mathrm{m}_{\mathrm{t}}\right), \mathrm{t}=1,2 \ldots, \mathrm{k}=1,2\right\}$ be a random sequence of consumption, labor and money holdings in an RBE. These are functions on the state space $\left(\mathrm{S}^{\infty}, \not{\beta}\left(\mathrm{S}^{\infty}\right)\right)$ and for any probability measure on $\left(\mathrm{S}^{\infty}, \not{\beta}\left(\mathrm{S}^{\infty}\right)\right)$, their expected utilities can be evaluated. More specifically, denoting by $m$ the stationary measure of an RBE, we define the defined by the stationary measure (or, empirical distribution). 
publicly assigned utility of agent $k$ with the stationary measure $m$ over equilibrium consumptionlabor-money holding sequences by

$$
\mathrm{U}_{\mathrm{m}}^{\mathrm{k}}=\mathrm{E}_{\mathrm{m}}\left[\sum_{\mathrm{t}=1}^{\infty} \beta^{\mathrm{t}-1} \frac{1}{1-\gamma}\left(\left(\xi_{\mathrm{t}} \mathrm{c}_{\mathrm{t}}^{\mathrm{k}}\left(\ell_{\mathrm{t}}^{\mathrm{k}}\right)^{\zeta}\right)^{1-\gamma}+\left(\xi_{\mathrm{t}} \mathrm{m}_{\mathrm{t}}{ }^{\mathrm{k}}\right)^{1-\gamma}\right) \mid \mathrm{I}_{\mathrm{t}}\right]
$$

Since a policy maker needs to evaluate different RBE allocations resulting from alternative public policies, (21) provides the social evaluation of such alternative sequences. Suppose that in a given RBE a sequence $\left\{\left(\tilde{c}_{t}^{\mathrm{k}}, 1-\tilde{\ell}_{\mathrm{t}}^{\mathrm{k}}, \tilde{\mathrm{m}}_{\mathrm{t}}\right), \mathrm{t}=1,2,3 \ldots, \mathrm{k}=1,2\right\}$ of random consumptions, labor and money holdings is specified. We denote by $\tilde{U}_{m}=\left(\tilde{U}_{m}^{1}, \tilde{U}_{m}^{2}\right)$ the social evaluation of this RBE. A monetary policy results in an RBE allocation $\left\{\left(c_{t}{ }^{k}, 1-\ell_{t}^{k}, m_{t}\right), t=1,2,3 \ldots, k=1,2\right\}$ and social evaluation $\mathrm{U}_{\mathrm{m}}=\left(\mathrm{U}_{\mathrm{m}}^{1}, \mathrm{U}_{\mathrm{m}}^{2}\right)$. Having defined in (21) what society regards as desirable, we finally can say that this last sequence is a long run Pareto improving allocation if the vector inequality $\tilde{\mathrm{U}}_{\mathrm{m}} \leq \mathrm{U}_{\mathrm{m}}$ holds. We are not raising here the question of how monetary policy should be conducted in order to attain these goals; we are only specifying what the goals should be.

\section{An Example}

For simplicity, the example does not focus on the monetary policy aspect but rather on the concept of long run Pareto improving allocation. To that end, consider an infinite horizon economy with complete market structure. Within this economy there is a leading sector using a technology which is similar to the one used in the investment sector of the model in Section 2. There is a large number of identical firms each led by an investor-entrepreneur. At each date an investor-entrepreneur uses the publicly available technology to produce output. The constant 
returns to scale technology employs two agents who live for one period: the investor with endowment of 1 and a worker who works for the investor and receives $25 \%$ of the output. At every $\mathrm{t}$ an investor makes a choice of allocating his endowment between two technologies $\mathrm{M}$ and $\mathrm{S}$ whose identities vary over time but at all times the uncertainty in the industry is represented by two states, $\mathrm{L}$ and $\mathrm{R}$. The long term empirical distribution of the realized states is $1 / 2$ for $\mathrm{L}$ and $1 / 2$ for $\mathrm{R}$ with no serial correlation, and hence the stationary measure is i.i.d. with the probability of each state being $1 / 2$. Trading and investments take place in the morning, output and consumption in the afternoon. Investors' beliefs are such that at each $\mathrm{t}$ an investor of that date is certain that either $\mathrm{L}$ or $\mathrm{R}$ will be realized. They hold Rational Beliefs hence $1 / 2$ of the time an investor is certain that $\mathrm{L}$ will be realized and $1 / 2$ of the time he is certain that $\mathrm{R}$ will be realized. The beliefs of all investors are perfectly correlated so that when one is certain that $\mathrm{L}$ will be realized, all are certain of that. Instead of assuming the agents to be short lived we could simply assume that at date $t$ they do not know the beliefs of prior investors.

The output possibilities are represented by the following function. If the investor at $t$ places $\mathrm{X}$ units in technology $\mathrm{S}$ and $\mathrm{Y}$ units in technology $\mathrm{M}$ subject to $\mathrm{X}+\mathrm{Y}=1$, output will be the following random variable

$$
\text { Output }_{\mathrm{t}} \equiv\left\{\begin{array}{lll}
2.80 \mathrm{X}+1.8 \mathrm{Y} & \text { if } & \mathrm{L} \text { is realized } \\
2 \mathrm{Y} & \text { if } & \mathrm{R} \text { is realized }
\end{array}\right.
$$

Hence when an investor is certain that $\mathrm{L}$ will be realized he selects $\mathrm{X}=1$ and $\mathrm{Y}=0$; when he is certain that $\mathrm{R}$ will be realized he selects $\mathrm{X}=0$ and $\mathrm{Y}=1$. Since the stationary measure is i.i.d. with probability of $\mathrm{L}$ being $1 / 2$, it follows that over the long run, the empirical distribution of 
outputs and individual shares of the two participants are

\begin{tabular}{|c|c|c|c|}
\hline proportion of time & output & investor's share & worker's share \\
\hline $25 \%$ & 2.800 & 2.100 & .700 \\
\hline $25 \%$ & 0 & 0 & 0 \\
\hline $25 \%$ & 2.000 & 1.500 & .500 \\
\hline$\underline{25 \%}$ & $\underline{1.800}$ & $\underline{1.350}$ & .450 \\
\hline Mean: & 1.650 & 1.2375 & .4125 \\
\hline
\end{tabular}

The "proportion of time" entries in the table are probabilities according to the stationary measure of outputs. It is to be noted that the free market allocation results in outstanding performance $25 \%$ of the time. However, in $25 \%$ of the time it has catastrophic consequences which propagate throughout the rest of the economy, generating significant social volatility. Now if society selects $\mathrm{X}=\frac{1}{15}$ and $\mathrm{Y}=\frac{14}{15}$ at all dates, the following allocation is socially feasible:

\begin{tabular}{|c|c|c|c|}
\hline proportion of time & output & investor's share & worker's share \\
\hline $25 \%$ & 1.867 & 1.400 & .467 \\
\hline $25 \%$ & 1.867 & 1.400 & .467 \\
\hline $25 \%$ & 1.867 & 1.400 & .467 \\
\hline $25 \%$ & 1.867 & 1.400 & .467 \\
\hline Mean: & 1.867 & 1.400 & .467 \\
\hline
\end{tabular}

Hence, although the free market allocation is ex-ante Pareto optimal relative to the beliefs of the agents, the second allocation stochastically dominates the first relative to the stationary measure. Any social decision maker with concave utility who holds the i.i.d. stationary measure will prefer the second allocation. Hence, the second allocation is a long term Pareto improvement in accord with our definition.

In our view the second allocation is an appropriate goal for stabilization policy. One may argue that in the free market allocation all agents in the economy have all the opportunities to hedge their positions and optimize given their own beliefs against all risks. This is entirely true but fails to address the fact that the first allocation results both in excess fluctuations as well as in 
a significant loss of social resources in the catastrophic states. Because of these lost resources the long term average consumption of investors and workers is higher in the second allocation than in the first. The example above can easily be extended to include durable capital investments which are entirely abandoned after the catastrophic states. This loss of social resources results in higher long term volatility of consumption but also in lower long term mean of the consumption process. Some may regard our example as one of social externalities of beliefs but this is merely a terminological resolution. Our position is supported by additional arguments but these will be postponed to a later paper due to limitation of time and space ${ }^{15}$.

\subsection{Some Illustrations of Forecast Distributions}

In Table 5 we present forecasts of GNP growth and inflation for 1991 made by the participants in the Blue Chip Forecasting at the start of that year. It is rather extraordinary that about half of the private forecasters predicted in January 1991 that 1991 will be a recession year and the other half disagreed. The actual growth rate in 1991 was $-.5 \%$ and the inflation rate $3.6 \%$. Now, suppose you place yourself in January 1991 and make a stationary econometric forecast of GNP growth without a non-stationary judgment about the conditions prevailing in 1991 . We have done so using a model of Stock and Watson (1999a),( 1999b),( 2001) and estimating it by employing a combination of diffusion indexes and averaged bivariate VAR forecasts utilizing a large number of U.S. time series. All non-judgmental stationary forecasts of GNP turned out

\footnotetext{
${ }^{15}$ We planned to reformulate the model of Section 2 to include simulation results on optimal monetary policy which targets short term interest rates. Unfortunately, the need to complete the manuscript in time for the Festschrift Conference in Honor of Ned Phelps prevented us from carrying out this work and the results will be reported later.
} 
Table 5: Blue Chip Forecasts of GNP Growth and Inflation for 1991

Forecasted Percent Change

January 1991

Forecast for 1991

$\begin{array}{ll}\text { Real } & \text { GNP } \\ \text { GNP } & \text { Price Deflator }\end{array}$

Sears Roebuck \& Co.

Amhold \& S. Bleichroeder

Prudential Bache

Chicago Corporation

Bostian Economic Research

Faimodel

Cahners Economics

Wayne Hummer \& Co. - Chicago

Nat'l. City Bank of Cleveland

Inforum - Univ. of Maryland

CRT Government Securities

Dun \& Bradstreet

Conference Board

Econoclast

First National Bank of Chicago

Univ. of Michigan M.Q.E.M.

Manufacturers Natl. Bank - Detroit

Turning Points (Micrometrics)

Brown Brothers Harriman

Dean Witter Reynolds, Inc

LaSalle National Bank

Northern Trust Company

Evans Economics

Morris Cohen \& Associates

Prudential Insurance Co.

Chrysler Corporation

Econoviews International Inc.

U.S. Trust Co.

Reeder Associates (Charles)

Siff, Oakley, Marks, Inc.

Morgan Stanley \& Co.

Eggert Economic Enterprises, Inc.

CoreStates Financial Corp.

Mortgage Bankers Assn. of America

Bank of America

E.I. Du Pont de Nemours \& Co.

National Assn. of Home Builders

Metropolitan Life Insurance Co.

Ford Motor Company

Chase Manhattan Bank

U.S. Chamber of Commerce

Manufacturers Hanover Trust Co.

Bankers Trust Co.

Laurence H. Meyer \& Assoc.

Security Pacific Nat'l. Bank

PNC Financial Corp.

UCLA Business Forecast

Merrill Lynch

Georgia State University

Equitable Life Assurance

Morgan Guaranty Trust Co.

Shawmut National Corp.

$1.6 \mathrm{H}$

1.2

1.1

1.1
1.0
1.0

0.9

0.8

0.7

0.7

0.6

0.5

0.5

0.5

0.4

0.2

0.2

0.1

0.0

0.0

$-0.1$

$-0.1$

$-0.1$

$-0.2$

$-0.3$

$-0.3$

$-0.3$

$-0.3$

$-0.4$

-0.4
-0.4

$-0.5$

$-0.5$

$-0.5$

$-0.5$

$-0.6$

$-0.7$

$-0.7$

$-0.7$

$-0.7$

$-0.7$

$-0.9$

$-1.1$

$-1.1$

$-1.2$

$-1.3 \mathrm{~L}$
4.2
4.8

3.3 $\mathrm{L}$

4.1

4.0
3.7

4.3

4.3

3.8

3.8

4.0

4.7

4.0

3.8

4.7

4.5

4.0

4.0

3.6

4.3
4.0

$5.0 \mathrm{H}$

4.5

3.9

4.3

4.9

4.7

3.9

4.3

4.3

4.8

4.5

4.5

4.0
$5.0 \mathrm{H}$

4.4

4.4

4.0
4.0

4.3

4.2

3.6

4.7

3.8
4.0

higher than most of the private forecasts. Picking another date, Table 6 exhibits the same information (but for GDP) for May 2000. The realized growth rate in 2000 was $4.1 \%$ and the inflation rate was $2.3 \%$. It is thus equally surprising to see that in May 2000, five months into the year, large variability in the forecasts is exhibited and almost all the GDP forecasts turned out to be wrong. We repeated our experiment with the stationary forecast and this time all non- 
judgmental stationary forecasts of GDP turned out lower than most of the private forecasts.

Table 6: Blue Chip Forecasts of GNP Growth and Inflation for 2000

\section{Forecasted Percent Change}

May 2000

Forecast for 2000

First Union Corp.

Turning Points (Micrometrics)

J P Morgan

Evans, Carroll \& Assoc.

Mortgage Bankers Assn. of Amer.

Goldman Sachs \& Co.

U.S. Trust Co.

US Chamber of Commerce

Banc of America Corp.

Morgan Stanley Dean Witter

Wayne Hummer Investments LLC

Bank One

Nomura Securities

Merrill Lynch

Perna Associates

National Assn. of Home Builders

Macroeconomic Advisers, LLC

Prudential Securities, Inc.

LaSalle National Bank

Conference Board

Wells Capital Management

DuPont

Northern Trust Company

Chicago Capital, Inc.

Deutsche Bank Securities

Chase Securities, Inc.

Credit Suisse First Boston

Comerica

Moody's Investors Service

Fannie Mae

Federal Express Corp.

SOM Economics. Inc.

National Assn. of Realtors

National City Corporation

Clear View Economics

Eggert Economic Enterprises, Inc.

WEFA Group

Eaton Corporation

Bear Stearns \& Co., Inc.

Ford Motor Company

Motorola

Standard \& Poors Corp.

UCLA Business Forecasting Proj.

Inforum - Univ. of Maryland

Prudential Insurance Co.

Weyerhaeuser Company

DaimlerChrysler AG

Georgia State University

Kellner Economic Advisers

Econoclast

Naroff Economic Advisors

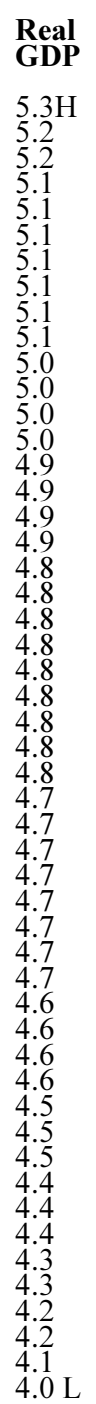

GDP

Price Deflator

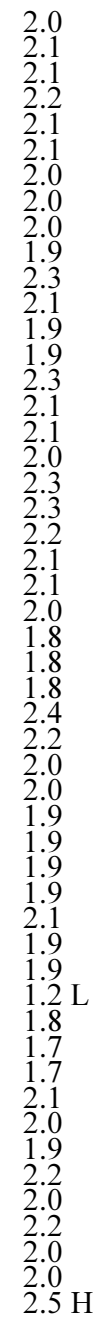

Hence, in 1991 private forecasters' judgement was conservative, placing their distribution below the stationary forecast while in May of 2000 their judgment was aggressive, placing their distribution above the stationary forecast.

Finally, we present in Figure 3 a chart of the distribution of private forecasts of GDP growth rate between 1990 and 2001. The forecasts are made in each quarter for GDP growth rate 
over the full year following the year of the forecast. Hence, in each quarter of a year the four forecasts are about the same year. For example in March, June, September and December of

\section{FIGURE 3: DISTRIBUTION OF PRIVATE FORECASTS OF GDP GROWTH}

1994 we have individual forecasts for the full year 1995. Figure 3 exhibits the 5 th percentile and the 95th percentile of the forecast distribution for each quarter in which the forecasts were made. The horizontal bars in Figure 3 show the realization of GDP growth a year later. For example, the bar in 1999 exhibits the annual growth rate realized in 2000 and forecasted in the four quarters of 1999. The distribution of forecasts fluctuates over time but exhibits persistence. Also, the pattern over the period 1996-2000 is rather interesting. As the economy went into high gear after 1995 the private forecasters did not raise their forecasts immediately, not believing in the idea of structural change due to the information "revolution." However, as the economy continued to generate growth rates in excess of $4 \%$ the private forecasters started moving their forecasts higher into the $4 \%-5 \%$ range. One must presume that they have done so because they believed in the idea of structural change and in the onset of a high growth regime for the U.S. economy for some years to come. Such a belief could not have been based on much data since the rates of realized productivity in the U.S. economy continued to fluctuate below $1.5 \%$ per year ${ }^{16}$, not sufficient to provide conclusive evidence for the onset of a high GDP growth regime. In May of 2000 the high forecast for 2000, among the Blue Chip panel, was 5.3\%! This small amount of data presented here provide some support to the diverse beliefs paradigm which we have offered in this paper.

\footnotetext{
16 The recorded productivity growth during these years was: $1.4 \%$ for $1996,1.0 \%$ for $1997,1.4 \%$ for 1998 and $.6 \%$ for 1999 . The BLS has not released any later data.
} 


\section{References}

Basu, S. (1996): "Procyclical Productivity: Increasing Returns or Cyclical Utilization?" The Quarterly Journal of Economics, 111 , 719 -751.

Bernanke, B.S., Gertler, M. (1989): "Agency Cost, Net Worth, and Business Fluctuations". American Economic Review, 79, 14 - 31.

Bernanke, B.S., Gertler, M. Gilchrist, S. (1999): The Financial Accelerator in a Quantitative Business Cycle Framework." In J. Taylor and M. Woodford (eds.) The Handbook of Macroeconomics, Volume 1C. Amsterdam: North-Holland, Chapter 21, 1342 -1385.

Burnside, C., Eichenbaum, M., Rebelo S.T. (1995): "Capital Utilization and Returns to Scale," in: J.J. Rotemberg and B.S. Bernanke, eds. NBER Macroeconomics Annual, Cambridge, MA: MIT Press.

Calvo, G. A. (1983): "Staggered Prices in a Utility-Maximizing Framework.” Journal of Monetary Economics, 12, 383 - 398.

Carlstrom, C., Fuerst, T. (1997): "Agency Cost, Net Worth, and Business Fluctuations: A Computable General Equilibrium Analysis". American Economic Review, 87, 893 - 910.

Clarida, R., Gali, J., Gertler, M. (1999): "The Science of Monetary Policy: A New Keynesian Perspective." Journal of Economic Literature, 37, 1661 - 1707.

Cole, H.L., Ohanian, L.E. (2000): "The Great Depression in the United States from a Neoclassical Perspective." Federal Reserve Bank of Minneapolis Quarterly Review, Winter, 23, 2-24

Diamond, P. A. (1976): "Cardinal Welfare, Individualistic Ethics and Interpersonal Comparisons of Utility: A Comment." Journal of Political Economy, 75, 765-766.

Dreze, J. (1970): "Market Allocation Under Uncertainty." European Economic Review, 2, 133 165.

Eichenbaum, M. (1991): "Real Business-Cycle Theory, Wisdom or Whimsy?" Journal of Economic Dynamics and Control, 15, 607 - 626.

Frydman, R., Phelps, E.S. (1983): Individual Forecasting and Aggregate Outcomes: "Rational Expectations" Examined. Cambridge: Cambridge University Press.

Greenwood, J., Hercowitz, Z., Huffman, G.W. (1988): "Investment, Capacity Utilization, and the Real Business Cycle." American Economic Review 78, 402 - 417.

Hammond, P.J. (1981): "Ex-ante and Ex-post Welfare Optimality uner Uncertainty." Economica 48, $235-250$.

Hammond, P.J. (1983): "Ex-post Optimality as a Dynamically Consistent Objective for Collective Choice Under Uncertainty." In Pattanaik, P.K., Salle, M. (ed.).: Social Choice and Welfare, Chapter 10, 175 - 205, Amsterdam: North Holland..

Jaffee, D. M., Stiglitz, J. (1990): "Credit Rationing." Chapter 16 in Friedman, B. M., Hahn, F. H. (ed.) Handbook of Monetary Economics Volume II, Amsterdam: North Holland.

Keynes, J. M. (1936): The General Theory of Employment, Interest and Money. Reprinted by Harbinger, Harcourt Brace and World, 1964.

King, R.G., Plosser, C.I., Rebelo, S.T. (1988): "Production, Growth and Business Cycles." Journal of Monetary Economics 21, 195 - 232.

King, R.G., Rebelo, S.T. (1999): "Resuscitating Real Business Cycles.” In J. Taylor and M. Woodford (eds.), Handbook of Macroeconomics, Volume 1B. Amsterdam: North- 
Holland, Chapter 14, 927 -1007.

Kiyotaki, N., Moore, J. (1997): “Credit Cycles.” Journal of Political Economy, 105 , 211 - 248.

Kurz, M. (1974): The Kesten-Stigum Model and the Treatment of Uncertainty in Equilibrium Theory. In Balch, M.S., McFadden, D.L., Wu, S.Y. (ed.).: Essays on eeonomic behavior under uncertainty, 389-399, Amsterdam: North Holland.

Kurz, M. (1994): On the Structure and Diversity of Rational Beliefs. Economic Theory 4, pp. 877 - 900 . (An edited version appears as Chapter 2 of Kurz, M. (ed.).: 1997)

Kurz, M. (ed.) (1996): Symposium: Rational Beliefs and Endogenous Uncertainty. Economic Theory, 8, 383 - 553.

Kurz, M. (ed) (1997): Endogenous Economic Fluctuations: Studies in the Theory of Rational Belief. Studies in Economic Theory, No. 6, Berlin and New York: Springer-Verlag.

Kurz, M. (1997a): Asset Prices with Rational Beliefs. In Kurz, M.(ed.). (1997), Chapter 9, 211 250.

Kurz, M. (1997b): On the Volatility of Foreign Exchange Rates. In Kurz, M. (ed.). (1997), Chapter 12, 317 - 352.

Kurz, M. (1998): Social States of Belief and the Determinants of the Equity Risk Premium in a Rational Belief Equilibrium. In Abramovich,Y.A., Avgerinos, E., Yannelis. N.C.(eds.).: Functional Analysis and Economic Theory, 171 - 220, Berlin and New York: Springer Verlag 1998.

Kurz, M., Beltratti, A. (1997) : The Equity Premium is No Puzzle. In Kurz, M. (ed.).: 1997, Chapter 11, 283 - 316.

Kurz, M., Schneider, M. (1996): Coordination and Correlation in Markov Rational Belief Equilibria. Economic Theory 8, pp. 489.

Kurz, M., Motolese, M. (2001): Endogenous Uncertainty and Market Volatility. Economic Theory, 17, 497 - 544.

Lindahl, E. (1939) : Studies in the theory of money and capital. London: George Allen and Unwin Ltd.

Lucas, R. E. Jr. (1972): "Expectations and the Neutrality of Money." Journal of Economic Theory, 4, 103-1024.

Mirrlees, J. A. (1974): "Notes On Welfare Economics, Information and Uncertainty. In Balch, M.S., McFadden, D.L., Wu, S.Y. (ed.).: Essays on eeonomic behavior under uncertainty, 243 -258, Amsterdam: North Holland.

Mishkin, F. (1982): "Does Unanticipated Money Matter? An Econometric Investigation.” Journal of Political Economy, 91, 22-51.

Motolese, M. (2000): "Endogenous Uncertainty and the Non-Neutrality of Money." Manuscript, Universitá Cattolica di Milano, May 8.

Motolese, M. (2001): "Money Non-Neutrality in a Rational Belief Equililbrium with Financial Assets. Economic Theory, 18, 97 - 16.

Myrdal, G. (1939) : Monetary equilibrium. Reprints of economic classics, New York: Augustus M. Kelley 1962

Nielsen, K. C. (1996): "Rational Belief Structures and Rational Belief Equilibria. Economic Theory, 8, 339 - 422.

Nielsen, K. C. (1998): “Monetary Union versus Floating Exchange Rates Under Rational Beliefs: 
the Role of Exogenous Uncertainty. Working paper, University of Copenhagen.

Nielsen, K. C. (2000): "Stabilizing, Pareto Improving Policies in an OLG Model with Incomplete Markets: The Rational Expectations and Rational Beliefs Case." Manuscript, Banco de España, May 19.

Phelps, E.S., Taylor, J.B. (1977): "Stabilizing Powers of Monetary Policy under Rational Expectations." Journal of Political Economy 85, 163 - 189.

Pigou, A.C. (1941): Employment and equilibrium. London: Macmillan and Co.

Radner, R. (1972): "Existence of equilibrium of plans, prices and price expectations in a sequence of Markets." Econometrica 40, 289-303.

Rotemberg, J. J., Woodford, M. (1999): “The Cyclical Behavior of Prices and Cost." NBER Working Paper 6909, Cambridge: National Bureau of Economic Research.

Sargent, T.J., Wallace, N. (1975): "Rational Expectations, the Optimal Monetary Instrument, and the Optimal Money Supply Rule." Journal of Political Economy 83, 241 - 254.

Silvestre, J. (1999): "Discrepancies Between Ex-Ante and Ex-Post Efficiency Under Subjective Probabilities." Working Paper, University of California at Davis, January, (forthcoming in Economic Theory, 2001).

Starr, R.(1976): "Optimal Production and Allocation Under Uncertainty." Quarterly Journal of Economics, 87, 81-95.

Stock, H. J., Watson, W. M. (1999a): "Diffusion Indexes." Department of Economics, Princeton University.

Stock, H. J., Watson, W. M. (1999b): "Forecasting Inflation." Department of Economics, Princeton University.

Stock, H. J., Watson, W. M. (2001): "Forecasting Output and Inflation: The Role of Asset Prices." Department of Economics, Princeton University, February.

Summers, L. H. (1986): "Some Skeptical Observations on Real Business Cycle Theory." Federal Reserve Bank of Minneapolis Quarterly Review 10, 23 - 27.

Taylor, J. B. (1980): "Staggered Contracts." Carnegie - Rochester Conference Series On Public Policy 39, 195-214.

Taylor, J. B. (1993): "Discretion Versus Policy Rules in Practice." Carnegie - Rochester Conference Series On Public Policy 39, 195-214.

Taylor, J.B. (ed.) (2000): Monetary Policy Rules. Chicago: Chicago University Press.

Thornton, H. (1802): An inquiry into the nature and effects of the paper credit of Great Britain. Edited with an introduction by F.A. v. Hayek, New York: Augustus K. Kelley 1962.

Wen, Y. (1998a): "Investment Cycles." Journal of Economic Dynamic and Control 22, 1139 1165.

Wen, Y. (1998b): "Can a Real Business Cycle Model Pass the Watson Test?" Journal of Monetary Economics 42, 185 - 203.

Woodford, M. (1999): "Interest and Prices, Chapter 2: Price-Level Determination Under InterestRate Rules." Mimeo, Princeton University, April.

Woodford, M. (2000): "Interest and Prices, Chapter 4: A Neo-Wicksellian Framework for the Analysis of Monetary Policy." Mimeo, Princeton University, September.

Woodford, M. (2001a): "Interest and Prices, Chapter 3: Optimizing Models with Nominal Rigidities." Mimeo, Princeton University, February, 2001. 
Woodford, M. (2001b): "Inflation Stabilization and Welfare." Working Paper 8071, National Bureau of Economic Research, Cambridge, Massachusetts, January.

Yun, T. (1996): "Nominal Price Rigidity, Money Supply Endogeneity, and Business Cycles." Journal of Monetary Economics 37, 345 - 370. 


\section{Appendix A: Rational Beliefs-A Brief Summary of the Definition}

The theory of Rational Beliefs (RB) (see Kurz (1994)) starts with the observation that the true probability of observed variables is not known; agents may assume the true process is non-stationary. Lacking knowledge, rational agents develop their own theories in order to form probability beliefs about future economic events. The second assumption is that at each date $t$ an agent has a great deal of data about past performance of the economy hence his reference is the empirical distribution derived from the frequency at which events occurred in the past. The third component of the theory is the observation that the economic life of an agent is short relative to the clock at which new data arrives. Hence, let $\mathrm{X} \subseteq \mathbb{R}^{\mathrm{N}}$ be the space of observables, $x_{t} \in X$ a vector of the $N$ observables and let $x=\left(x_{0}, x_{1}, x_{2}, \ldots\right)$ be the random data from 0 to infinity. The history from $t$ on is $x^{t}=\left(x_{t}, x_{t+1}, x_{t+2}, \ldots\right)$, hence $x^{0}=x$. The history up to $\mathrm{t}$ is $\mathrm{I}_{\mathrm{t}}=\left(\mathrm{x}_{0}, \mathrm{x}_{1}, \mathrm{x}_{2}, \ldots, \mathrm{x}_{\mathrm{t}}\right)$ and date $\mathrm{t}$ is large so that the empirical distribution of the process can be discovered. The agent's life $\mathrm{L}$ is the span when he makes decisions and $\mathrm{L}$ is very short relative to $\mathrm{t}$. An agent's belief may be correct or not but the little data - $\left(\mathrm{x}_{\mathrm{t}}, \mathrm{x}_{\mathrm{t}+1}, \mathrm{x}_{\mathrm{t}+2}, \ldots, \mathrm{x}_{\mathrm{t}+\mathrm{L}}\right)$ - generated during his own economic life is too small to provide a reliable test of his theory. Even if these limited observations could negate his theory with some confidence, such evidence becomes available too late, after most economic decisions have been made. Thus, the rationality of a belief $\mathrm{Q}$ cannot be judged the compatibility of a belief $\mathrm{Q}$ with the limit of the data in the future. Instead, the RB theory defines rationality in terms of its compatibility with the empirical distribution of past data. We now explain the rationality conditions of the theory.

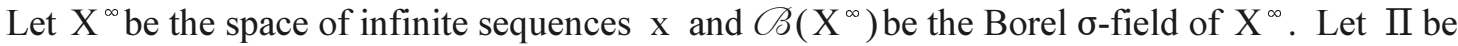
the true probability on $\left(\mathrm{X}^{\infty}, \not\left(\mathrm{X}^{\infty}\right)\right)$ under which the data is generated; this process may be nonstationary. For each finite dimensional set $\mathrm{B} \in \mathscr{B}\left(\mathrm{X}^{\infty}\right)$ agents compute the empirical frequency of the event defined by

where

$$
m_{n}(B)(x)=\frac{1}{n} \sum_{k=0}^{n-1} 1_{B}\left(x^{k}\right)=\left\{\begin{array}{l}
\text { The relative frequency that B occurred } \\
\text { among } n \text { observations since date } 0
\end{array}\right\}
$$

$$
1_{B}(y)=\left\{\begin{array}{lll}
1 & \text { if } & y \in B \\
0 & \text { if } & y \notin B
\end{array} .\right.
$$

The RB theory assumes the data generating process is stable in the sense that the limits above exist $\Pi$ a.e. This is Property 1. It implies that an empirical distribution exists and agents learn from it a probability $\mathrm{m}$ on $\left(\mathrm{X}^{\infty}, \not{B}\left(\mathrm{X}^{\infty}\right)\right)$. We show that (i) $\mathrm{m}$ is unique; (ii) $\mathrm{m}$ is stationary and hence is called "the stationary measure of II." Since $\mathrm{m}$ is learned from the data, there is no disagreement among agents about it. The probability $\mathrm{m}$ is their common empirical knowledge.

Agents who do not know the true probability $\Pi$ discover a probability $m$ induced by $\Pi$. If an economy is stationary, $m=\Pi$ but agents could not know this fact. What are the restrictions which the knowledge of $\mathrm{m}$ places on the beliefs of rational agents? To explore this we introduce

Definition 1: (Property 2) A process $\left\{\mathrm{x}_{\mathrm{t}}, \mathrm{t}=1,2,3, \ldots\right\}$ with probability $\Pi$ on $\left(\mathrm{X}^{\infty}, \mathscr{B}\left(\mathrm{X}^{\infty}\right)\right)$ is said to be Weak Asymptotic Mean Stationary- WAMS - if for each finite dimensional event $\mathrm{B} \in \mathscr{B}\left(\mathrm{X}^{\infty}\right)$

$$
\lim _{n \rightarrow \infty} \frac{1}{n} \sum_{k=0}^{n-1} \Pi\left(B^{(k)}\right)=\stackrel{\circ}{m} \Pi(B) \quad \text { exists. }
$$


We show that the collection $\stackrel{\circ}{\mathrm{m}}(\mathrm{B})$ induces a unique probability $\mathrm{m}^{\Pi}$ on $\left(\mathrm{X}^{\infty}, \mathscr{B}\left(\mathrm{X}^{\infty}\right)\right)$ which is stationary. Since this holds for any WAMS probability $\mathrm{Q}$, we denote by $\mathrm{m}^{\mathrm{Q}}$ the probability on $\left(\mathrm{X}^{\infty}\right.$, $\left.\not\left(X^{\infty}\right)\right)$ induced by the above analytical property which $\mathrm{Q}$ satisfies. The central result of the RB theory is the following:

Theorem 1: Properties 1 and 2 are equivalent and $\mathrm{m}(\mathrm{A})=\mathrm{m}^{\Pi}(\mathrm{A})$ for all events $\mathrm{A} \in \mathcal{B}\left(\mathrm{X}^{\infty}\right)$.

Agents compute $\mathrm{m}$ from the data and Theorem 1 leads to a natural definition of what it means for a probability belief $\mathrm{Q}$ to be "compatible with the data", which $\mathrm{m}$ represents:

Definition 2: A probability belief $\mathrm{Q}$ is said to be compatible with the observed data $m$ if

(i) $\mathrm{Q}$ is a WAMS probability on $\left(\mathrm{X}^{\infty}, \mathscr{B}\left(\mathrm{X}^{\infty}\right)\right)$,

(ii) $\mathrm{m}^{\mathrm{Q}}(\mathrm{A})=\mathrm{m}(\mathrm{A}) \quad$ for all events $\mathrm{A} \in \mathscr{B}\left(\mathrm{X}^{\infty}\right)$.

Condition (ii) is the main implication. Now consider a rational agent with a stable belief $\mathrm{Q}$. He knows $\mathrm{m}^{\mathrm{Q}}$ by the analytic conditions above. If $\mathrm{m}^{\mathrm{Q}} \neq \mathrm{m}$, it would prove that $\mathrm{Q}$ is not the truth. Indeed, it would prove that $\mathrm{Q}$ is not compatible with the data $\mathrm{m}$. This proposes a natural definition of an RB:

Definition 3: A probability belief $\mathrm{Q}$ on $\left(\mathrm{X}^{\infty}, 囚\left(\mathrm{X}^{\infty}\right)\right)$, is said to be a Rational Belief $(\mathrm{RB})$ relative to $\mathrm{m}$ if $\mathrm{Q}$ is compatible with the known data $\mathrm{m}$.

An agent who holds a rational belief $\mathrm{Q}$ relative to $\mathrm{m}$ must then satisfy the rationality conditions

$$
\mathrm{m}^{\mathrm{Q}}(\mathrm{B})=\mathrm{m}(\mathrm{B}) \text { for all sets } \mathrm{B} \in \mathscr{B}\left(\mathrm{X}^{\infty}\right) \text {. }
$$

These are the central restrictions of the RB theory.

The implication of $(\star)$ is that under RB agents may disagree about probabilities of short term events but not about long term averages. Note that (i) $\Pi$ is a Rational Belief and hence REE is an RBE; (ii) $\mathrm{m}$ is an RB although it is possible that $\mathrm{m} \neq \Pi$; (iii) an RB Q and the true $\Pi$ may disagree on timing or sequencing; (iv) an RB Q and the true $\Pi$ may put different probabilities on important rare events; (v) an RB Q allows optimism/pessimism relative to $\mathrm{m}$.

Three Observations

(i) If agents believe the economy is stationary then $\mathrm{Q}^{\mathrm{k}}=\mathrm{m}$. Thus, in an RBE agents may believe the economy is non-stationary and disagree about unknown regime parameters (e.g. mean value function) of the process.

(ii) When holding diverse belief agents' beliefs affects demands and equilibrium maps have the general form

$$
\mathrm{p}_{\mathrm{t}}=\Phi\left(\mathrm{I}_{\mathrm{t}}, \mathrm{Q}_{\mathrm{t}}{ }^{1}, \mathrm{Q}_{\mathrm{t}}^{2}, \ldots, \mathrm{Q}_{\mathrm{t}}^{\mathrm{H}}\right)
$$

where $\left(\mathrm{Q}_{\mathrm{t}}{ }^{1}, \mathrm{Q}_{\mathrm{t}}{ }^{2}, \ldots, \mathrm{Q}_{\mathrm{t}}{ }^{\mathrm{H}}\right)$ are date $\mathrm{t}$ conditional probabilities. In such equilibria beliefs act as a propagation mechanism of economic fluctuations. Hence, the RBE theory proposes that economic fluctuations have an endogenous component propagated within the economy. Kurz (1974) called it Endogenous Uncertainty.

(iii) Disagreement among rational agents implies their conditional probabilities fluctuate over time. For example, consider a finite state Markov economy. A belief $\mathrm{Q}^{\mathrm{k}}$ is represented by a sequence of selections from, say, 2 different Markov matrices $\left\{\mathrm{G}_{1}{ }^{\mathrm{k}}, \mathrm{G}_{2}{ }^{\mathrm{k}}\right\}$ which $\mathrm{k}$ believes are possible. $\mathrm{m}$ is represented by a single matrix $\Gamma$. If agents disagree, $Q^{k} \neq m$ imply that $G_{j}{ }^{k} \neq \Gamma$ for $j=1,2$. Rationality requires the time average of the $\mathrm{G}_{\mathrm{j}}{ }^{\mathrm{k}}$ used by $\mathrm{k}$ to equal $\Gamma$. Agent $\mathrm{k}$ would be irrational if he used only one matrix, say 
$\mathrm{G}_{1}{ }^{\mathrm{k}} \neq \Gamma$, since the time average under $\mathrm{G}_{1}{ }^{\mathrm{k}}$ is not $\Gamma$. When rational agents disagree they must use varying matrices over time.

The main problem now is te simplification of the rationality conditions $(\star)$. Since agents hold diverse non-stationary beliefs, the problem is to find a simple mathematical tool for describing nonstationarity. The tool developed is the Conditional Stability Theorem (Kurz and Schneider (1996) and Nielsen (1996)). To explain this theorem note that we want to describe in a tractable way the nonstationarity of a process on $\left((\mathrm{X})^{\infty}, \mathscr{B}\left((\mathrm{X})^{\infty}\right)\right.$. The Conditional Stability Theorem describes all the nonstationarity using artificial variables $\mathrm{y}_{\mathrm{t}} \in \mathrm{Y}$ with a marginal probability space $\left((\mathrm{Y})^{\infty}, \mathcal{B}\left((\mathrm{Y})^{\infty}, \mu\right)\right.$. It postulates $(\mathrm{X} \times \mathrm{Y})$ to be the state space, defines a universal probability $\mathrm{Q}$ on the space $\left((\mathrm{X} \times \mathrm{Y})^{\infty}\right.$, $\mathscr{B}\left((\mathrm{X} \times \mathrm{Y})^{\infty}\right)$ and defines the desired non-stationary probability to be $\mathrm{Q}_{\mathrm{y}}$, the conditional probability of $\mathrm{Q}$ with respect to the sequence $\mathrm{y}=\left(\mathrm{y}_{1}, \mathrm{y}_{2}, \ldots\right)$. Thus $\mathrm{Q}$ must satisfy the condition that for all $A \in ß \beta\left(\mathrm{X}^{\infty}\right)$ and $\mathrm{B} \in ß\left(\mathrm{Y}^{\infty}\right)$

$$
\mathrm{Q}(\mathrm{A} \times \mathrm{B})=\int_{\mathrm{B}} \mathrm{Q}_{\mathrm{y}}(\mathrm{A}) \mu(\mathrm{dy}) .
$$

The conditional probability space $\left((\mathrm{X})^{\infty}, \mathscr{B}\left((\mathrm{X})^{\infty}, \mathrm{Q}_{\mathrm{y}}\right)\right.$ is non-stationary since probabilities of events in $\mathscr{B}\left((\mathrm{X})^{\infty}\right)$ are not time independent: they change with the parameters $\mathrm{y}_{\mathrm{t}}$ which are time dependent. If $\mathrm{Q}_{\mathrm{y}}$ reflect the non-stationarity of the system, then we interpret $\left\{\mathrm{y}_{\mathrm{t}}, \mathrm{t}=1,2, \ldots\right\}$ as a mathematical description of that non-stationarity. This approach is commony used where $\mathrm{Y}$ is the set of possible "regimes" (finite or infinite) and $y_{t}$ identifies the regime at $t$. Here we use this method to describe the perceived non stationarity of an agent. Thus, $\mathrm{Q}_{\mathrm{y}_{\mathrm{t}}}{ }^{\mathrm{t}}$ is the date $\mathrm{t}$ probability belief of future observables by $\mathrm{k}$ and $\mathrm{y}_{\mathrm{t}}{ }^{\mathrm{k}}$ reflects the "perception" or "assessment" of agent $\mathrm{k}$. The assessment variables $\left\{\mathrm{y}_{\mathrm{t}}{ }^{\mathrm{k}}, \mathrm{t}=1,2, \ldots\right\}$ are generated by the agent himself, providing a vocabulary to describe his belief in the non-stationarity of the observables. From an informational perspective, assessment variables are privately perceived parameters indicating how an agent interprets current information. These purely subjective variables should not be taken to be objective and transferable "information". Since even within an infinite horizon model each family member lives for $\mathrm{L}_{2}$ periods, at $\mathrm{t}$ he does not know $\mathrm{y}_{\tau}{ }^{\mathrm{k}}$ for dates $\tau$ not in his own lifetime. In case of our two agents $\left(y_{t}^{1}, y_{t}^{2}\right)$ may be correlated and jointly distributed with observables. Agents do not know these distributions and cannot learn them from data since $\mathrm{k}$ "knows" only his own parameter $\mathrm{y}_{\mathrm{t}}{ }^{\mathrm{k}}$.

This approach leads to a technical difficulty. To be compatible with the earlier development, how do we know when a conditional system $\left((\mathrm{X})^{\infty}, \mathscr{B}\left((\mathrm{X})^{\infty}, \mathrm{Q}_{\mathrm{y}}{ }^{\mathrm{k}}\right)\right.$ is stable and Properties 1 and 2 satisfied? And how do we compute the stationary measure of such a conditional system? For answers, note that since the conditional system is intended to describe all the non-stationarity, we can assume the joint system to be stationary. Now, for any joint system $\left((X \times Y)^{\infty}, \mathcal{B}\left((X \times Y)^{\infty}\right), Q\right)$, the marginal measure $Q_{X^{\infty}}$ is defined by

$$
\mathrm{Q}_{\mathrm{X}^{\infty}}(\mathrm{A})=\mathrm{Q}\left(\mathrm{A} \times \mathrm{Y}^{\infty}\right)=\int_{\mathrm{Y}^{\infty}} \mathrm{Q}_{\mathrm{y}}(\mathrm{A}) \mu(\mathrm{dy}) \text { for all } \mathrm{A} \in \mathscr{B}\left(\mathrm{X}^{\infty}\right)
$$

Theorem 2: (Conditional Stability Theorem, Kurz and Schneider [1996] Theorem 2) Let $\left((\mathrm{X} \times \mathrm{Y})^{\infty}, \mathscr{B}\left((\mathrm{X} \times \mathrm{Y})^{\infty}\right), \mathrm{Q}\right)$ be stationary and ergodic and let $\mathrm{Y}$ be countable then

(a) $\left(\mathrm{X}^{\infty}, \not\left(\mathrm{X}^{\infty}\right), \mathrm{Q}_{\mathrm{y}}, \mathrm{T}\right)$ is stable and ergodic for $\mathrm{Q}$ a.a. $\mathrm{y}$;

(b) The stationary measure of $Q_{y}$ is independent of $y$ for $Q$ a.a. $y$ and if we denote it by $m^{Q_{y}}$ then it satisfies the condition $\mathrm{m}^{\mathrm{Q}_{\mathrm{y}}}=\mathrm{Q}_{\mathrm{X}^{\infty}}$.

Consider an example which we use later when $\mathrm{y}_{\mathrm{t}}^{\mathrm{k}} \in \mathrm{Y}=\{0,1\}, \mathrm{Q}^{\mathrm{k}}$ is a probability belief on the joint process $\left\{\left(\mathrm{x}_{\mathrm{t}}, \mathrm{y}_{\mathrm{t}}^{\mathrm{k}}\right), \mathrm{t}=1,2, \ldots\right\}$ which is a Markov process and, conditionally on $\mathrm{y}_{\mathrm{t}-1}^{\mathrm{k}}$, the distribution of $\mathrm{y}_{\mathrm{t}}^{\mathrm{k}}$ is independent of other observables. Then the effective belief $\mathrm{Q}_{\mathrm{y}}{ }^{\mathrm{k}}$ is defined by two transition functions 
$\mathrm{F}_{1}^{\mathrm{k}}$ and $\mathrm{F}_{2}^{\mathrm{k}}$ as follows

$$
Q_{y_{t}}{ }^{k}=\left\{\begin{array}{lll}
F_{1}^{k} & \text { if } & y_{t}{ }^{k}=1 \\
F_{2}^{k} & \text { if } & y_{t}{ }^{k}=0 .
\end{array}\right.
$$

The marginal measure $\mathrm{Q}_{\mathrm{X}^{\infty}}^{\mathrm{k}}$ is the probability of a stationary Markov process uniquely defined by a transition function $\mathrm{F}^{\mathrm{k}}$, computed by the simple expression ( which we use again later):

$$
\mathrm{F}^{\mathrm{k}}=\mathrm{F}_{1}^{\mathrm{k}} \mu^{\mathrm{k}}\left(\mathrm{y}_{\mathrm{t}}^{\mathrm{k}}=1\right)+\mathrm{F}_{2}^{\mathrm{k}} \mu^{\mathrm{k}}\left(\mathrm{y}_{\mathrm{t}}{ }^{\mathrm{k}}=0\right) .
$$

Kurz-Motolese [2001, Section 2] provides a detailed and formal definition of a Rational Belief Equilibrium (RBE) and compares it to other equilibrium concepts. 


\section{APPENDIX B: The Computational Model}

This appendix explores several computational issues which have not been discussed in the text. We assume the symmetric case where $\beta_{1}=\beta_{2}=\beta=.99$ reflects the quarterly model and $\gamma_{1}=\gamma_{2}=\gamma=1.5$ is empirically reasonable. We also assumed: $\sigma=.35, \zeta=3.5, v^{*}=1.0045$ and $\delta=.025$ as familiar from the RBC literature. Our main objective here is to provide a complete statement of the equilibrium conditions as computed.

\section{Non-Negativity of Investments}

To handle the non-negative inputs to investments we introduced two elements. First, we defined the problem of selecting an optimal vector of $\left(n_{t}{ }^{\mathrm{kM}}, \mathrm{n}_{\mathrm{t}}^{\mathrm{kS}}\right)$ by requiring the agents to select a positive fraction of the total input $n_{t}{ }^{k}$ where the proportions take the form

$$
\begin{aligned}
& \mathrm{n}_{\mathrm{t}}^{\mathrm{kM}}=\left[\frac{\mathrm{e}^{-\chi_{\mathrm{i}} \mathrm{x}_{\mathrm{t}}{ }^{\mathrm{k}}}}{1+\mathrm{e}^{-\chi_{\mathrm{i}} \mathrm{x}_{\mathrm{t}}}}\right] \mathrm{n}_{\mathrm{t}}{ }^{\mathrm{k}} \\
& \mathrm{n}_{\mathrm{t}}^{\mathrm{kS}}=\left[\frac{1}{1+\mathrm{e}^{-\chi_{\mathrm{i}} \mathrm{k}_{\mathrm{t}}^{\mathrm{k}}}}\right] \mathrm{n}_{\mathrm{t}}{ }^{\mathrm{k}}
\end{aligned}
$$

where $\chi_{i}=1$. Here choice variables for each agent are $\left(x_{t}{ }^{k}, n_{t}{ }^{k}\right)$. Note that if total input is positive then each one of the individual inputs are positive as well, by construction. Secondly, we imposed a penalty on negative deviations from the steady state of each of the inputs $\left(\mathrm{n}_{\mathrm{t}}^{\mathrm{kM}}, \mathrm{n}_{\mathrm{t}}^{\mathrm{kS}}\right)$ which have the following form.

$$
\begin{aligned}
& \tau_{\mathrm{i}}\left[\left(\mathrm{i}_{\mathrm{t}}^{\mathrm{kS}}-\mathrm{i}^{\mathrm{kS} *}\right)+\frac{\mathrm{e}^{-\chi_{\mathrm{iS}}\left(\mathrm{i}_{\mathrm{t}}^{\mathrm{SS}}-\mathrm{i}^{\mathrm{kS} *}\right)}}{\chi_{\mathrm{iS}}}\right], \tau_{\mathrm{i}}=.3, \chi_{\mathrm{iS}}=10, \\
& \tau_{\mathrm{i}}\left[\left(\mathrm{i}_{\mathrm{t}}^{\mathrm{kM}}-\mathrm{i}^{\mathrm{kM} *}\right)+\frac{\mathrm{e}^{-\chi_{\mathrm{iM}}\left(\mathrm{i}_{\mathrm{t}}^{\mathrm{kM}}-\mathrm{i}^{\mathrm{kM} *}\right)}}{\chi_{\mathrm{iM}}}\right], \tau_{\mathrm{i}}=.3, \chi_{\mathrm{iM}}=10 .
\end{aligned}
$$

Note that the linear parts of these penalties are zero at steady state and the two parameters

$$
\text { B - } 1
$$


regulate the first and second derivatives at steady state.

\section{Indeterminacy in the Riskless Economy}

The indeterminacy of the optimal allocation of assets at the steady state of the riskless economy is a well known problem for perturbation models. This is due to the perfect substitution among all financial assets that have the same rate of return without risk. This problem does not have a fully satisfactory analytical solution and our ad-hoc approach is to select quadratic penalties for all assets traded in the model. The penalty is imposed on deviations from steady state values of all variables. The penalty is set at the universal value of .001 which is less than the allowed error of $10^{-3}$ in the Euler Equations and hence has no material effect in the risky economy. As for the inputs into the investment sector, we wanted to make sure that the small penalty introduced here does not affect the optimal choice between the two inputs which are central to the functioning of the model. For this reason we set the penalty to be proportional to the steady state proportions of the two inputs. More specifically, for the return parameters $\mathrm{d}_{1}, \mathrm{~d}_{2}$, $\mathrm{S}_{1}$ and $\mathrm{s}_{2}$ of the two investment projects $\mathrm{M}$ and $\mathrm{S}$ let

$$
\alpha^{\mathrm{S}}=\frac{1}{2} \frac{\left(\mathrm{d}_{2}-\mathrm{d}_{1}\right)}{\left(\mathrm{s}_{1}-\mathrm{d}_{1}\right)} \text { and } \alpha^{\mathrm{M}}=1-\alpha^{\mathrm{S}}
$$

be the steady state proportions (or the full hedging proportions in the REE) of the total inputs into the two projects $\mathrm{S}$ and $\mathrm{M}$. The exact quadratic penalties were then set at

$$
\begin{aligned}
& \frac{1}{\alpha^{\mathrm{S}}}\left[\tau_{\mathrm{I}} \frac{\left(\mathrm{i}_{\mathrm{t}}^{\mathrm{kS}}-\mathrm{i}^{\mathrm{kS} *}\right)^{2}}{2}\right] \alpha^{\mathrm{S}}=.25, \tau_{\mathrm{I}}=.001 \\
& \frac{1}{\alpha^{\mathrm{M}}}\left[\tau_{\mathrm{I}} \frac{\left(\mathrm{i}_{\mathrm{t}}^{\mathrm{kM}}-\mathrm{i}^{\mathrm{kM} *}\right)^{2}}{2}\right] .
\end{aligned}
$$

B - 2 


\section{The revised optimization problem of agent $k$}

Given the above write the optimization problem of agents as follows, for $\mathrm{k}=1,2$ :

$$
\begin{aligned}
& \underset{\mathrm{m}_{\mathrm{t}}{ }^{\mathrm{k}}, \mathrm{l}_{\mathrm{t}}^{\mathrm{k}}, \mathrm{b}_{\mathrm{t}}{ }^{\mathrm{k}}, \mathrm{i}_{\mathrm{t}}{ }^{\mathrm{k}}, \mathrm{x}_{\mathrm{t}}{ }^{\mathrm{k}}, \mathrm{k}_{\mathrm{t}}{ }^{\mathrm{kd}}}{ }\left\{\mathrm { E } _ { \mathrm { Q } } ^ { \mathrm { k } } \sum _ { \mathrm { t } = 1 } ^ { \infty } \left[\frac { 1 } { 1 - \gamma } \left[\left(\mathrm{c}_{\mathrm{t}}{ }^{\mathrm{k}} \xi_{\mathrm{t}}\left(\mathrm{l}_{\mathrm{t}}^{\mathrm{k}}\right)^{\zeta}\right]^{1-\gamma}+\left(\mathrm{m}_{\mathrm{t}}{ }^{\mathrm{k}} \xi_{\mathrm{t}}\right)^{1-\gamma}\right.\right.\right. \\
& +\xi_{t}^{1-\gamma}\left(-\tau_{K} \frac{\left(k_{t}^{k d}-k^{k d *}\right)^{2}}{2}-\tau_{B} \frac{\left(b_{t}{ }^{k}-b^{k *}\right)^{2}}{2}\right. \\
& -\frac{1}{\alpha^{\mathrm{S}}}\left[\tau_{\mathrm{I}} \frac{\left(\mathrm{n}_{\mathrm{t}}^{\mathrm{kS}}-\mathrm{n}^{\mathrm{kS} *}\right)^{2}}{2}\right]+\tau_{\mathrm{i}}\left[\left(\mathrm{n}_{\mathrm{t}}^{\mathrm{kS}}-\mathrm{n}^{\mathrm{kS} *}\right)+\frac{\mathrm{e}^{-\chi_{\mathrm{iS}}\left(\mathrm{n}_{\mathrm{t}}^{\mathrm{kS}}-\mathrm{n}^{\mathrm{kS} *}\right)}}{\chi_{\mathrm{iS}}}\right] \\
& \left.\left.\left.-\frac{1}{\alpha^{M}}\left[\tau_{\mathrm{I}} \frac{\left(\mathrm{n}_{\mathrm{t}}^{\mathrm{kM}}-\mathrm{n}^{\mathrm{kM} *}\right)^{2}}{2}\right]+\tau_{\mathrm{i}}\left[\left(\mathrm{n}_{\mathrm{t}}^{\mathrm{kM}}-\mathrm{n}^{\mathrm{kM} *}\right)+\frac{\mathrm{e}^{-\chi_{\mathrm{iM}}\left(\mathrm{n}_{\mathrm{t}}^{\mathrm{kM}}-\mathrm{n}^{\mathrm{kM} *}\right)}}{\chi_{\mathrm{iM}}}\right]\right)\right]\right\}
\end{aligned}
$$

subject to

$$
\begin{aligned}
& c_{t}{ }^{k}=\left(1-l_{t}^{k}\right) w_{t}+\frac{k_{t-1}^{k}}{u^{*}}\left(q_{t}{ }^{s}+R_{t}\right)+\frac{m_{t-1}^{k} \varrho_{t}+b_{t-1}^{k}}{u^{*} \pi_{t}}-k_{t}^{k d} q_{t}{ }^{s}-n_{t}{ }^{k}-b_{t}{ }^{k} q_{t}{ }^{b}-m_{t}{ }^{k} \\
& \mathrm{n}_{\mathrm{t}}^{\mathrm{k}}=\mathrm{n}_{\mathrm{t}}^{\mathrm{kM}}+\mathrm{n}_{\mathrm{t}}^{\mathrm{kS}} \\
& \mathrm{k}_{\mathrm{t}}^{\mathrm{k}}=\mathrm{k}_{\mathrm{t}}^{\mathrm{kd}}+\mathrm{i}_{\mathrm{t}}^{\mathrm{k}} \\
& \mathrm{i}_{\mathrm{t}-1}^{\mathrm{k}}=\kappa_{\mathrm{t}}^{\mathrm{S}} \mathrm{n}_{\mathrm{t}-1}^{\mathrm{kS}}+\kappa_{\mathrm{t}}^{\mathrm{M}} \mathrm{n}_{\mathrm{t}-1}^{\mathrm{kM}} \\
& n_{t}^{k M}=\left(\frac{e^{-x_{i} x_{t}{ }^{k}}}{1+e^{-x_{i} x_{t}{ }^{k}}}\right) n_{t}{ }^{k} \\
& \mathrm{n}_{\mathrm{t}}^{\mathrm{kS}}=\left(\frac{1}{1+\mathrm{e}^{-\mathrm{x}_{\mathrm{i}} \mathrm{x}_{\mathrm{t}}^{\mathrm{k}}}}\right) \mathrm{n}_{\mathrm{t}}^{\mathrm{k}} \text {. }
\end{aligned}
$$

The above optimization uses the following definitions:

B - 3 


$$
\begin{aligned}
& \kappa_{\mathrm{t}}^{\mathrm{S}}=\mathrm{s}_{1}+\frac{\mathrm{s}_{2}-\mathrm{s}_{1}}{1+\mathrm{e}^{-\chi^{\varphi} \varphi_{\mathrm{t}}}} \\
& \mathrm{\kappa}_{\mathrm{t}}^{\mathrm{M}}=\mathrm{d}_{1}+\frac{\mathrm{d}_{2}-\mathrm{d}_{1}}{1+\mathrm{e}^{-\chi^{\varphi} \varphi_{\mathrm{t}}}}, \quad \chi^{\varphi}=3 \\
& \mathrm{w}_{\mathrm{t}}=\mathrm{A} v_{\mathrm{t}}(1-\sigma)\left(\frac{\mathrm{k}_{\mathrm{t}-1}}{\mathrm{v}^{*} \mathrm{~L}_{\mathrm{t}}}\right)^{\sigma} \\
& \mathrm{R}_{\mathrm{t}}=\mathrm{A} v_{\mathrm{t}} \sigma\left(\frac{\mathrm{k}_{\mathrm{t}-1}}{\mathrm{v}^{*} \mathrm{~L}_{\mathrm{t}}}\right)^{\sigma-1}-\delta \mathrm{q}_{\mathrm{t}}^{\mathrm{s}} \\
& 2-\left(\ell_{\mathrm{t}}^{1}+l_{\mathrm{t}}^{2}\right)=\mathrm{L}_{\mathrm{t}} \\
& \mathrm{k}_{\mathrm{t}}^{1}+\mathrm{k}_{\mathrm{t}}^{2}=\mathrm{k}_{\mathrm{t}} \\
& \mathrm{y}_{\mathrm{t}}=A v_{\mathrm{t}} \mathrm{L}_{\mathrm{t}}\left(\frac{\mathrm{k}_{\mathrm{t}-1}}{v^{*} L_{\mathrm{t}}}{ }^{\sigma}\right.
\end{aligned}
$$

and the money transition equation for the economy

$$
\mathrm{m}_{\mathrm{t}}=\mathrm{m}_{\mathrm{t}-1} \frac{\varrho_{\mathrm{t}}}{\mathrm{v}^{*} \pi_{\mathrm{t}}} .
$$

\section{The Euler Equations And The Equilibrium Conditions}

$$
\begin{aligned}
& \mathrm{c}_{\mathrm{t}}^{\mathrm{k}}=\frac{1}{\zeta} \mathrm{w}_{\mathrm{t}} \mathrm{l}_{\mathrm{t}}^{\mathrm{k}} \\
& \mathrm{q}_{\mathrm{t}}^{\mathrm{s}}\left(\mathrm{c}_{\mathrm{t}}{ }^{\mathrm{k}}\right)^{-\gamma}\left(\ell_{\mathrm{t}}^{\mathrm{k}}\right)^{\zeta(1-\gamma)}+\tau_{\mathrm{K}}\left(\mathrm{k}_{\mathrm{t}}^{\mathrm{kd}}-\mathrm{k}^{\mathrm{kd}{ }^{*}}\right) \\
& =\beta E_{Q^{k}}\left(c_{t+1}^{k}\right)^{-\gamma}\left(\ell_{t+1}^{k}\right)^{\zeta(1-\gamma)}\left(\frac{q_{t+1}^{s}+R_{t+1}}{\left(v^{*}\right)^{\gamma}}\right) \\
& \mathrm{q}_{\mathrm{t}}{ }^{\mathrm{b}}\left(\mathrm{c}_{\mathrm{t}}{ }^{\mathrm{k}}\right)^{-\gamma}\left(\ell_{\mathrm{t}}\right)^{\mathrm{k}} \zeta(1-\gamma)+\tau_{\mathrm{B}}\left(\mathrm{b}_{\mathrm{t}}{ }^{\mathrm{k}}-\mathrm{b}^{\mathrm{k}^{*}}\right) \\
& =\beta \mathrm{E}_{\mathrm{Q}^{k}}\left(\mathrm{c}_{\mathrm{t}+1}^{\mathrm{k}}\right)^{-\gamma}\left(\mathrm{l}_{\mathrm{t}+1}^{\mathrm{k}}\right)^{\zeta(1-\gamma)}\left(\frac{1}{\pi_{\mathrm{t}+1}\left(\mathrm{u}^{*}\right)^{\gamma}}\right)
\end{aligned}
$$

B - 4 


$$
\begin{aligned}
& \left(c_{t}^{k}\right)^{-\gamma}\left(l_{t}^{k}\right)^{\zeta(1-\gamma)}-\left(m_{t}^{k}\right)^{-\gamma}=\beta E_{Q^{k}}\left(c_{t+1}^{k}\right)^{-\gamma}\left(l_{t+1}^{k}\right)^{\zeta(1-\gamma)}\left(\frac{\varrho_{t+1}}{\pi_{t+1}\left(v^{*}\right)^{\gamma}}\right) \\
& \left(c_{t}^{k}\right)^{k}\left(\ell_{t}^{k}\right)^{\zeta(1-\gamma)}+\frac{\tau_{I}}{\alpha^{S}}\left(n_{t}^{k S}-n^{k S^{*}}\right)+\tau_{i}\left(1-e^{-\chi_{i S}\left(n_{t}^{k S}-n^{k S^{*}}\right)}\right) \\
& =\beta \mathrm{E}_{\mathrm{Q}^{k}}\left(\mathrm{c}_{\mathrm{t}+1}^{\mathrm{k}}\right)^{-\gamma}\left(\ell_{\mathrm{t}+1}^{\mathrm{k}}\right)^{\zeta(1-\gamma)}\left(\frac{\mathrm{q}_{\mathrm{t}+1}^{\mathrm{s}}+\mathrm{R}_{\mathrm{t}+1}}{\left(\mathrm{v}^{*}\right)^{\gamma}}\right) \kappa_{\mathrm{t}+1}^{\mathrm{S}} \\
& \left(c_{t}^{k}\right)^{-\gamma}\left(\ell_{t}^{k}\right)^{\zeta(1-\gamma)}+\frac{\tau_{I}}{\alpha^{M}}\left(n_{t}^{k M}-n^{k M *}\right)+\tau_{i}\left(1-e^{-x_{i M}\left(n_{t}^{k M}-n^{k M}\right.}\right) \\
& =\mathrm{BE}_{\mathrm{Q}^{k}}\left(\mathrm{c}_{\mathrm{t}+1}^{\mathrm{k}}\right)^{-\gamma}\left(\ell_{\mathrm{t}+1}^{\mathrm{k}}\right)^{\zeta(1-\gamma)}\left(\frac{\mathrm{q}_{\mathrm{t}+1}^{\mathrm{s}}+\mathrm{R}_{\mathrm{t}+1}}{\left(\mathrm{v}^{*}\right)^{\gamma}}\right) \kappa_{\mathrm{t}+1}^{\mathrm{d}}
\end{aligned}
$$

and the equilibrium conditions: $\quad \mathrm{m}_{\mathrm{t}}{ }^{1}+\mathrm{m}_{\mathrm{t}}{ }^{2}=\mathrm{m}_{\mathrm{t}}$

$$
\begin{aligned}
& \mathrm{b}_{\mathrm{t}}{ }^{1}+\mathrm{b}_{\mathrm{t}}{ }^{2}=0 \\
& \mathrm{k}_{\mathrm{t}}^{1 \mathrm{~d}}+\mathrm{k}_{\mathrm{t}}^{2 \mathrm{~d}}=\frac{\mathrm{k}_{\mathrm{t}-1}}{\mathrm{v}^{*}}(1-\delta) .
\end{aligned}
$$

\section{The Steady State}

In the steady state let $\pi^{*}=1$, and given $\alpha^{*}=\alpha^{\mathrm{S}}$ let

$$
\mathrm{x}^{1 *}=\mathrm{x}^{2 *}=-\frac{1}{\chi_{\mathrm{i}}} \ln \left(\frac{1}{\alpha *}-1\right) .
$$

From (3), aggregating over $c_{t}{ }^{k}$ and $l_{t}^{k}$, we can write

$$
\mathrm{c}^{*}=\frac{1}{\delta} \mathrm{w}^{*}\left(2-\mathrm{L}^{*}\right)
$$

and

$$
\mathrm{c}^{1^{*}}=\mathrm{c}^{2^{*}}=\left(1-\frac{\mathrm{L}^{*}}{2}\right) \frac{\mathrm{w}^{*}}{\zeta} .
$$

From (5) we can deduce

$$
\mathrm{q}^{\mathrm{b}^{*}}=\frac{\beta}{\left(\mathrm{v}^{*}\right)^{\gamma} \pi^{*}}
$$

B - 5 
and from (6) we have

$$
\mathrm{m}^{1^{*}}=\left(1-\frac{\beta \varrho^{*}}{\left(\mathrm{v}^{*}\right)^{\gamma} \pi^{*}}\right)\left(\frac{\mathrm{c}^{*}}{2}\right)^{-\gamma}\left(1-\frac{\mathrm{L}^{*}}{2}\right)^{\zeta(1-\gamma)} .
$$

From (4) we have that

$$
\mathrm{q}^{\mathrm{s}^{*}}=\beta\left(\frac{\mathrm{q}^{\mathrm{s}^{*}}+\mathrm{R}^{*}}{\left(\mathrm{u}^{*}\right)^{\gamma}}\right)
$$

and from (7)

$$
1=\beta\left(\frac{\mathrm{q}^{\mathrm{s}^{*}}+\mathrm{R}^{*}}{\left(\mathrm{u}^{*}\right)^{\gamma}}\right) \kappa^{*}
$$

where $\kappa^{*}=\mathrm{E}_{\varphi} \kappa_{\mathrm{t}}^{\mathrm{S}}=\mathrm{E}_{\varphi} \kappa_{\mathrm{t}}^{\mathrm{M}}=.9$ by the assumption on the existence of a perfect hedge. Hence from (10) and (11)

$$
\mathrm{q}^{\mathrm{s}^{*}}=\frac{1}{\mathrm{\kappa}^{*}}
$$

Also, from (10)

$$
\mathrm{R}^{*}=\left(\frac{\left(\mathrm{u}^{*}\right)^{\gamma}}{\beta}-1\right) \mathrm{q}^{\mathrm{s}}
$$

Finally, using the above definitions we have

$$
\begin{gathered}
\mathrm{r}^{*}=\left(\frac{\left(\mathrm{u}^{*}\right)^{\gamma}}{\beta}-1+\delta\right) \mathrm{q}^{\mathrm{s}^{*}} \\
\mathrm{k}^{*}=\left(\frac{\mathrm{r}^{*}}{\mathrm{~A} \sigma}\right)^{\frac{1}{\sigma-1}} \mathrm{u}^{*} \mathrm{~L}^{*} \\
\mathrm{w}^{*}=\mathrm{A}(1-\sigma)\left(\frac{\mathrm{r}^{*}}{\mathrm{~A} \sigma}\right)^{\frac{\sigma}{\sigma-1}} \\
\mathrm{~B}-6
\end{gathered}
$$




$$
\begin{aligned}
& \mathrm{y}^{*}=\mathrm{AL}^{*}\left(\frac{\mathrm{k}^{*}}{\mathrm{u}^{*} \mathrm{~L}^{*}}\right)^{\sigma} \\
& \mathrm{n} *=\left(1-\frac{1-\delta}{\mathrm{u}^{*}}\right) \frac{\mathrm{k} *}{\mathrm{\kappa} *} \\
& \mathrm{c}^{*}=\mathrm{y}^{*}-\mathrm{n} *
\end{aligned}
$$

We finally specify the symmetry conditions

$$
\ell^{1 *}=l^{2 *}=1-\mathrm{L}^{*} / 2 ; \mathrm{m}^{2^{*}}=\mathrm{m}^{1^{*}} ; \mathrm{m}^{*}=\mathrm{m}^{1^{*}}+\mathrm{m}^{2^{*}} ; \mathrm{n}^{1^{*}}=\mathrm{n}^{2^{*}}=\mathrm{n}^{*} / 2 ; \mathrm{b}^{1^{*}}=\mathrm{b}^{2^{*}}=0 \text {. }
$$

\section{The Perturbation Structure}

We specify here how we formulated the perturbation model. We specify the perception models and show exactly where we place the perturbation variable which is denoted by $\varepsilon$. The equation system is then

$$
y_{t}^{k}=\sigma_{z_{k}} z_{t}^{y^{k}}
$$

where $\mathrm{z}_{\mathrm{t}}^{\mathrm{y}^{\mathrm{k}}}$ is a realization of a normal i.i.d. random variable $\tilde{\mathrm{z}}_{\mathrm{t}}^{\mathrm{y}^{\mathrm{k}}} \sim \mathrm{N}(0,1)$.

$$
\log v_{t+1}^{k}=\lambda_{v} \log v_{t}^{k}+\varepsilon\left(\lambda^{k v} y_{t}^{k}+\sigma_{z^{k v}} \hat{z}_{t+1}^{k v}\right), \quad z_{\hat{t}}^{k v} \sim N(0,1)
$$

$$
\begin{gathered}
\log \varrho_{\mathrm{t}+1}^{\mathrm{k}}=\log \mathrm{u}^{*}+\lambda_{\varrho}\left(\log \varrho_{\mathrm{t}}^{\mathrm{k}}-\log \mathrm{u}^{*}\right)+\varepsilon\left(\lambda^{\mathrm{k} \varrho} \mathrm{y}_{\mathrm{t}}^{\mathrm{k}}+\varepsilon \sigma_{\mathrm{z}^{\mathrm{ke}}} \hat{\mathrm{z}}_{\mathrm{t}+1}^{\mathrm{e}}\right) \quad, \quad \hat{\mathrm{z}}_{\mathrm{t}}^{\mathrm{k} \varrho} \sim \mathrm{N}(0,1) \\
\varphi_{\mathrm{t}+1}^{\mathrm{k}}=\varepsilon\left(\lambda^{\mathrm{k} \varphi} \mathrm{y}_{\mathrm{t}}^{\mathrm{k}}\right)+\sigma_{\mathrm{z}^{\mathrm{k} \varphi}} \hat{\mathrm{z}}_{\mathrm{t}+1}^{\mathrm{k} \varphi}, \quad \hat{\mathrm{z}}_{\mathrm{t}}^{\mathrm{k} \varphi} \sim \mathrm{N}(0,1) .
\end{gathered}
$$



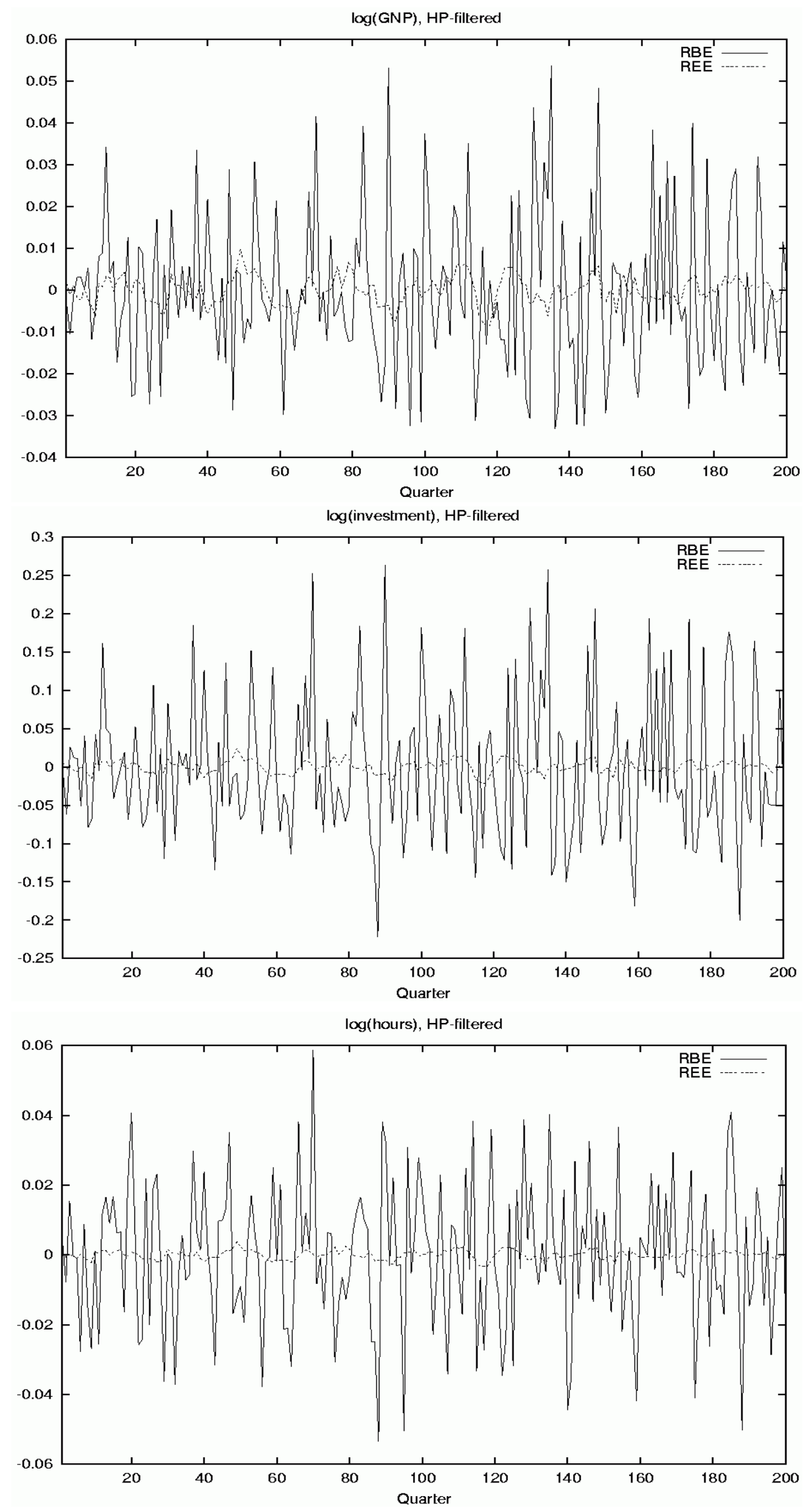

Figure 1 

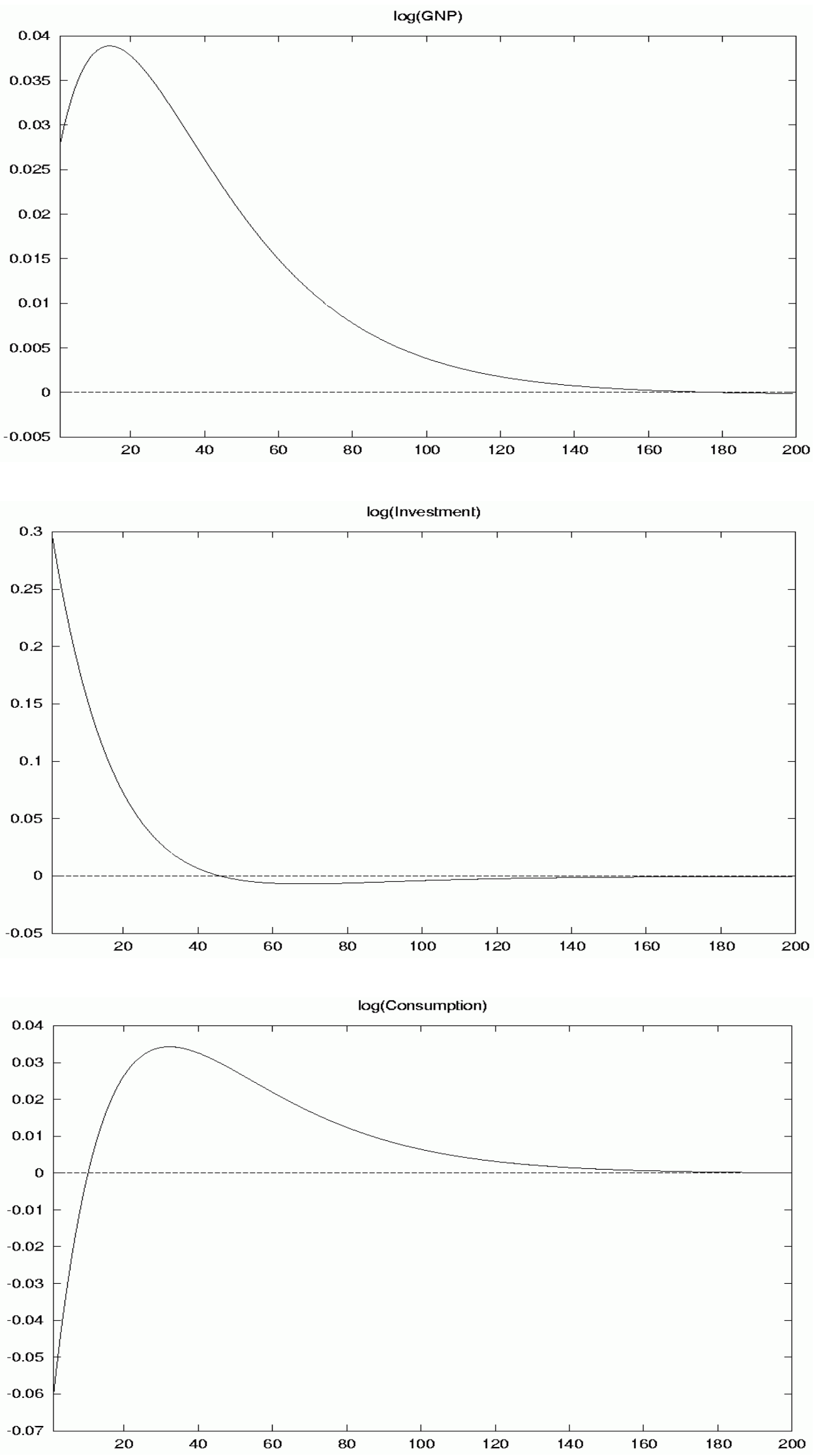

Figure 2: Impulse response to a $+2 \%$ monetary shock 

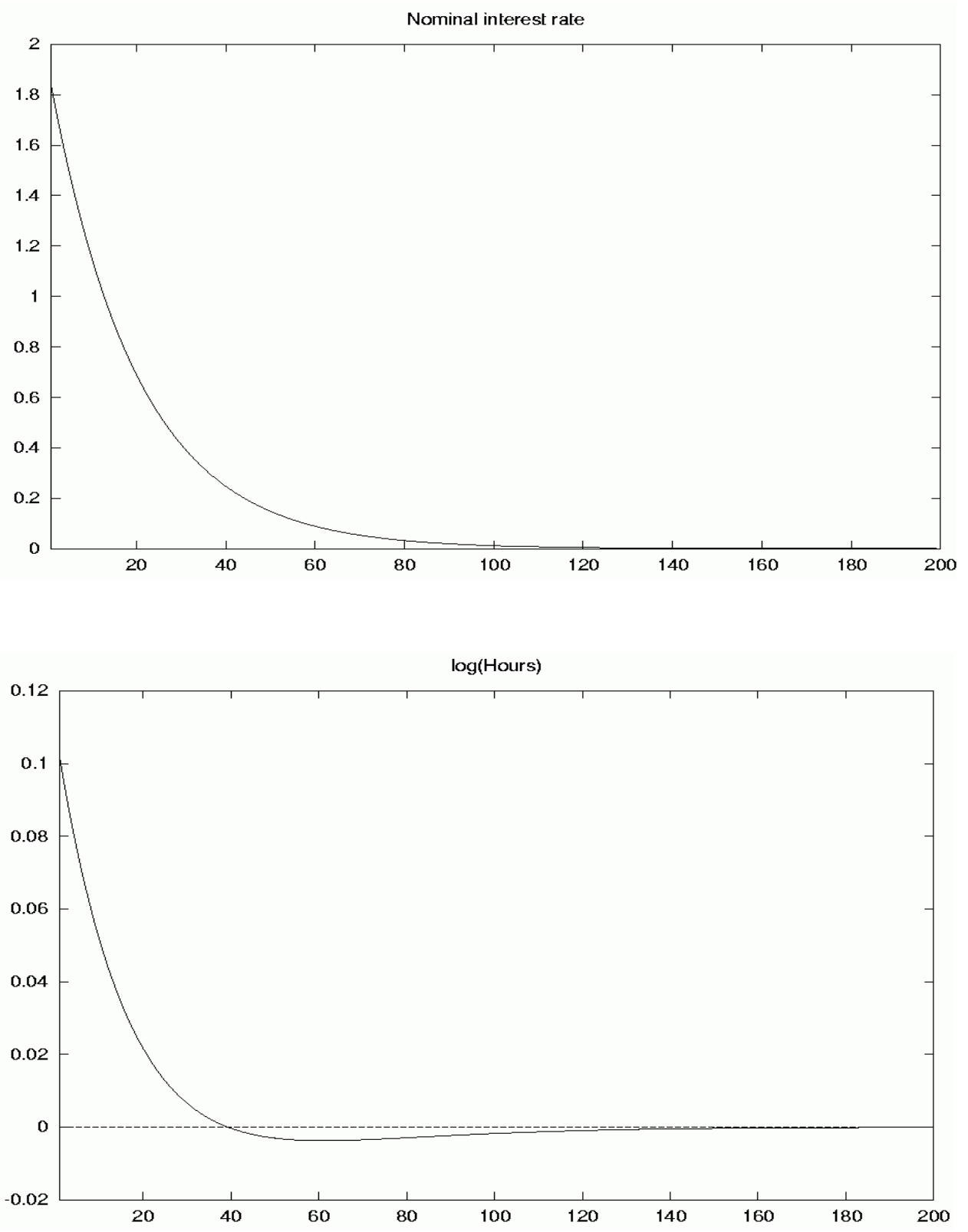

Figure 2 (continued): Impulse response to a $+2 \%$ monetary shock 


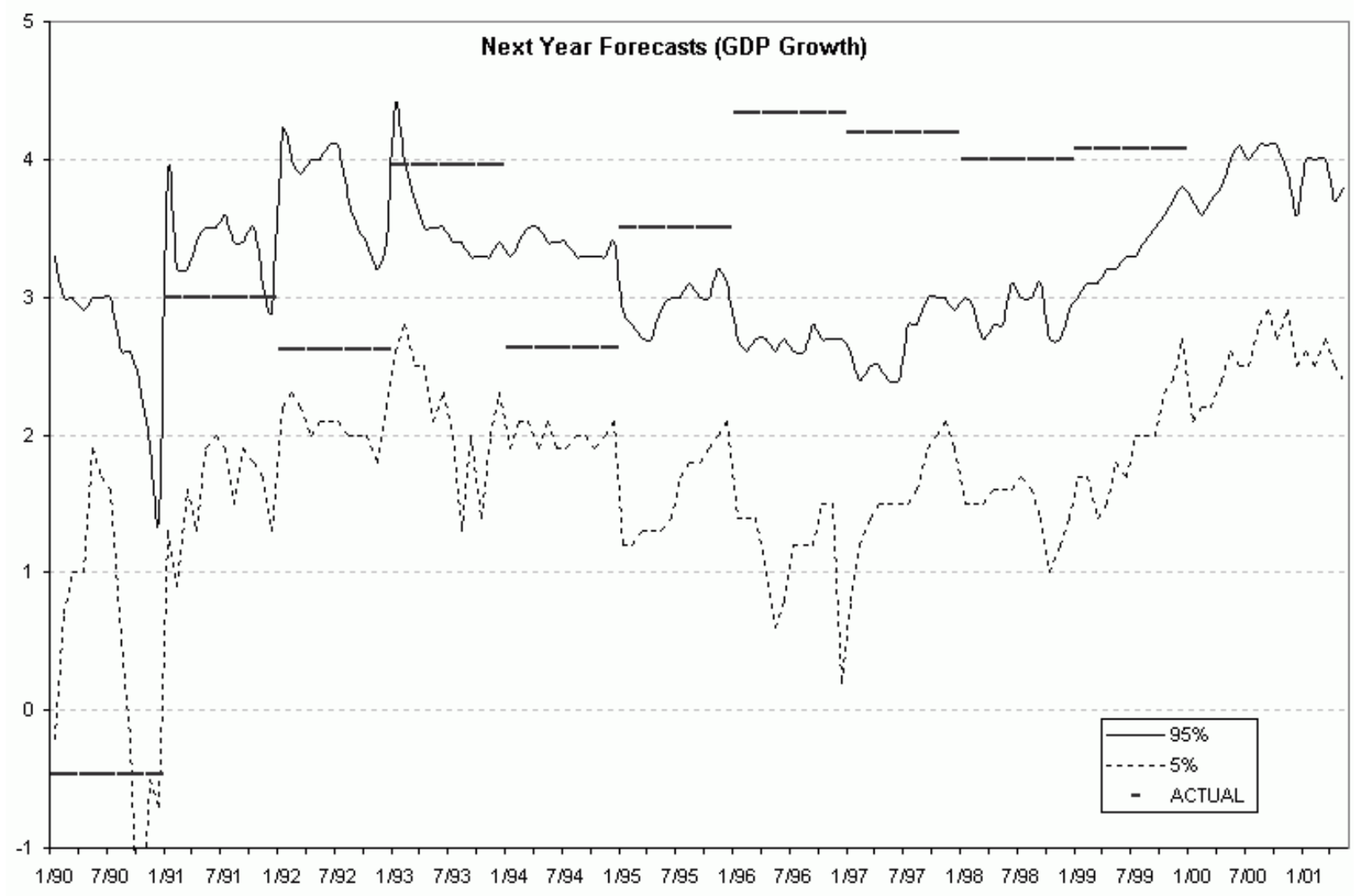

Figure 3 